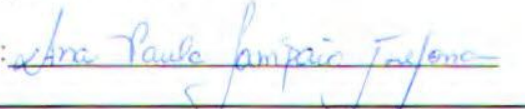

\title{
Smart Home - uma interface para o gerenciamento de redes domésticas
}

\author{
Luis Fernando Oratti
}

Orientador: Prof. Dr. Onofre Trindade Junior

Dissertação apresentada ao Instituto de Ciências Matemáticas e de Computação - ICMC-USP, como parte dos requisitos para obtenção do título de Mestre em Ciências de Computação e Matemática Computacional.

USP - São Carlos

Novembro/2001 


\section{A Comissão Julgadora:}

Prof. Dr. Onofre Trindade Junior

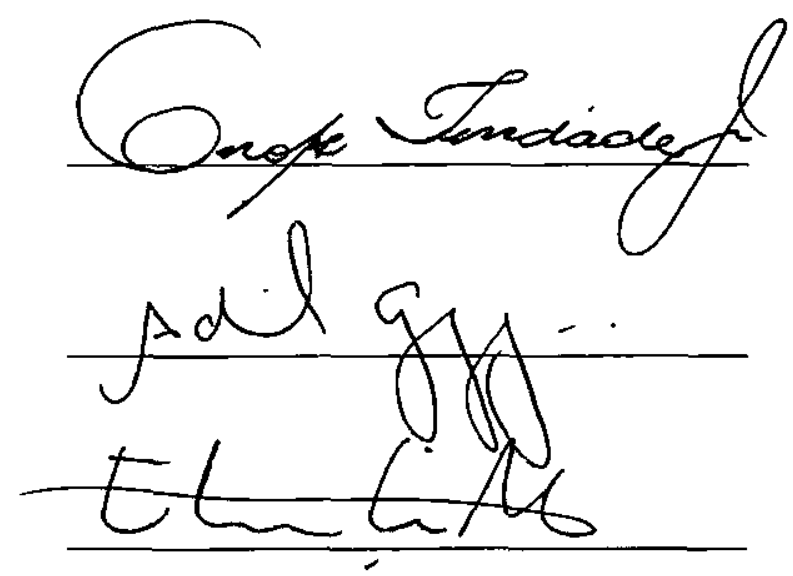

Prof. Dr. Edvaldo Assunção 


\section{Agradecimentos}

Primeiramente, a Deus por todas as pessoas especiais que tem colocado em meu caminho e por todas as oportunidades a mim concedidas.

Não conheço palavras suficientes para expressar a gratidão que tenho por minha mãe e meu pai, Leonor e Anísio, que em todos os momentos de minha vida tem me apoiado de maneira incondicional. Aos meus irmãos Alexandre, Leandro e à "recém-irmã" Carla. Amo vocês!

Ao meu meu amigo e orientador Onofre que, mais do que transmitir ensinamentos técnicos com extrema sabedoria, soube com suas atitudes ensinar sobre a vida. Valeu mestre!

A todos os meus familiares. Como não poderia deixar de ser, meus agradecimentos especiais para Avó Adélia, Tia Regina, Tio Luiz, Tia Jú, Aline e Carina. Vocês são brilhantes!

À minha prima Sônia e seus filhos, Carlos, Alexandre e Bruna, pela participação efetiva em mais este momento de minha trajetória. Vocês são ótimos!

À minha namorada Andressa por ter suportado minha ausência e principalmente meus momentos de mau humor. Você é iluminada!

Aos amigos da República, Wal, Rodrigo "Japinha", Hudson, Fabrício e Neoci, pelos momentos que não sairão da lembrança. Até a próxima!

Aos amigos da terrinha, João, Vagner, Haroldo, Lincoln e Maristela, pelo companherismo de todos. Também aos demais amigos da FEF pelo apoio incondicional. Um grande abraço! Amigos para sempre!

Aos companheiros do "velho" LCAD por tudo que aprendi convivendo com vocês. Agradecimentos especiais aos amigos Luciano, Kléber, Maxweel, Luciana, Viviane, Emílio, Alexandre. As lembranças serão imortais!

A todos os amigos que adquiri neste período de permanência em São Carlos, saibam que com cada um de vocês aprendi algo. Especialmente ao Tiago, Arion, Werley, Sérgião, Jorge, Álvaro, Rodrigo "Kbção", Reginaldo, "Maluquinho", Marcelo, Carlos. Valeu galera!

À CAPES pelo apoio financeiro, sem o qual este trabalho não seria realizado. 


\section{Dedicatória}

Dedico este trabalho a meus pais que sempre me apoiaram incondicionalmente. Anísio e Leonor 


\section{Índice}

INTRODUÇÃO .....................................................................................................15

1.1 CONTEXTO

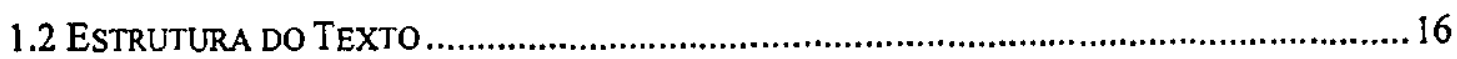

REVISÃO BIBLIOGRÁFICA...............................................................................18

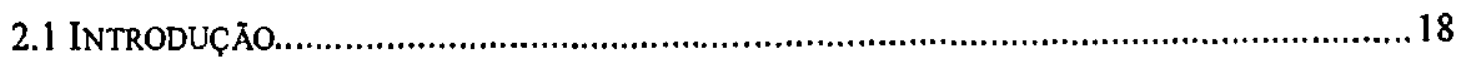

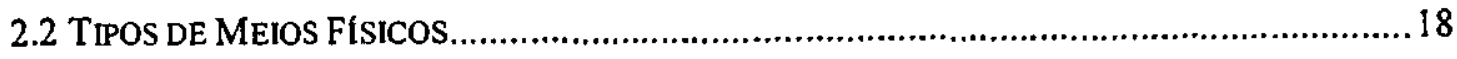

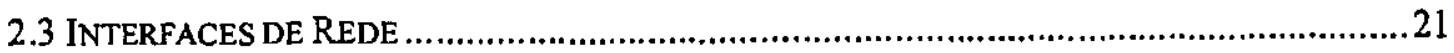

2.4 PADRÒES PARA INTERLIGAÇÃo DE DISPOSITIVOS DOMÉSTICOS.......................................23

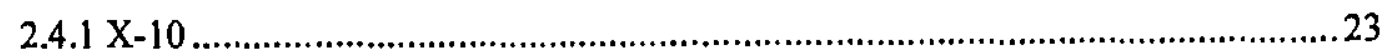

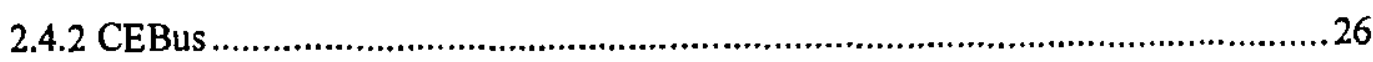

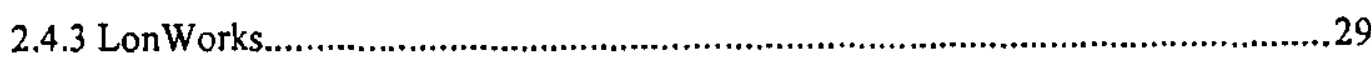

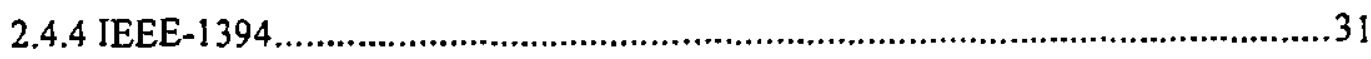

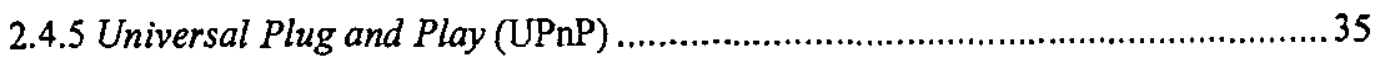

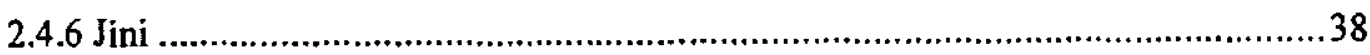

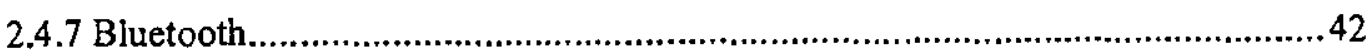

2.5 COMPARAÇÃO ENTRE OS PADRÕES APRESENTADOS....................................................4

2.6 MÉTODOS DE IDENTIFICAÇÃO BIOMÉTRICOS ............................................................48

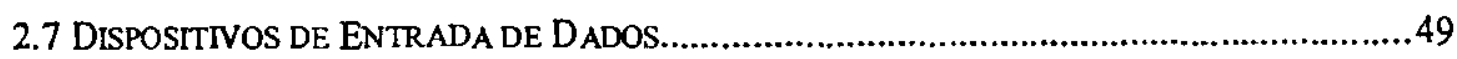

2.8 PICTOGRAFIA _.............................................................................................

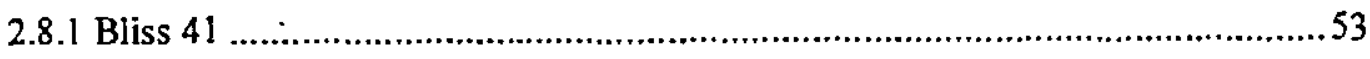

2.9 SISTEMAS DE GERENCIAMENTO DE REDES DOMÉSTICAS.............................................56

2.9.1 Classificação das Ferramentas de Gerenciamento .............................................56

2.9.2 Interface de Configuração Home-Net (HCT) ………………..........................57

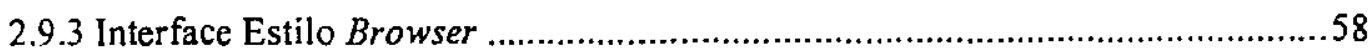




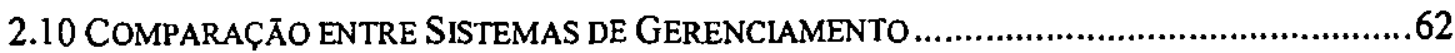

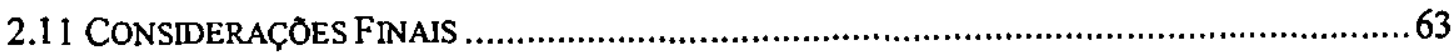

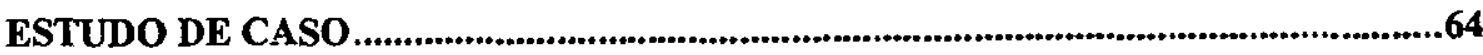

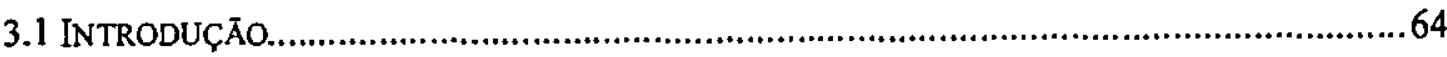

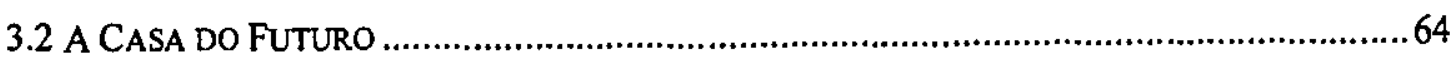

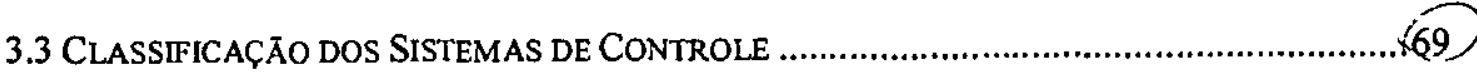

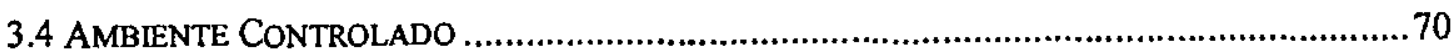

3.4.1 Subsistemas de Controle de Grupo........................................................... 71

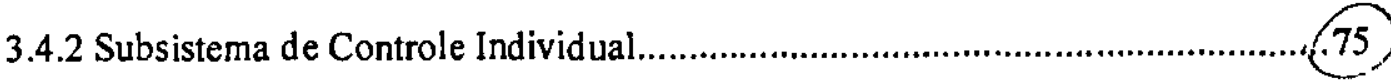

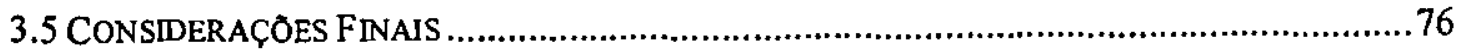

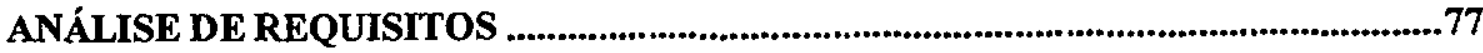

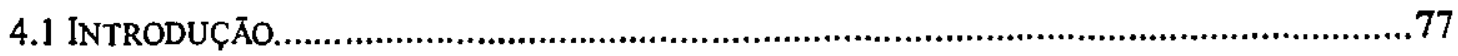

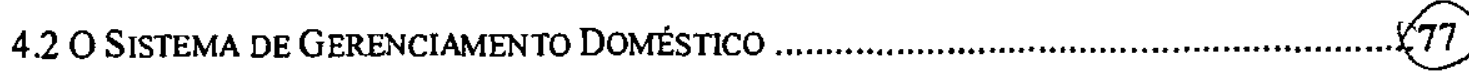

4.3 ESPECIFICAÇÃO DOS REQUISITOS DE HARDWARE ................................................. 78

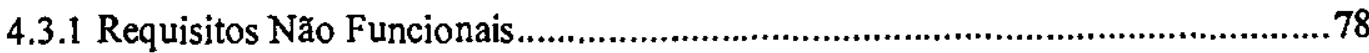

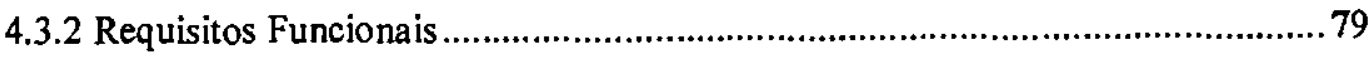

4.4 ESPECIFICAÇÃO DE REQUISITOS DE SOFTWARE.................................................... 80

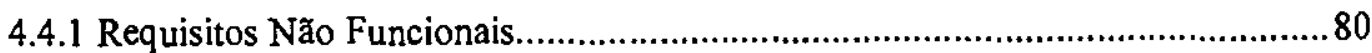

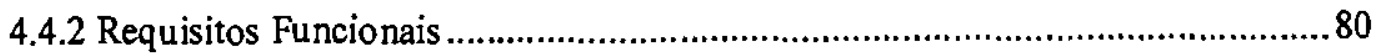

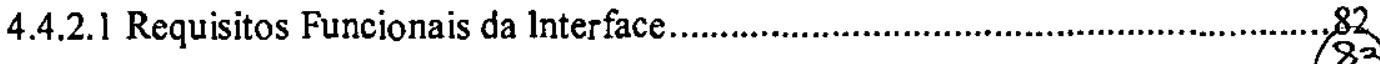

4.5 LINGUAGEM DE REPRESENTAÇĀO DE COMANDOS..................................................... 84

4.5.1 Representação de Comandos em Backus-Naur Form (BNF) ............................. 84

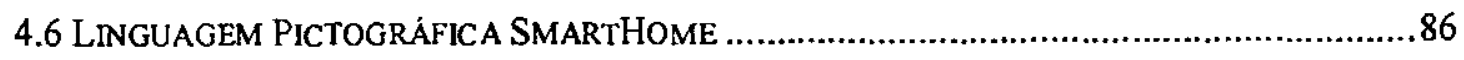

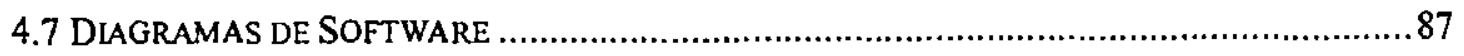

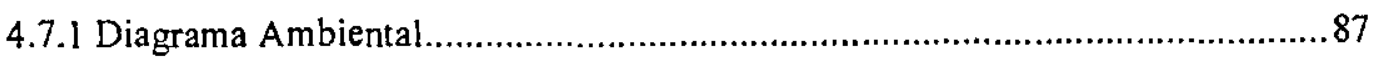




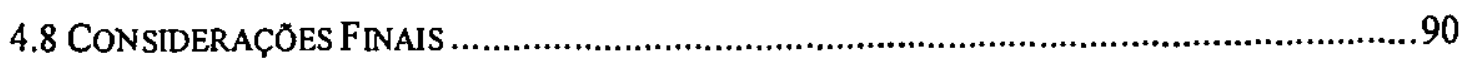

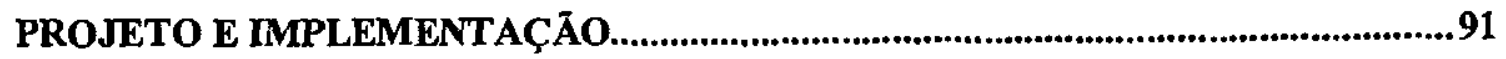

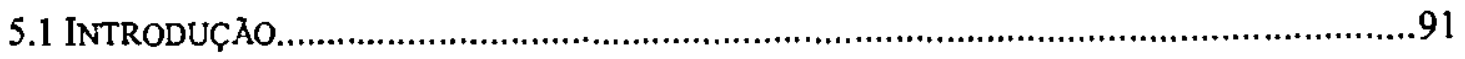

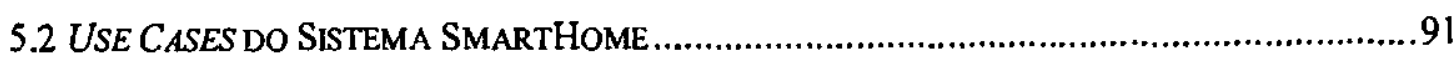

5.2.1 Use Case "Executar Sentença" ..............................................................92

5.2.2 Use Case "Cadastrar Preferência"............................................................94

5.2.3 Use Case "Configurar Dispositivo" .......................................................95

5.2.4 Use Case "Configurar Ambiente" ..........................................................96

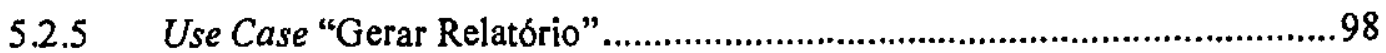

5.2.6 Use Case "Editar Dispositivo" ............................................................ 100

5.2.7 Use Case "Cadastrar Usuário" .............................................................. 101

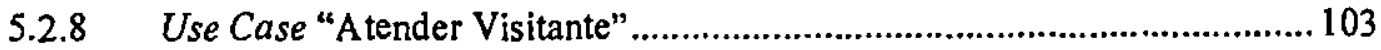

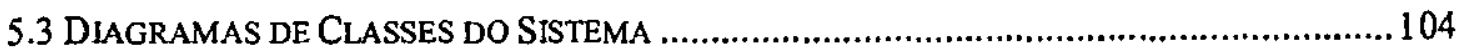

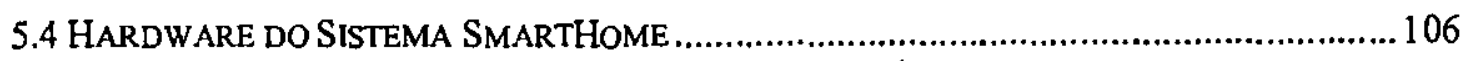

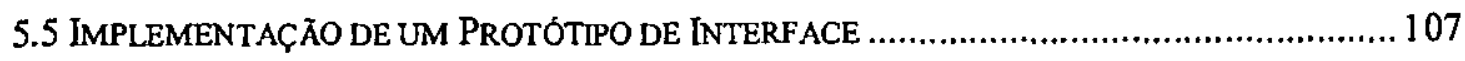

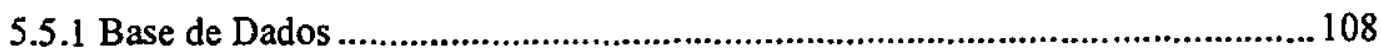

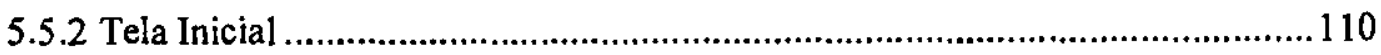

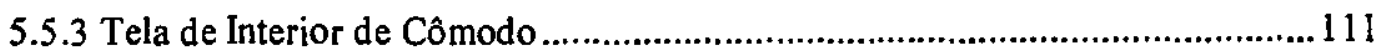

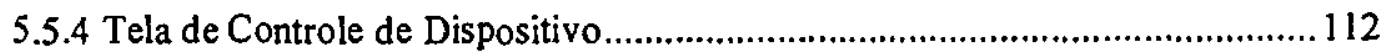

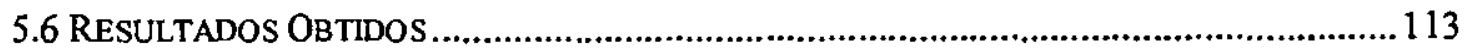

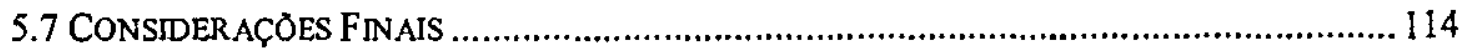

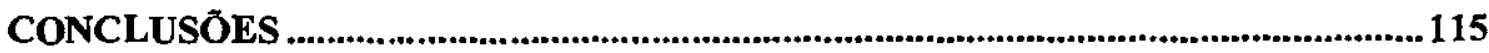

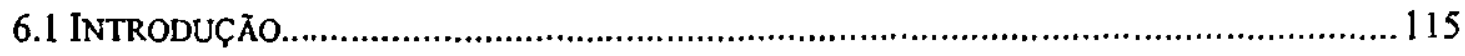

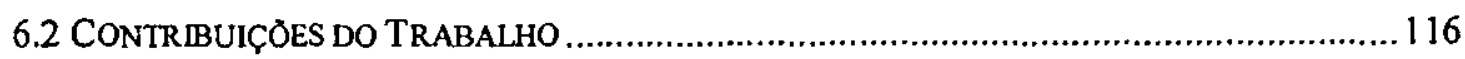

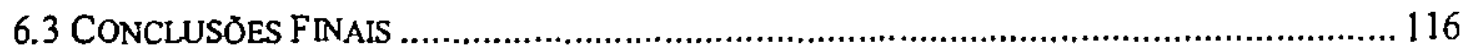

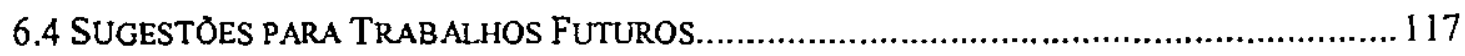




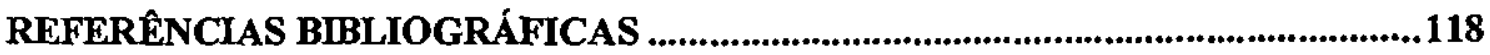

SUBSISTEMA DE CONTROLE INDIVIDUAL .....................................................122

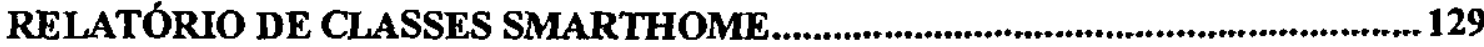




\section{Lista de Figuras}

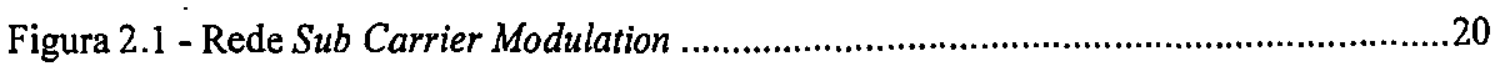

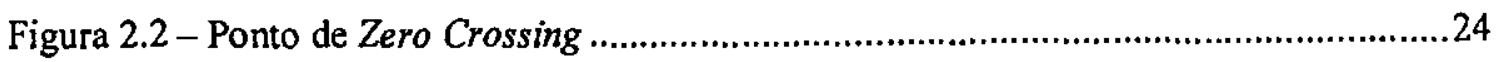

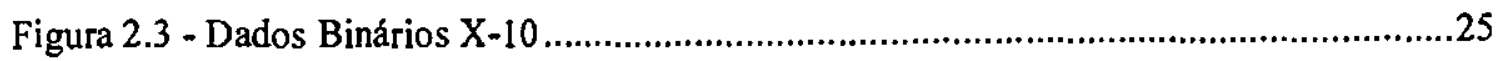

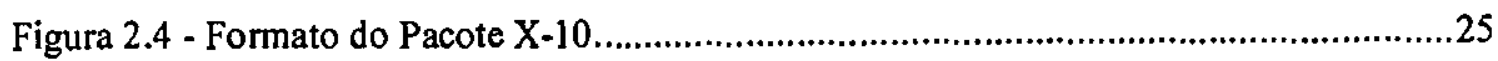

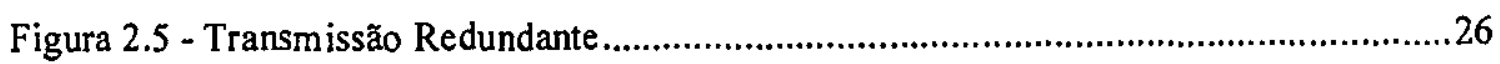

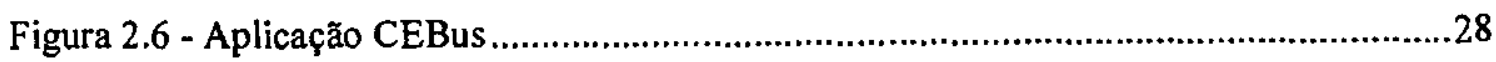

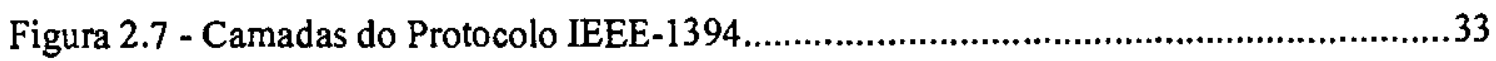

Figura 2.8 - Sincronização dos Pontos de Controle do Usuário ............................................36

Figura 2.9 - Pontos de Controle, Dispositivos Controlados e Pontes ................................... 37

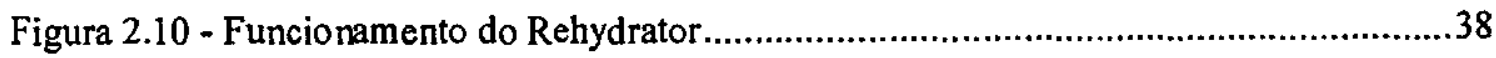

Figura 2.11 - Funcionamento do Protocolo de Lookup.....................................................40

Figura 2.12 - Funcionamento do Protocolo Join............................................................40

Figura 2.13 - Transferência da interface do serviço de Lookup para o cliente........................41

Figura 2..14 - Interação Cliente-Servidor ...................................................................... 41

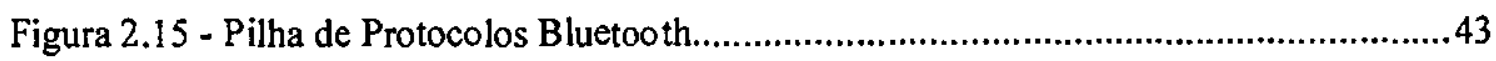

Figura 2.16 - Evolução do símbolo chinês do homem .....................................................52

Figura 2.17 - Símbolo Bliss Indicador de "Coisa" ..........................................................54

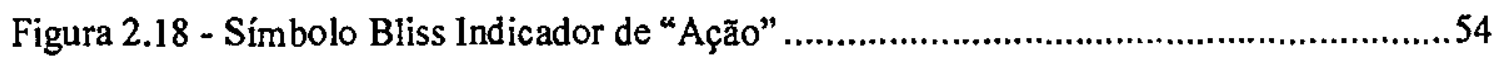

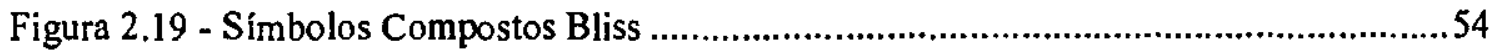

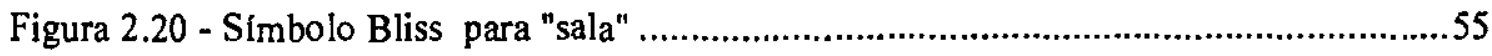

Figura 2.21 - Uso de Apontadores para criação de novas palavras .....................................55

Figura 2.22 - Sentença Bliss "Hoje em casa eu escrevo para você" ...................................... 55

Figura 2.23 - Sentença Imperativa "Por favor escreva para mim!" ......................................56

Figura 2.24 - Sentença Interrogativa: "Você tem um carro?".............................................56

Figura 2.25 - Interface de Programação Gráfica Home-Net ............................................. 58 
Figura 2.26 - Interface Estilo Browser ....................................................................59

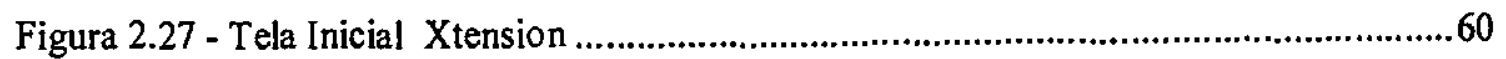

Figura 2.28 - Interface Gráfica XTension ................................................................61

Figura 4.1 - Ícone representativo de "sujeito" - Geladeira .................................................86

Figura 4.2 - f́cone representativo de "ação" - Conectar ...................................................... 86

Figura 4.3 - Sentença SmartHome - "Fogão Exibir Lista de Receitas" ................................87

Figura 4.4 - Diagrama Ambiental do Sistema SmartHome.............................................88

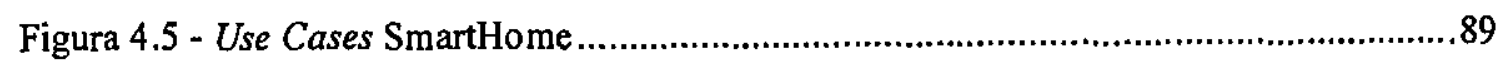

Figura 5.1 - Use Case "Executar Sentença" .................................................................. 92

Figura 5.2 - Diagrama de Interação - Use Case "Executar Sentença" ..................................93

Figura 5.3 - Use Case "Cadastrar Preferência" ...............................................................99

Figura 5.4 - Diagrama de Interação - Use Case "Cadastrar Preferência" ............................... 95

Figura 5.5 - Use Case "Configurar Dispositivo"..........................................................95

Figura 5.6 - Diagrama de Interação - Use Case "Configurar Dispositivo" ............................96

Figura 5.7 - Use Case "Configurar Ambiente" ...................................................................

Figura 5.8 - Diagrama de Interação - Use Case "Configurar Ambiente" ...............................98

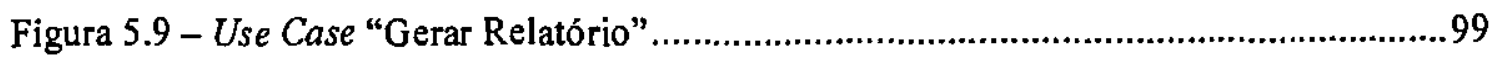

Figura 5.10 - Diagrama de Interação - Use Case "Gerar Relatório" ......................................99

Figura 5.1] - Use Case "Editar Dispositivo".......................................................... 100

Figura 5.12 - Diagrama de Interação - Use Case "Editar Dispositivo" ................................. 101

Figura 5.13 - Use Case "Cadastrar Usuário" ..................................................................101

Figura 5.14 - Diagrama de Interação - Use Case "Cadastrar Usuário".................................102

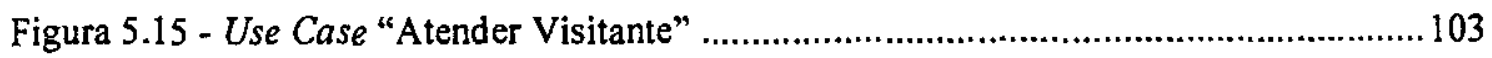

Figura 5.16 - Diagrama de Interação - Use Case "Atender Visitante" .................................104

Figura 5.17 - Diagrama de Classes SmartHome - Classes Funcionais .............................. 105

Figura 5.18 - Diagrama de Classes SmartHome - Classes Tipo Interface........................... 106 
Figura 5.19 - Diagrama de Hardware SmartHome ....................................................... 107

Figura 5.20 - Interface Inicial - SmartHome............................................................ 110

Figura 5.21 - Interface de Interior da Cozinha - SmartHome .......................................111

Figura 5.22 - Tela de Controle da TV - SmartHome ...................................................112 


\section{Lista de Tabelas}

Tabela 2.1 - Interfaces de Rede..

Tabela 2.2 - Protocolos de Comunicação entre Dispositivos Domésticos .. 46

Tabela 2.3 - Comparação entre Sistemas de Gerenciamento .62 


\section{Resumo}

No mundo moderno as pessoas estão cada vez mais atarefadas e este acúmulo de tarefas ocasiona uma alta demanda por sistemas e dispositivos que facilitem seu dia-a-dia. Setores empresariais diversos voltaram sua atenção a esse mercado emergente. $O$ interesse se estende desde empresas fabricantes de computadores e equipamentos eletro-eletrônicos até companhias fornecedoras de energia elétrica, gás e água. Atualmente, o grande desafio consiste em integrar as diversas tecnologias utilizadas por uma grande diversidade de fabricantes de sistemas e dispositivos.

O principal objetivo deste trabalho é o projeto de um sistema de gerenciamento de residencias com interface simplificada, o SmartHome, de fácil utilização por pessoas idosas e/ou inválidas. A análise de requisitos do sistema é baseada em um estudo de caso de uma residência futurista. $E$ introduzida uma linguagem gráfica para a representação das sentenças de comando aceitas pelo sistema.

O desenvolvimento do sistema foi feito utilizando-se uma metodologia baseada na notação UML. Um protótipo da interface do sistema SmartHome foi implementado, permitindo que usuários possam realizar requisições por meio do mouse ou reconhecimento de voz. O mouse no protótipo substitui a tela sensivel a toques prevista no projeto da interface, para facilidade de desenvolvimento.

Os testes iniciais mostraram que a interface SmartHome uniformiza o modo de uso dos dispositivos conectados na rede doméstica. Adicionalmente, a interface apresenta um elevado grau de intuição com a utilização de uma linguagem de comandos gráfica e comandos por voz, o que reduz o período de aprendizado de novos usuários. 


\section{Abstract}

In modern world people have been busier and busier. This amount of daily tasks calls for systems and devices that facilitate everyday life. Several business sectors have turned their attention to this emerging market. This attention comes from computer manufacturers, electric/electronic household appliances manufacturers and energy, gas and water suppliers. Nowadays, the great challenge is to integrate the great variety of technologies used by several manufacturers of systems and devices.

The main objective of this work is the design of a home management system with an undemanding interface, the SmartHome, of easy use by elderly or disabled people. System's requirements analysis is based on a case study of a futuristic home. This work also presents a graphic language to represent the command sentences recognized by the system.

System development was done using an UML-based methodology. A prototype of the SmartHome's interface was implemented, allowing users to accomplish requests through mouse or voice commands. The mouse is a low cost replacement for the touch screen specified in the SmartHome's design for the development phase.

Initial tests showed that the SmartHome's interface can make uniform the use of different appliances connected to the home network. Additionally, the interface is highly intuitive due to the use of a graphical command language and voice commands, reducing the time for new users to operate the sysem. 


\section{Capítulo1}

Introdução

\subsection{Contexto}

O setor de automação doméstica é um dos nichos de mercado mais atrativos para as empresas fabricantes de computadores, equipamentos de áudio e vídeo, eletrodomésticos e empresas de tecnologia da informação. O grande desafio reside em integrar as diversas tecnologias utilizadas pelos diversos fabricantes. Nos últimos anos tem-se presenciado o surgimento de diversos protocolos de comunicação com tal objetivo.

Os ambientes residencial e empresarial estão mais integrados do que nunca. Um forte indicador deste fato é o surgimento do termo "escritório virtual", que nada mais é do que um escritório dentro das residências, tornado possível pelo crescimento da abrangência da Internet na sociedade moderna. A tendência é que todos os dispositivos de uma residência façam parte de uma rede e disponibilizem seus serviços a qualquer morador permitindo, inclusive, o acesso remoto de suas funcionalidades, independente da aplicação ser comercial ou residencial.

Devido a miniaturização crescente dos componentes eletrônicos e o aumento do poder computacional dos microprocessadores tornou-se factível a construção de dispositivos domésticos inteligentes. A contínua queda do cus to dos processadores aliada ao surgimento de novos protocolos de comunicação permite a construção de sistemas de controle aptos a prover uma funcionalidade muito maior que a provida pelos mesmos dispositivos tomados isoladamente.

A finalidade principal do desenvolvimento tecnológico é a melhoria da qualidade de vida das pessoas. Uma interface de gerenciamento doméstico amigável pode ser extremamente útil a pessoas que possuem algum tipo de limitação, seja física ou mental. 
Adicionalmente, a utilização de um sistema de automação doméstica por pessoas comuns pode tornar o dia-a-dia mais agradável.

Este trabalho trata da especificação e prototipagem de uma interface de gerenciamento de dispositivos integrados em uma rede doméstica. O projeto propõe a especificação de um novo componente de hardware denominado "Janela Virtual", cuja principal função é servir como porta de entrada para o sistema, eventualmente agregando algumas funcionalidades adicionais.

O software de gerenciamento propð̃e uma interface homem-sistema baseada em reconhecimento de voz e toques nas "Janelas Virtuais" distribuídas pelo ambiente. A sistemática de requisição e confirmação das tarefas é feita de uma maneira simples através do uso de uma linguagem de comandos pictográfica e famílias de ícones.

\subsection{Estrutura do Texto}

Este texto encontra-se dividido em cinco capítulos. No segundo capítulo são apresentados os conceitos referentes aos principais meios físicos utilizados no projeto de redes de computadores e as diversas tecnologias voltadas para a implementação de redes domésticas. É apresentada uma análise comparativa entre os diversos protocolos de interligação de dispositivos domésticos em rede. Também são revistas algumas técnicas de comunicação baseadas em linguagens pictográficas e alguns métodos de identificação biométricos. Finalmente, são apresentados alguns sistemas existentes para gerenciamento de redes domésticas.

No terceiro capítulo é apresentado um estudo de caso de uma residência virtual automatizada. Foram identificados os diversos sistemas de controle necessários e é apresentada uma proposta genérica para a classificação de sistemas de controle levando em consideração as suas caracteristicas mais importantes.

O quarto capítulo trata da especificação de requisitos da interface, apresenta os comandos disponíveis, mostra a estrutura da linguagem de comandos pictográfica e apresenta uma descrição dos componentes visuais que integram a interface.

O quinto capítulo apresenta o projeto e a implementação do protótipo da interface de gerenciamento. A fase de projeto utilizou uma modelagem orientada a objetos. Todos os diagramas gerados estão inseridos neste capítulo. O protótipo implementado evidencia 
algumas das características essenciais da interface proposta.

$O$ apêndice $A$ apresenta uma lista dos dispositivos domésticos considerados na definição da interface do sistema de controle e suas funçôes principais. O Apêndice B contém um relatório das classes do sistema proposto, incluindo seus respectivos atributos e métodos. 


\section{Capítulo 2}

\section{Revisão Bibliográfica}

\subsection{Introdução}

Este capítulo tem como objetivo principal apresentar os diversos conceitos relacionados ao desenvolvimento deste trabalho. A seção 2.2 discute as principais características relacionadas aos meios físicos utilizados na interligação de dispositivos em rede. As principais interfaces utilizadas para a transmissão de dados são apresentadas na seção 2.3. Na seção 2.4 é apresentada uma rápida análise dos motivos que impulsionam o surgimento de um elevado número de padrões voltados para a interligação de dispositivos domésticos, suas subseções descrevem vários dos padrões existentes. Uma tabela com as características referentes aos padrões de comunicação em redes domésticas é apresentada na seção 2.5 .

Os principais métodos de identificação de usuários por meio de padrões biométricos são apresentados na seção 2.6. As principais formas de uma interação homem-computador estão descritas na seção 2.7. A seção 2.8 apresenta o conceito de pictografia e introduz a linguagem de comunicação pictográfica Bliss 41 . Na seção 2.9 são apresentadas três interfaces de gerenciamento de ambientes domésticos juntamente com suas principais características. Um quadro comparativo entre as funcionalidades da interface é apresentado na seção 2.10.

\subsection{Tipos de Meios Físicos}

A idéia de uma casa inteligente é mais antiga que a idéia de redes de computadores. Devido à heterogeneidade dos dispositivos conectados em uma rede doméstica, os profissionais da área não chegaram a um consenso sobre qual a melhor tecnologia para esta finalidade [ALL00]. 
Em relação às necessidades individuais dos dispositivos que integram a rede, o projeto deve considerar fatores como: a relação custo-benefício, o meio de transmissão utilizado (possivelmente uma combinação de diferentes meios físicos), a confiabilidade da informação transmitida e a segurança do sistema.

Na transmissão, o meio fisico interliga todos os componentes de uma rede, podendo ser: par trançado, cabo coaxial, fibra ótica, insta lação elétrica, ondas de rádio e luz infravermelha. Todos os meios físicos citados apresentam vantagens e desvantagens. Uma análise de requisitos se faz necessária na seleção do meio físico mais apropriado. A análise deve considerar características como taxa de transmissão de dados e confiabilidade. Seguem as características relativas aos diferentes meios fisicos.

\section{Par Trançado}

O meio clássico de interligação de computadores em rede é o par trançado (TP). A trança dos fios minimiza a interferência eletromagnética e o custo de instalação é baixo. A taxa mais comum de transmissão de dados é de $10 \mathrm{Mbits} / \mathrm{s}$, embora taxas de $100 \mathrm{Mbits} / \mathrm{s}$ estejam se tornando muito comuns e já estão disponíveis interfaces operando a $1 \mathrm{Gbits} / \mathrm{s}$. $\mathrm{O}$ melhor momento para a instalação do cabeamento TP é durante o projeto e construção de um edifício [FEN00].

\section{Cabo Coaxial}

Indicado para transmissão em alta velocidade, como transmissão de sinais de rádio freqüência (RF). A malha de cobre que reveste $o$ cabo previne interferências eletromagnéticas. Entretanto, para a maioria das aplicações domésticas o cabo coaxial é muito caro, sendo recomendado neste contexto somente na transmissão de sinais de TV e vídeo [FEN00].

\section{Fibra Ótica}

Não necessita de repetidores nos limites do ambiente doméstico, é imune a interferências eletromagnéticas e apresenta alta taxa de transmissão de dados com cabo de diâmetro reduzido. É recomendada para a transmissão de grandes quantidades de informação, como na transmissão digital de sinais de áudio e vídeo.

São citados como pontos negativos o custo das interfaces óticas e o custo do cabeamento. Como a maioria das aplicações domésticas não necessita de alta velocidade de comunicação, não é muito utilizada em ambientes domésticos [COR98]. 


\section{Rede Elétrica}

Utiliza os cabos de energia existentes na grande maioria das residências. É uma solução muito interessante em ambientes domésticos devido à eliminação dos custos relativos ao cabeamento [SHW96].

Levando em consideração que a rede elétrica não foi projetada para a transmissão de dados, este meio apresenta uma baixa taxa de transmissão associada ao risco de choques elétricos, ruídos na linha, alta taxa de atenuação do sinal transmitido e problemas relativos à segurança da informação transmitida [WAD00].

No final 1999, a companhia Media Fusion anunciou uma nova tecnologia para a transmissão de dados sobre a rede elétrica a taxas elevadas. Propõe-se que cada residência seja equipada com um pacote de comunicação básico que inclui um controlador e várias tomadas que permitem a conexão de qualquer dispositivo doméstico à rede, como mostrado na figura 2.1. Cada conector possui um identificador único que é utilizado pelo sistema para realizar o roteamento dos pacotes transmitidos

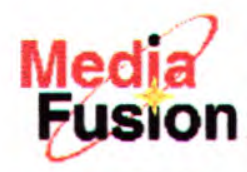

\section{Home "LAN" Overview}
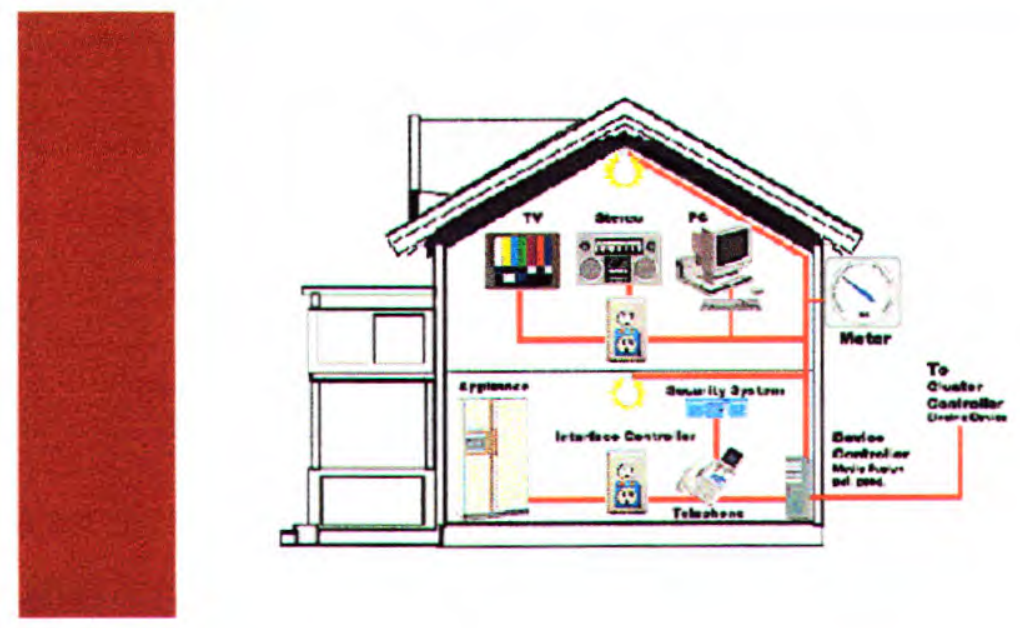

Figura 2.1 - Rede Sub Carrier Modulation

A tecnologia proposta realiza a transmissão dos dados utilizando o campo magnético gerado ao redor de um condutor percorrido por uma corrente elétrica. De forma simplista, o método proposto, Sub Carrier Modulation, processa e escreve os dados na onda eletromagnética gerada ao redor das linhas de transmissão utilizando software e 
hardware proprietários. Permite que a rede elétrica transmita dados de telefonia, rádio, vídeo e Internet para qualquer lugar a uma taxa de transmissão de 2.5Gbps [MED00].

\section{Sem Fio}

Sistemas sem fio operando em RF, microondas ou infra-vermelho (IR) usam diferentes técnicas de modulação para a transmissão dos dados. Em relação aos meios físicos de transmissão, os meios sem fio apresentam uma maior flexibilidade, facilidade de instalação, mobilidade e eliminação do cabeamento. Os meios físicos sem fio são recomendados no projeto de automação de residências já construídas [AXE98].

Os sistemas sem fio são altamente dependentes da frequência de transmissão utilizada. Neste caso são características relevantes da transmissão a largura de banda e a distância de alcance. Em geral quanto maior a frequência, maior a quantidade de dados transmitidos.

\subsection{Interfaces de Rede}

Os computadores possuem alguns tipos de interfaces padrão. Caso o computador năo tenha a interface com a tecnologia de rede desejada é possível adicionar uma placa extensora que liga o computador à rede em questão. A porta paralela, a RS-232 e algumas outras integram o conjunto de interfaces disponfveis em computadores do tipo PC.

As principais interfaces utilizadas pelos padrōes de redes domésticas são apresentadas na tabela 2.1 [AXE98]. A tabela 2.1 mostra os vários protocolos possíveis para a interligação de dispositivos em rede, sejam eles domésticos ou não. Apresenta a quantidade máxima de dispositivos possíveis, a taxa máxima de transmissão de dados, tamanho da área coberta pela rede e forma de transmissão de dados. 
Tabela 2.1 - Interfaces de Rede

\begin{tabular}{|c|c|c|c|c|}
\hline Interface & $\begin{array}{c}\text { Forma de } \\
\text { Transmissão }\end{array}$ & $\begin{array}{c}\text { Número } \\
\text { Máximo de } \\
\text { Dispositivos } \\
\text { Suportados }\end{array}$ & $\begin{array}{l}\text { Comprimento } \\
\text { Máximo (m) }\end{array}$ & $\begin{array}{c}\text { Taxa Máxima } \\
\text { de Transmissão } \\
\text { de dados } \\
\text { (bits/sec) }\end{array}$ \\
\hline Ethernet & Serial & 1024 & $\begin{array}{c}100 \text { entre } h u b \mathrm{e} \\
\text { dispositivo }\end{array}$ & $10 \mathrm{M}, 100 \mathrm{M}, 1 \mathrm{G}$ \\
\hline Firewire & Serial & 64 & 15 & $400 \mathrm{M}$ \\
\hline $\mathrm{I} 2 \mathrm{C}$ & Serial & 40 & 18 & $400 \mathrm{~K}$ \\
\hline $\begin{array}{l}\text { IEEE-488 } \\
\text { (GPIB) }\end{array}$ & Paralelo & 15 & 60 & $8 \mathrm{M}$ \\
\hline $\operatorname{IrDA}$ & $\begin{array}{c}\text { Serial } \\
\text { Infravermelho }\end{array}$ & 2 & 6 & $115 \mathrm{k}$ \\
\hline Microwire & Serial & 8 & 10 & $2 \mathrm{M}$ \\
\hline MIDI & $\begin{array}{l}\text { Serial (Loop de } \\
\text { Corrente) }\end{array}$ & 2 & 49 & $31.5 \mathrm{~K}$ \\
\hline $\begin{array}{c}\text { Parallel Printer } \\
\text { Port }\end{array}$ & Paralelo & $\begin{array}{c}2, \text { ou } 8 \text { com } \\
\text { suporte a daisy- } \\
\text { chain }\end{array}$ & $10-30$ & $8 \mathrm{M}$ \\
\hline $\begin{array}{c}\text { RS-232 } \\
\text { (TIA/EIA-232) }\end{array}$ & Serial & 2 & $50-100$ & $\begin{array}{l}20 \mathrm{k}(115 \mathrm{k} \text { com } \\
\text { alguns drivers) }\end{array}$ \\
\hline $\begin{array}{c}\text { RS-485 } \\
\text { (TIA/EIA-485) }\end{array}$ & Serial & 32 & 4000 & $10 \mathrm{M}$ \\
\hline USB & Serial & 127 & 30 com hub & $\begin{array}{l}12 \mathrm{M} \text { (USB1.1) } \\
240 \mathrm{M} \text { (USB2.0) }\end{array}$ \\
\hline HomePNA & $\begin{array}{c}\text { Serial sobre rede } \\
\text { telefônica }\end{array}$ & 25 & $\begin{array}{c}160 \text { entre } \\
\text { dispositivos }\end{array}$ & $10 \mathrm{M}$ \\
\hline HomeRF & Serial sem fio & 127 & 100 & $2 \mathrm{M}$ \\
\hline
\end{tabular}




\begin{tabular}{|c|c|c|c|c|}
\hline HomePLUG & $\begin{array}{c}\text { Serial sobre rede } \\
\text { elétrica }\end{array}$ & Indeterminado & $\begin{array}{l}\text { Toda rede } \\
\text { elétrica que não } \\
\text { passe por um } \\
\text { transformador }\end{array}$ & $14 \mathrm{M}$ \\
\hline$X-10$ & $\begin{array}{c}\text { Serial, onda de } \\
\text { Sinal de } 120 \mathrm{KHz} \\
\text { sobre onda } \mathrm{AC} \\
\text { de } 60 \mathrm{~Hz} \text { da } \\
\text { instalação } \\
\text { elétrica }\end{array}$ & $\begin{array}{c}16 \text { por House } \\
\text { Code }\end{array}$ & $\begin{array}{l}\text { Toda rede } \\
\text { elétrica que não } \\
\text { passe por um } \\
\text { transformador }\end{array}$ & 360 \\
\hline $\begin{array}{l}\text { Sub Carrier } \\
\text { Modulation }\end{array}$ & Serial & Indeterminado & $\begin{array}{c}\text { Toda a rede } \\
\text { elétrica }\end{array}$ & $2.5 \mathrm{G}$ \\
\hline
\end{tabular}

\subsection{Padrões para Interligação de Dispositivos Domésticos}

É possível dividir os protocolos existentes para interligação de dispositivos domésticos em dois grandes grupos: protocolos de baixo nível e de alto nivel. Os protocolos de baixo nível tratam basicamente da forma como os dados são transmitidos no meio físico, controle de colisão de pacotes e endereçamento de dispositivos. Os protocolos de alto nivel tratam de assuntos relacionados à administração da rede, como inclusão de dispositivos e serviços oferecidos.

A seguir são apresentadas as principais características dos padrões destinados à interligação de dispositivos em redes domésticas.

\subsubsection{X-10}

\section{Introdução}

Os dispositivos em uma residência. normalmente. não têm qual quer ligação entre eles exceto os fios que transportam a energia necessária para o seu funcionamento. No $\mathrm{X}-10 \mathrm{a}$ comunicação entre os dispositivos pode ser realizada com a utilização de sinais que trafegam 
Um objetivo inicial do padrão X-10, que permanece até hoje, é a manufatura de dispositivos baratos e fáceis de instalar, dispensando o emprego de pessoas qualificadas.

\section{Funcionalidades}

O padrão X-10 é voltado para a produção de dispositivos com baixo custo e em grandes quantidades. Atualmente, os produtos X-10 que necessitam de uma maior banda de transmissão não utilizam a instalação elétrica como meio físico devido à limitada taxa de transmissão de dados.

$\mathrm{O}$ padrão $\mathrm{X}-10$ colaborou de forma ativa para o desenvolvimento da indústria da automação doméstica. Em 1984, foi desenvolvido um equipamento no formato de um vídeo cassete que era conectado a TV e funcionava como uma interface gráfica para o gerenciamento da rede [RYE00]. Este foi o início do surgimento de vários gerenciadores de tarefas domésticas.

As aplicações para redes de controle baseadas no padrão X-10 são em sua maioria voltadas ao controle de dispositivos do tipo liga-desliga. $O$ mercado dispõe de produtos mais complexos, porém sua penetração no mercado de automação é baixa.

Hoje, é possivel o acesso remoto à rede doméstica por meio da Internet com o uso de interfaces $\mathrm{PC} / \mathrm{X}-10$ que atuam como bridges, traduzindo os comandos X-10 em TCP/IP e vice-versa.

\section{Componentes Funciona is do Protocolo}

O pacote transmitido em X-10 é baseado em um frame simples com oito bits precedido de um código inicial. O método de transmissão de frames é a parte mais complicada do protocolo. O ponto central do funcionamento dos dispositivos X-10 é a detecção do cruzamento em zero do sinal de tensão alternada da rede de energia elétrica (Zero Crossing), de acordo com a figura $2.2[\mathrm{X}-100]$.

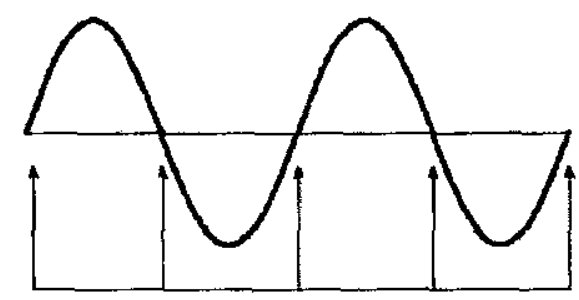

Figura 2.2 - Ponto de Zero Crossing

O objetivo é que a transmissão dos dados seja realizada o mais próximo possível do zero, 
mais precisamente dentro de um intervalo de 200 microssegundos a partir da detecção do ponto de Zero Crossing. O dado binário é transmitido através do envio de pulsos com freqüência de $120 \mathrm{KHz}$.

Um "1" binário é definido neste padrão como a presença de um pulso seguida da ausência de pulso. Um " 0 " binário foi definido como a ausência de um pulso seguida pela presença de um pulso, conforme a figura 2.3 .
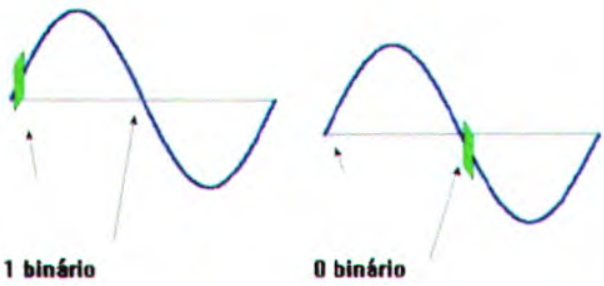

Figura 2.3 - Dados Binários X-10

O receptor abre sua janela de recepção duas vezes por período da onda de $60 \mathrm{~Hz}$, ou seja, 120 vezes por segundo. A janela de recepção procura por pulsos que representam dados no protocolo X-10.

Um código de transmissão completo é formado por onze ciclos do sinal elétrico alternado. Os primeiros dois ciclos representam um código inicial (Start Code). Os próximos quatro ciclos representam um código de endereçamento (House Code) e os últimos cinco ciclos representam um código de endereçamento (Number Code) ou um código de função (Function Code), como mostrado na figura 2.4.

Ciclos de Sinal Elétrico

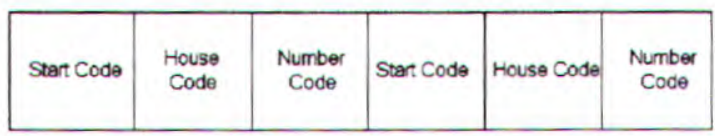

Codigo transmitido quando o bit de endereçamento este selecionedo

\begin{tabular}{|c|c|c|c|c|c|}
\hline Start Code & $\begin{array}{c}\text { House } \\
\text { Code }\end{array}$ & $\begin{array}{c}\text { Function } \\
\text { Code }\end{array}$ & Stert Code & House Code & $\begin{array}{c}\text { Function } \\
\text { Code }\end{array}$ \\
\hline
\end{tabular}

Codigo transmitido quando o bit de funçao está selecionado

Figura 2.4 - Formato do Pacote X-10

A informação completa (Start Code, House Code, Key Code) deve ser transmitida em grupos de dois frames seguidos de três ciclos de sinal elétrico entre transmissões, conforme 
figura 2.5 .

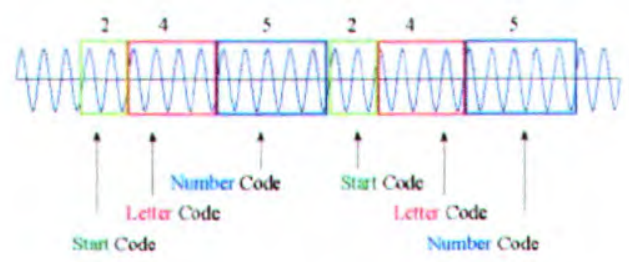

Figura 2.5 - Transmissão Redundante

Uma vez que o código inicial tenha sido transmitido com sucesso, os quatro bits seguintes são enviados (House Code). Os quatro primeiros bits do House Code representam letras. $\mathrm{Na}$ transmissão dos dados restantes que integram o House Code, os dados são interpretados de acordo com o estado do último bit transmitido, um endereço (bf $=0$ ) ou uma função $(\mathrm{bf}=1)$.

O protocolo X-10 transmite duas vezes cada dado para tornar a transmissão mais confiável e para permitir o uso de repetidores na linha de transmissão.

\subsubsection{CEBus}

\section{Introdução}

O protocolo CEBus [EIA00], também conhecido por IS-60 e EIA-600, nasceu do esforço da Consumers Electronic Association (CEA) para padronizar controles por infravermelho em aparelhos de áudio e vídeo. Em 1984 a Electronic Industries Association (EIA) iniciou um trabalho cujo objetivo era a formulação de um padrão para redes de comunicação de aparelhos eletrodomésticos. Este padrão foi denominado Consumer Electronic Bus (CEBus).

A especificação completa do protocolo CEBus foi divulgada em 1992 com base na contribuição de diversos grupos. Em 1994 foi criado o Conselho das Indústrias CEBus (CIC) formado por membros integrantes das empresas que fornecem produtos e serviços CEBus. Os principais colaboradores foram os fabricantes de dispositivos e prestadores de serviços, incluindo empresas elétricas, de gás e telefonia. Atualmente o CIC é um agente de certificação, administrador da marca e logotipos relacionados.

Uma rede EIA-600 fornece uma padronização da comunicação para troca de pacotes, controles e dados entre os dispositivos integrantes da rede. O padrão teve por meta um grau 
elevado de flexibilidade e diminuição dos custos dos dispositivos domésticos [WAC00].

São objetivos do padrão CEBus:

- Encorajar o desenvolvimento de unidades de interface de baixo custo embutidas em dispositivos que trabalhem com o padrão;

- Acomodar os diversos meios físicos de transmissão;

- Suportar a distribuição de serviços de áudio e vídeo de banda larga com diversidade de formatos, analógicos ou digitais;

- Usar uma estratégia de comunicação distribuída sem um nó controlador central;

- Permitir que dispositivos e componentes sejam adicionados ou removidos da rede sem a ruptura do funcionamento desta e com um envolvimento mínimo do usuário (esta funcionalidade é referida como plug and play);

- Prover uma maneira amigável para que os dispositivos consigam acessar o meio de comunicação. Toda aplicação de tempo crítico tem uma maior prioridade para acesso ao meio.

Um dos principais objetivos da especificação é a compatibilidade. O protocolo inclui uma linguagem de aplicação comum (CAL) que permite que os dispositivos na rede troquem mensagens de comando e status como meio de prover a interoperabilidade entre dispositivos de diversos fabricantes. A CAL define uma sintaxe de comandos comuns e várias subunidades funcionais chamadas contextos. Cada contexto é dividido em objetos que representam várias funçőes de controle do contexto. Objetos são adicionalmente definidos por um conjunto de variáveis de instância que especificam o modo de operação do objeto.

\section{Funcionalidades}

O padrão CEBus permite a transmissão de dados por vários meios físicos: rede elétrica, par trançado, cabo coaxial, sinal infravermelho, sinal de rádio freque ência e fibra ótica. Permite o projeto de redes híbridas, ou seja, compostas por diferentes meios físicos. Todos os meios fisicos transmitem pacotes de controle em um canal na taxa de $8 \mathrm{Kbps}$ e dados em taxas variáveis dependendo do meio físico.

Mensagens podem ser endereçadas a um dispositivo ou a um grupo de dispositivos. Assim é possível a realização de comunicação tipo multicast por meio de um endereço único (endereço de grupo). O fabricante decide se o dispositivo permite comunicação de grupo ou 
não e o número máximo de grupos a que pode pertencer.

A rede não necessita de um nó controlador no barramento. Todo os nós sentem o barramento e somente o destinatário responde à ação solicitada. Desta forma o aparelho de TV pode receber um sinal infravermelho que não the é endereçado e sim a um grupo de luzes. Um roteador embutido no aparelho de TV retransmite a mensagem através de meios físicos distintos e no momento que o dispositivo destinatário recebe o sinal ele realiza a ação especificada, de acordo com a figura 2.6 .

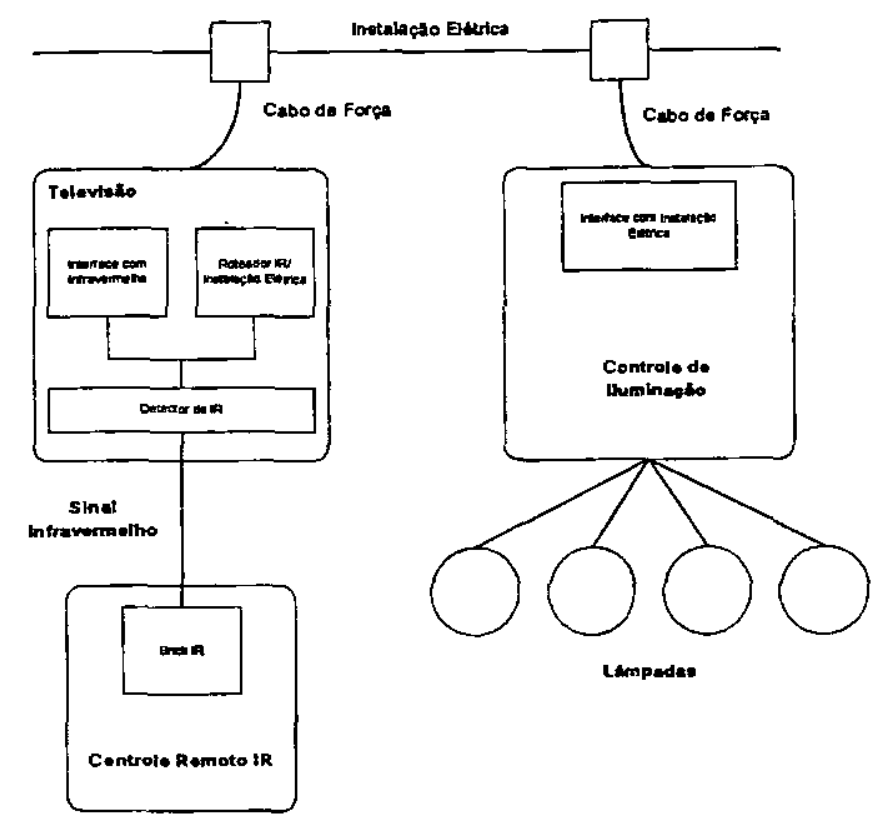

Figura 2.6 - Aplicaçăo CEBus

\section{Componentes Funcionais do Protocolo}

O padrão define um conjunto mínimo de funcionalidades, incluindo a CAL (Common Aplication Language). Dispositivos desenvolvidos de acordo com o padrão CEBus devem necessariamente conter tais funcionalidades [EIA00].

O padrão CEBus é composto por três camadas: Camada de Enlace de Dados, Camada de Rede e Camada de Aplicação. A Camada de Enlace retira pacotes do meio físico e os transfere à Camada de Rede e vice-versa. Esta camada mantém os endereços do sistema mesmo durante uma queda de energia.

A Camada de Rede toma serviços da Camada de Enlace e fornece seus serviços à Camada de Aplicação. Tem por função gerar um identificador próprio na configuração inicial 
do sistema ou na reiniciação, depois de configurado.

A Camada de Aplicação toma serviços da Camada de Rede e fornece seus serviços aos aplicativos. Possui a CAL que fornece um conjunto de comandos estendidos. Desta forma padroniza a comunicação entre dispositivos de fabricantes distintos.

\subsubsection{LonWorks}

\section{Introdução}

Uma rede operacional local (LON) consiste de dispositivos inteligentes, ligados por um ou mais meios fisicos, que se comunicam utilizando um protocolo de comunicação comum. Os nós enviam mensagens uns aos outros em resposta a mudanças ocorridas em suas variáveis e realizam ações em resposta às mensagens recebidas. Produtos desenvolvidos utilizando a tecnologia LonWorks podem ser interligados usando uma ferramenta de gerenciamento de rede [INT00].

\section{Funcionalidades}

O protocolo LonTalk proporciona aos projetistas de produtos a criação de dispositivos compatíveis, independentemente do fabricante. Para aplicações prioritárias que limitam o atraso máximo das mensagens, o protocolo fornece uma solução baseada em níveis de prioridade. Desta forma o acesso ao meio é garantido ao nó com maior prioridade tão logo a transmissão de qualquer mensagem em progresso seja finalizada.

A taxa máxima de transmissão de dados do protocolo LonTalk é de 1,25 Mbps, suficiente para mais de 500 transações por segundo.

Todos os nós projetados com base no padrão Lonworks, independentemente do fabricante, podem responder aos comandos dos nós projetados para realizar funções de gerenciamento da rede, garantindo assim a interoperabilidade dos dispositivos.

\section{Componentes do Protocolo}

Os principais elementos do padrão LonWorks são:

- Protocolo LonTalk;

- Neuron Chip.

O padrão LonWorks utiliza um protocolo de comunicação (LonTalk) para padronizar a 
comunicação na LON, o qual define um padrão para troca de informações de controle e estado. O protocolo LonTalk é um conjunto de serviços que possibilita a comunicação confiável entre os nós e faz o uso eficiente do meio de comunicação.

O projeto do protocolo LonTalk segue o modelo de referência da Organização de Padrões Internacionais para Interconexão de Sistemas Abertos (ISO/OSI) o qual prescreve a estrutura para protocolos abertos de comunicação. Para simplificar o roteamento das mensagens, o protocolo LonTalk define uma forma de endereçamento hierárquico usando endereços de domínio, sub-rede e nó. Um domínio é definido como uma coleção lógica de nós em um ou mais canais de comunicação. A comunicação é realizada entre nós sobre um domínio comum. Múltiplos domínios podem ocupar o mesmo canal e vários domínios podem ser usados como forma de evitar interferência entre nós em diferentes redes.

Um grupo de dispositivos é uma coleção lógica de nós dentro de um domínio, mas os membros não compartilham o mesmo canal de comunicação. Os grupos são um meio eficiente de usar a largura de banda para implementar uma comunicação "um para muitos".

Cada nó possui um ID de 48 bits, atribuído durante o processo de fabricação. Este ID é usado como um endereço de rede durante a instalação e configuração. Também pode ser lido e usado por programas aplicativos como um número serial único.

O Neuron Chip é o processador utilizado na tecnologia LonWorks. Todo nó Lonworks contém um Neuron Chip para processar as mensagens do protocolo LonTalk. Cada Neuron Chip possui três processadores residentes de 8 bits: Dois processadores são dedicados ao processamento do protocolo LonTalk e um terceiro dedicado ao processamento do programa aplicativo. Neuron Chips são programados na linguagem denominada Neuron $C$ que fornece uma plataforma de suporte aos objetos Lonworks. A linguagem de programação possui um tipo de dado para variável de rede que permite a comunicação de valores entre os dispositivos de diferentes fabricantes. A linguagem também suporta uma função do tipo "when" que é usada para agendar a execução de tarefas em eventos pré-definidos pelo usuário. $\mathrm{O}$ Neuron $\mathrm{C}$ fornece uma sintaxe para declaração de um grande número de objetos de E/S.

O Neuron Chip possui as seguintes funções implementadas:

- Software de comunicação do protocolo LonTalk;

- Um driver gerenciador de eventos;

- Suporte em tempo de execução dos objetos de $\mathrm{I} / \mathrm{O}$; 
Bibliotecas aritméticas, lógicas e de conversão.

\subsubsection{IEEE-1394}

\section{Introdução}

IEEE-1394 é uma interface digital que integra equipamentos de entretenimento, comunicação e computação. Fornece uma especificação não proprietária e de alta velocidade para interconexão de dispositivos digitais [HOF00].

A interface digital IEEE-1394 é padronizada pelo IEEE (Instituto dos Engenheiros Elétricos e Eletrônicos) e permite a troca de dados a altas velocidades, cerca de $400 \mathrm{Mbps}$, entre equipamentos multimídia como filmadoras, computadores e equipamentos de áudio e vídeo digital [IEE00].

O barramento pode transportar uma variedade de tipos diferentes de sinais digitais como vídeo comprimido, áudio digitalizado e comandos de controle de equipamentos em uma interface serial. O padrão 1394 fornece também uma estrutura de barramento paralelo, denominado "backplane", adicionando assim flexibilidade à estrutura fisica do barramento. Possui um conector multimídia padronizado. A estrutura do barramento possibilita uma evolução progressiva, com um custo efetivo que vai ao encontro da demanda multimidia emergente [FUNO0].

\section{Funcionalidades}

O protocolo é centrado nos seguintes pontos básicos [LEE00]:

- Padrões de hardware e software para o transporte de dados a 100, 200 ou $400 \mathrm{Mbps}$;

- Aplicaçð̃es multimídia com taxas de transferência de dados em tempo real;

- Não é necessária a conversão dos dados digitais em analógicos;

- Conexão e desconexão de dispositivos sem a perda de dados ou ruptura da rede;

- Configuração automática plug and play;

- Facilidade de uso sem a necessidade de terminadores individuais ou configurações elaboradas;

- Topologia flexivel; 
- Protocolo não-proprietário não havendo necessidade de licença para o desenvolvimento de produtos;

- O gerenciamento do barramento fornece a configuração completa do barramento serial otimizando a arbitração, garantia de alimentação elétrica para todos os dispositivos, identificador de canal síncrono e notificação de erros.

O barramento serial pode integrar diversos subsistemas dentro de uma unidade. Pode conectar sistemas incompativeis como dispositivos ATM (Asynchronous Transfer Mode), equipamentos de vídeo digital, discos de vídeo digital (DVDs) e sistemas MPEG, entre outros [IEE98].

\section{Componentes do Protocolo}

Três camadas são especificadas proporcionando a um dispositivo (host) a comunicação com outro dispositivo periférico [LEE00], conforme a figura 2.7 .

O padrão IEEE-1394 segue uma arquitetura de registrador de estado e controle, como definido no pađrão IEEE-1212. Os 16 bits de maior ordem do endereço representam a identificação do nó. Um nó é um dispositivo endereçável em um barramento serial. A identificação do nó é dividida em dois campos: os 10 bits de ordem maior especificam a identificação do barramento e os 6 bits de ordem menor especificam a identificação do nó. É possível o endereçamento de 1023 barramentos com 63 nós por barramento.

Cada nó possui três conectores, embora o padrão permita até 27 conectores por dispositivo.

Uma "ponte-barramento" liga barramentos de tipos iguais ou diferentes. Uma interface IEEE-1394/PCI dentro de um PC constitui uma "ponte-barramento" que funciona como um dispositivo atuando como controlador do barramento.

A Camada Física possui três funçōes primárias: transferência de dados, arbitração e especificação das interfaces elétrica e mecânica. Esta camada recebe os dados da Camada de Enlace e os transforma em sinais elétricos alimentando o barramento. Realiza um serviço de arbitragem para permitir que um nó acesse o barramento e garante que apenas um nó esteja transmitindo seus dados num determinado instante. Especifica a interface mecânica para o barramento serial e o "backplane", embora os diferentes tipos de barramento tenham Camadas Físicas diferentes, e fornece uma solução para a codificação de dados e acesso ao meio fisico. 


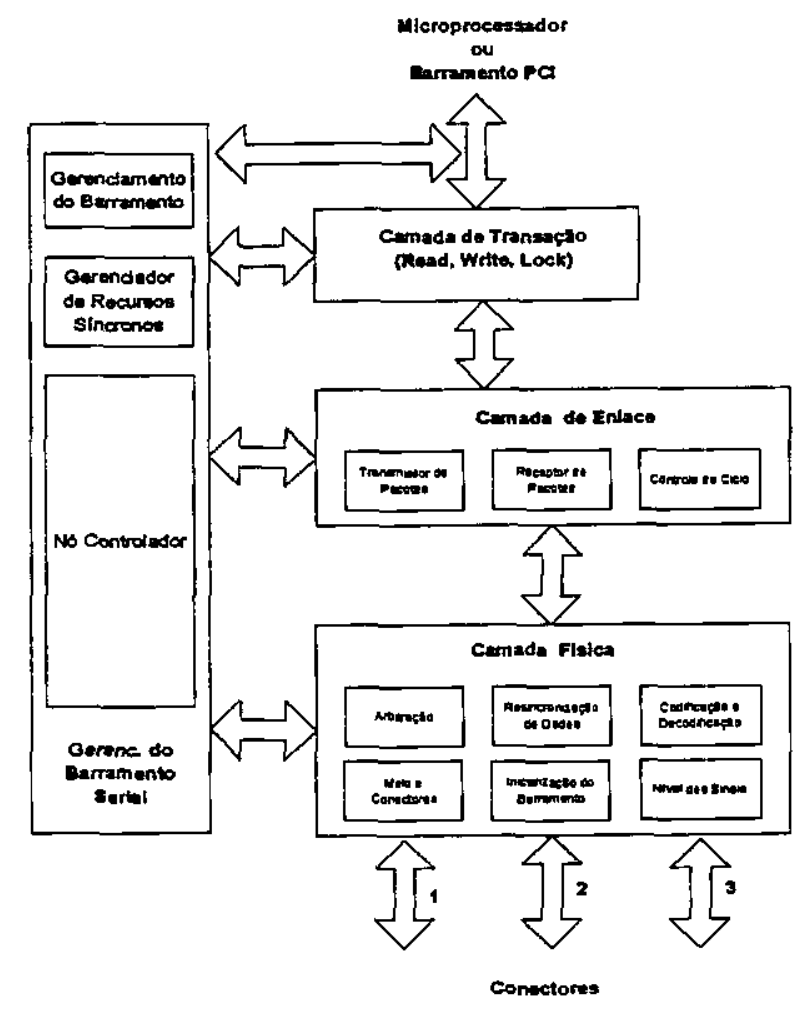

Figura 2.7 - Camadas do Protocolo IEEE-1394

Durante a transmissão de um pacote a interface opera no modo half duplex, permitindo a transmissão em ambos os sentidos. $\mathrm{Na}$ transferência de dados, dois sinais estão ativos no barramento: Data e Strobe. O sinal Data é acompanhado pelo sinal de Strobe que muda de estado quando são enviados pela linha de dados dois bits iguais consecutivamente.

A Camada de Enlace é a interface entre a Camada Física e a Camada de Transação. Esta camada tem como funções principais:

- Conferir os dados recebidos;

- Enviar e receber dados síncronos e assíncronos;

- Examinar a informação contida no cabeçalho e determinar qual é o tipo da transação em progresso.

Uma das funções mais importantes dentro do protocolo é a de transferência de dados entre os dispositivos do barramento. A unidade de dados básica da camada é o pacote e seu ack correspondente. Há dois tipos de transmissões de dados: assíncronas e síncronas.

Transmissão Assíncrona - transmite uma quantidade variável de dados para um nó específico. Um ack é retornado para o nó fonte quando a transmissão é realizada com sucesso. 
Todas as ações na transmissão assíncrona são separadas por intervalos durante os quais o barramento permanece ocioso.

Transmissão Síncrona - transmite uma quantidade variável de dados em intervalos regulares com endereçamento simplificado. Não necessita de ack proveniente do dispositivo de destino. O tamanho máximo do pacote é determinado pelo processo de gerenciamento do barramento.

O protocolo IEEE-1394 usa um mecanismo request-response com confirmações geradas em cada fase [FUN00]. A Camada de Transação só realiza transaçóes assíncronas, permitindo a execução de transações atômicas com a utilização de chaves. Esta camada fornece seus serviços para a Camada de Enlace e para a Camada de Gerenciamento do Barramento.

O padrão IEEE-1394 utiliza um sistema de gerenciamento do barramento que fornece conectividade com uma grande quantidade de dispositivos. O sistema de gerenciamento não necessariamente é implementado em um PC, podendo estar implementado em um dispositivo microprocessado qualquer, por exemplo, um aparelho de TV.

O gerenciamento do barramento fornece os seguintes serviços:

- Um gerenciador de barramento que realiza o broadcast do pacote de início do ciclo;

- Um gerenciador de recursos síncronos, no caso dos nós permitirem comunicação sincrona;

- Um controlador do barramento (opcional).

No mínimo um nó, em um barramento serial, deve possuir um gerenciador de recursos síncronos se o barramento permite transações síncronas. O gerenciador de recursos síncronos fornece as facilidades necessárias para a alocação e desalocação de recursos, canais e banda de transmissão de forma que a comunicação síncrona possa ser realizada. $\mathrm{Na}$ ausência de um gerenciador do barramento o gerenciador de recursos síncronos pode realizar o gerenciamento. 


\subsubsection{Universal Plug and Play (UPnP)}

\section{Introdução}

A arquitetura UPnP é uma arquitetura de rede aberta projetada para fornecer comunicação simples entre dispositivos e serviços distribuídos de diversos fabricantes [UNI99].

O custo, tamanho e consumo de energia dos computadores, incluindo processamento, armazenamento e displays, estão caindo abruptamente. Por conseguinte tornou-se viável a interligação de dispositivos standalone como câmeras digitais, dispositivos tocadores de áudio, telefones móveis e palmtops.

O modelo UPnP é a World Wide Web. A Web teve sucesso pela utilização de protocolos abertos e os formatos de dados HTTP e HTML. É este aspecto da Web que garante a interação de clientes e servidores com diferentes sistemas operacionais, chips e plataformas de servidores. O objetivo é a obtenção de uma alta flexibilidade na especificação de todo e qualquer componente da rede [SAL99].

De uma maneira geral, os dispositivos normalmente conseguem uma funcionalidade maior quando interligados. Um cenário possível é a captura de uma imagem digital combinada com sua manipulação em um PC, armazenamento e transferência por e-mail.

\section{Funcionalidades}

O padrão UPnP, desenvolvido pela Microsoft Corporation juntamente com outros fabricantes de dispositivos domésticos, permite a um sistema computacional se autoconfigurar dentro de uma rede. Adicionalmente permite que dispositivos inteligentes identifiquem outros na rede. Quando um dispositivo é inserido na rede ele se auto-anuncia e oferece seus serviços sem a necessidade de uma configuração complexa [SAL99].

A Internet criou o conceito de comunicação simples, universal, independente da tecnologia de transmissão e independente de um único fabricante. $\mathrm{O}$ protocolo IP (Internet Protocol) é a base do UPnP devido à sua habilidade de permitir a conexão de diferentes meios fisicos e a interoperação entre hardware e so ftware de diversos fabricantes.

\section{Componentes do Protocolo}

O padrão UPnP é uma arquitetura distribuída no nível de aplicação, onde os nós lógicos da rede são pontos de controle do usuário, dispositivos controlados ou pontes. O protocolo SSDP (Simple Service Discovery Protocol) permite que os outros dispositivos da rede 
saibam da existência de dispositivos e os respectivos endereços IP, necessários para o estabelecimento da conexão TCP/IP, constituindo-se assim em uma ferramenta para a busca de serviços na rede. O resultado de uma busca do protocolo SSDP é uma URL (Uniform Resource Locator). O Hostname embutido na URL pode ser resolvido em um endereço IP que pode ser usado para estabelecer uma conexão [UN199]. O mecanismo consiste da realização de um multicast baseado no protocolo UDP (User Datagram Protocol), objetivando a descoberta de um serviço de Lookup disponível. A partir deste momento a comunicação visando o registro e a consulta dos dispositivos é baseada no protocolo TCP/IP. Os nós da rede podem ser adicionados e removidos da rede, de forma dinâmica e transparente, por meio de um registro que especifica a vida útil do dispositivo.

Uma GENA (Generic Eventing Notification) permite que um dispositivo possa iniciar a comunicação com um ou mais dispositivos que tenham expressado a intenção de receber informações sobre alterações em uma determinada variável. Toda mudança na tabela de estados do serviço (SST) gera um evento para notificar todos os pontos de controle do usuário interessados em tal mudança.

Os pontos de controle do usuário estão sincronizados com os dispositivos controlados. Os pontos de controle do usuário possuem uma interface com o usuário usada para comunicação com um ou mais dispositivos controlados remotamente. A diferença básica entre um ponto de controle do usuário e um dispositivo controlado é que o ponto de controle do usuário é sempre um iniciador da comunicação. Após a realização da comunicação inicial o ponto de controle do usuário está apto a receber notificações de eventos dos dispositivos controlados, conforme a figura 2.8 .

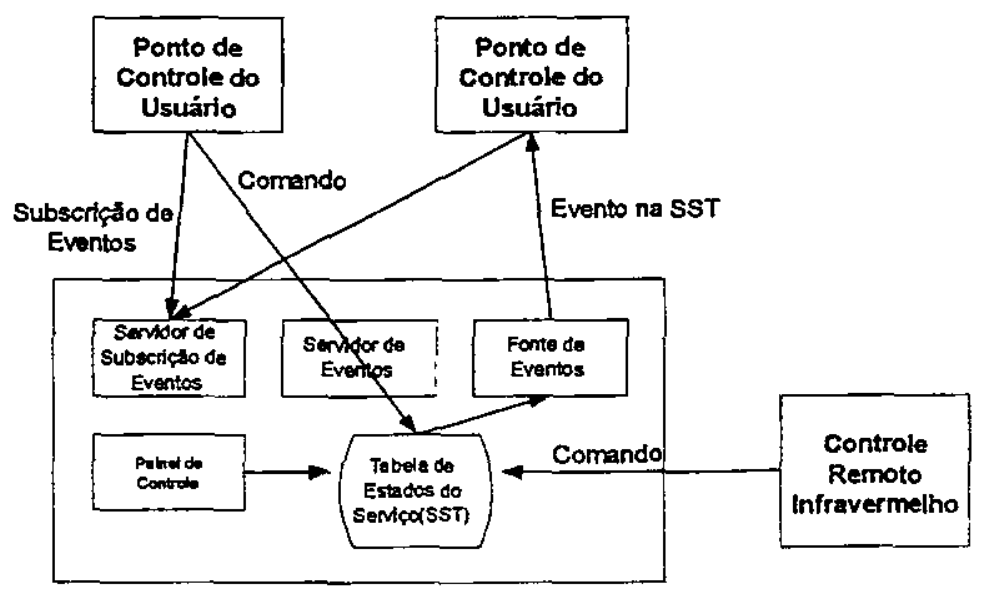

Figura 2.8 - Sincronização dos Pontos de Controle do Usuário 
No padrão UPnP as bridges ligam dispositivos que não são nativos UPnP com dispositivos UPnP nativos. A ponte aparece para pontos de controle dos usuários como um conjunto de dispositivos controlados, como apresentado na figura 2.9.

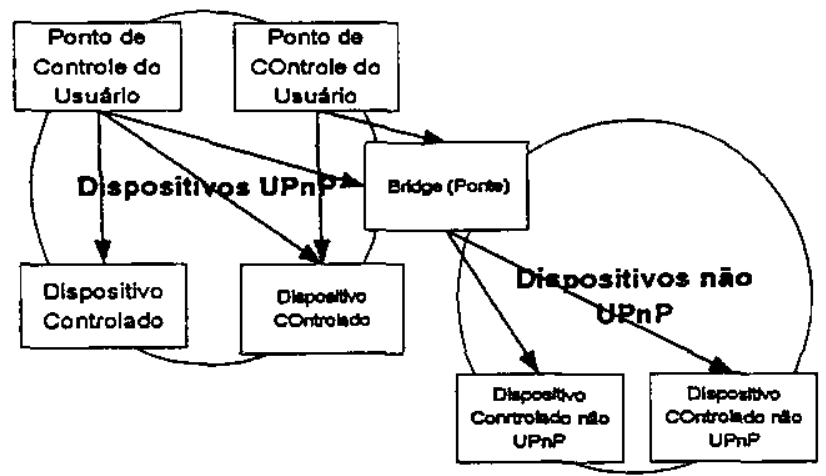

Figura 2.9 - Pontos de Controle, Dispositivos Controlados e Pontes

Uma entidade controlável no protocolo UPnP é um serviço. Toda instância de um serviço inclui:

- Uma tabela de estados do serviço (SST) que representa seu estado corrente, constituindo uma fonte de informações;

- Um servidor de controle, que aceita comandos do protocolo SCP (Service Control Protocol). SCP é um protocolo usado para invocar comandos sobre um serviço e retornar os resultados obtidos. Há somente um SCP por serviço;

- Um servidor de subscrição de eventos.

A SST consiste de linhas do tipo:

VARIÁ VEL, TIPO, VALORES LEGAIS, VALOR PADRÃO, VALOR CORRENTE. Esta representação assegura que o estado de um serviço seja facilmente disponível a múltiplos pontos de controle do usuário.

O modelo de dispositivo UPnP é o modelo de um dispositivo controlado ou uma ponte que emula o controle de dispositivos nativos. Um dispositivo UPnP fornece um ou mais serviços. Geralmente um dispositivo representa uma entidade física como um VCR (Vídeo Cassete Recorder), mas também um PC emulando um VCR pode ser entendido como um dispositivo.

Todo dispositivo possui um identificador global único UDN (Unique Device Name). $\mathrm{O}$ UDN é um identificador UPnP único impossivel de ser alterado. Toda associação persistente 
entre dispositivos deve obrigatoriamente armazenar o UDN com o objetivo de identificar sem ambiguidades o dispositivo alvo.

O UPnP é construído sobre o protocolo HTTP e usa o mesmo padrão de endereçamento da Web, ou seja, URLs. As URLs normalmente contêm uma identificação da familia de protocolos (http) para a qual a URL é válida, um Hostname e um caminho. Uma amostra de alocação de um serviço é mostrada abaixo:

http://device.local/description/path/description.xml

Segue que "device.local" é o Hostname do dispositivo controlado e "description/path/description.xml" é o caminho e o nome do documento de descrição do dispositivo. Sempre que um Hostname muda sua URL ficam automaticamente cancelados todos os registros do dispositivo em todos os pontos de controle do usuário.

Um Rehydrator é um módulo de software que expõe uma API para aplicações e invoca comandos de um serviço ou consultas a estados dos serviços. A função primária do Rehydrator é fazer a interface entre API e SCP que invoca os comandos, conforme a figura 2.10 .

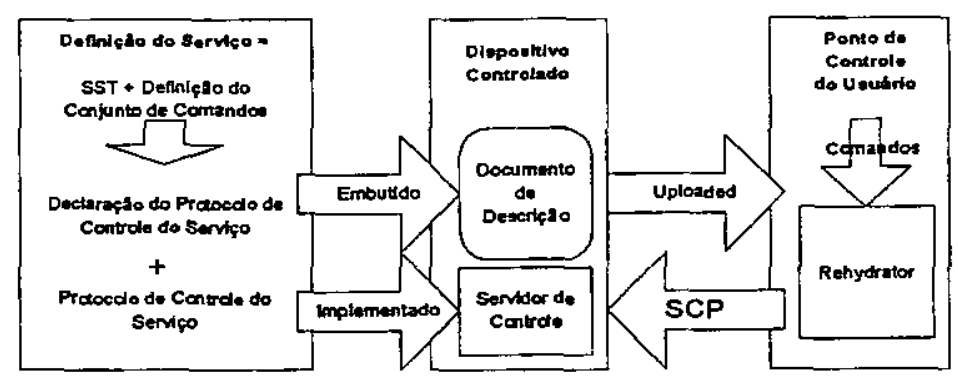

Figura 2.10 - Funcionamento do Rehydrator

\subsubsection{Jini}

\section{Introdução}

Jini é uma tecnologia de rede baseada na linguagem de programação Java voltada à comunicação de dispositivos eletrônicos que vão de computadores a eletrodomésticos. A proposta combina grupos de dispositivos e software dentro de um sistema distribuído simples e dinâmico que é capaz de alterar dinamicamente sua topologia [VEN99].

A idéia base é a formação de uma federação de equipamentos onde alguns fornecem 
serviços enquanto outros consomem. O objetivo é tornar a rede flexível e facilmente administrada. Os recursos podem ser implementados em hardware ou software. $O$ dinamismo da rede é alcançado pela adição e subtração de serviços automaticamente, ou seja, não é necessária a intervenção humana para a reconfiguração da rede após os eventos [JIN99].

Um sistema Jini é composto dos seguintes componentes:

- Uma infraestrutura básica que permite a criação de serviços federados;

- Uma linguagem de programação que permite a implementação de serviços distribuídos confiáveis;

- Serviços que fazem parte do sistema.

\section{Funcionalidades}

A tecnologia Jini está apta a fornecer a infra-estrutura necessária aos sistemas distribuídos baseados em dispositivos microprocessados [VEN99].

O protocolo Jini permite que serviços implementados em hardware ou software se cadastrem em uma rede através da propriedade que a linguagem de programação Java possui de movimentar linhas de código. Assim é possível que aplicações sofisticadas sejam desenvolvidas com base na linguagem de programação Embedded Java e sejam armazenadas e executadas em dispositivos com recursos limitados, inclusive dispositivos do tipo embedded.

O protocolo Jini define um conjunto de regras e serviços que disciplinam uma federação de dispositivos onde alguns fornecem enquanto outros consomem serviços. Não é necessário que a implementação de um serviço use o modelo de programação Jini, mas os serviços devem usar o modelo para que ocorra a interação com a infra-estrutura da tecnologia Jini. Não há a necessidade de um nó controlador central na rede.

A principal característica do protocolo está centrada na simplicidade proporcionada ao usuário na utilização dos recursos disponíveis na rede. Os serviços Discovery, Join e Lookup fazem com que o usuário não necessite conhecer detalhes da configuração da rede como acontece nos protocolos de rede utilizados atualmente.

\section{Componentes do Protocolo}

Serviço é o conceito mais importante na arquitetura Jini. Um serviço é uma entidade que pode ser usada por uma pessoa, um programa ou outro serviço. Um serviço pode ser 
armazenamento de dados, um canal de comunicação ou computação fornecida a outro usuário, programa filtro ou dispositivo de hardware. Os serviços se comunicam usando um protocolo de serviço, aberto, constituído por um conjunto de interfaces escritas na linguagem de programação Java. Por exemplo, a impressão de um documento requisitada por um processador de texto é um serviço na arquitetura Jini.

O serviço de Lookup intermedia a transação entre fornecedores e consumidores de serviços. É um mecanismo central no sistema sendo o maior ponto de contato entre o sistema e os seus usuários, mapeando interfaces para serviços e indicando a função desempenhada pelo serviço.

A movimentação de código proporcionada pela linguagem Java assegura que a interface do serviço esteja sempre atualizada, pois quem disponibiliza a interface ao serviço de Lookup é o próprio provedor do serviço.

Quando um dispositivo é conectado à rede imediatamente usa o protocolo Discovery com o objetivo de descobrir a locação de um serviço de Lookup na rede, realizando um broadcast, conforme mostrado na figura 2.11 .

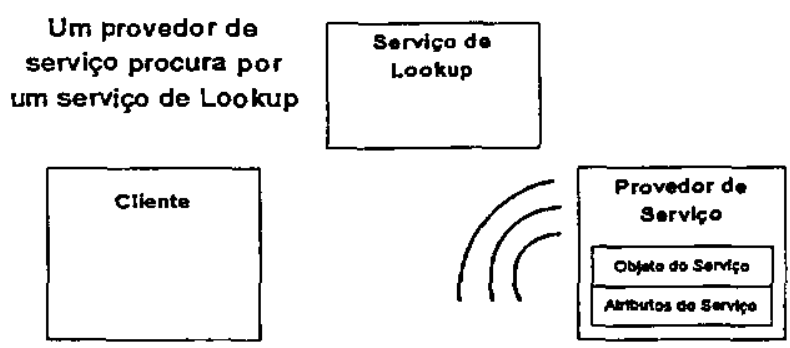

Figura 2.11 - Funcionamento do Protocolo de Lookup

Após a busca o serviço é registrado no servidor de Lookup usando o protocolo Join. Tal registro contém uma interface Java que inclui métodos invocados pelo usuário no momento da execução do serviço, ver figura 2.12 .

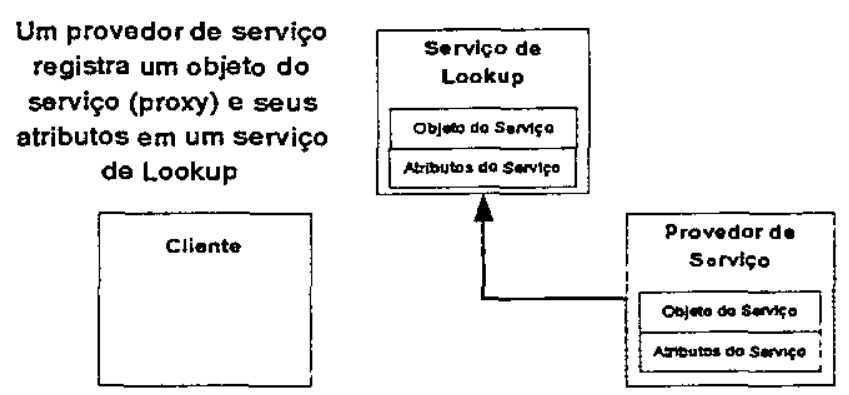

Figura 2.12 - Funcionamento do Protocolo Join 
Um membro da rede obtém informações sobre um determinado tipo de serviço através dos atributos da interface registrada junto ao servidor de Lookup. $O$ código da interface é então transferido, conforme a figura 2.13.

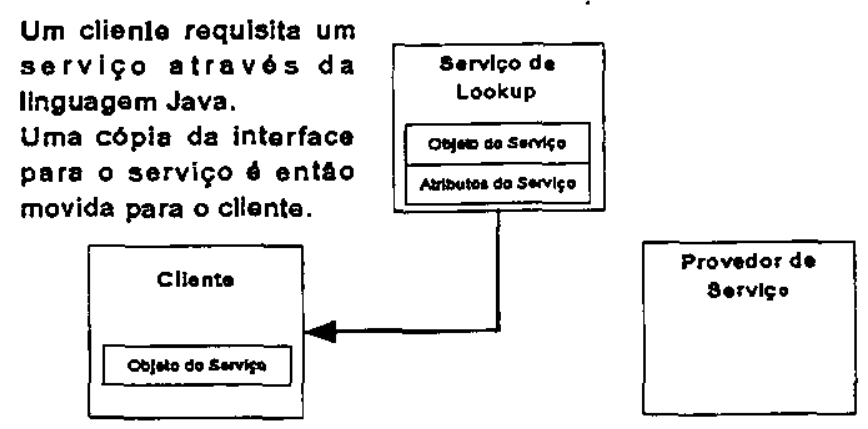

Figu ra 2.13 - Transferência da interface do serviço de Lookup para o cliente

A partir desse ponto o cliente invoca diretamente o serviço desejado sem a intervenção do Lookup, de acordo com a figura 2.14.

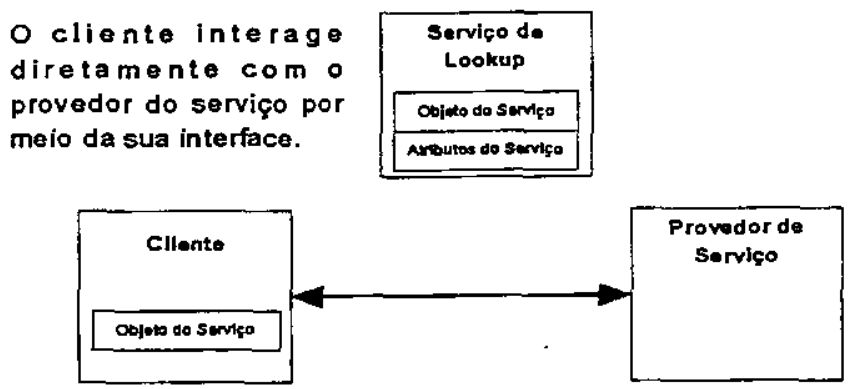

\section{Figura 2..14 - Interação Cliente-Servidor}

A comunicação entre serviços é realizada usando RMI (Remote Method Invocation). A comunicação entre serviços não é um sèrviço que possa ser descoberto e usado, é parte da infra-estrutura da tecnologia Jini. O método RMI não só permite a movimentação de dados entre objetos da rede como também a movimentação de objetos completos, inclusive códigos.

O acesso a muitos dos serviços no sistema Jini é baseado em uma permissão de acesso cedida durante um certo periodo de tempo (lease). Caso um lease não seja renovado antes de ser liberado, entende-se que o recurso não é necessário, o cliente fathou ou não foi permitida a renovação da permissão. Conseqũentemente o usuário e o provedor do recurso entendem que o recurso pode ser liberado.

A arquitetura Jini permite a ocorrência de eventos distribuídos. Um objeto pode permitir que outros objetos que tenham interesse em seus eventos recebam uma notificação da ocorrência dos mesmos. Isto permite que programas baseados em eventos distribuídos sejam 
escritos de maneira confiável possibilitando a opção de crescimento futuro.

A infra-estrutura do padrão é composta por um conjunto de componentes que são agrupados de forma a construir uma federação. São componentes fundamentais da arquitetura:

- Um sistema distribuído seguro com comunicação baseada em RMI fornecido pela plataforma Java;

- Os protocolos Discovery e Join que permitem aos serviços descobrir, tomar parte e anunciar seus serviços aos outros membros da federação;

- O serviço de Lookup que atua como um repositório de serviços. Os serviços são registrados no Lookup como objetos escritos em Java. Tais objetos atuam como proxies para o serviço em questão.

\subsubsection{Bluetooth}

\section{Introdução}

Bluetooth é essencialmente um protocolo voltado à interligação, sem fiação, de dispositivos microprocessados com reduzida intervenção por parte do usuário. São características objetivadas pelo padrão: robustez, baixa complexidade, baixo consumo e baixo custo [BLU01].

\section{Funcionalidades}

O padrão Bluetooth é uma tecnologia nova que utiliza comunicação entre dispositivos através de ondas de rádio, objetiva substituir as conexđ̃es por meio de cabos tanto de dispositivos portáteis quanto dispositivos eletrônicos fixos. Conseqũentemente tais links de rádio substituirão uma grande quantidade de cabos proprietários [COM01].

O protocolo Bluetooth pretende interligar inúmeros dispositivos, como por exemplo, PDAs (Personal Digital Assistents), laptops, geladeiras, termostatos e muitos outros. Pode ainda ser usado para transformar o telefone celular em um controle remoto doméstico, controlando desde o forno de microondas até o sistema de áudio e vídeo [BLU01].

Permite a implementação de sistemas distribuídos baseados nos conceitos piconet e scaternet. Dois ou mais dispositivos que compartilham o mesmo canal formam uma piconet. Múltiplas piconets em uma mesma área ou em um mesmo sistema de comunicação formam uma scaternet. 
A transmissão de dados, entre dois dispositivos no padrão Bluetooth, é realizada em modo full duplex. Implementa dois modos de comunicação entre integrantes da rede: comunicação "um-para-um" e "um-para-muitos". No primeiro tipo a comunicação pode ser síncrona ou assíncrona e no segundo caso somente comunicação assíncrona é possível. Atualmente, o padrão Bluetooth apresenta uma taxa bruta de transmissão de dados de 1 Mbps.

\section{Componentes do Protocolo}

São componentes do padrão Bluetooth: comunicação por meio de rádio e os protocolos Baseband, de Gerenciamento de Canais (LMP), de Interface Controladora do Host (HCI), de Controle de Link Lógico e Aplicação (L2CAP) e RFCOMM. A pilha de protocolos Bluetooth é apresentada na figura 2.15:

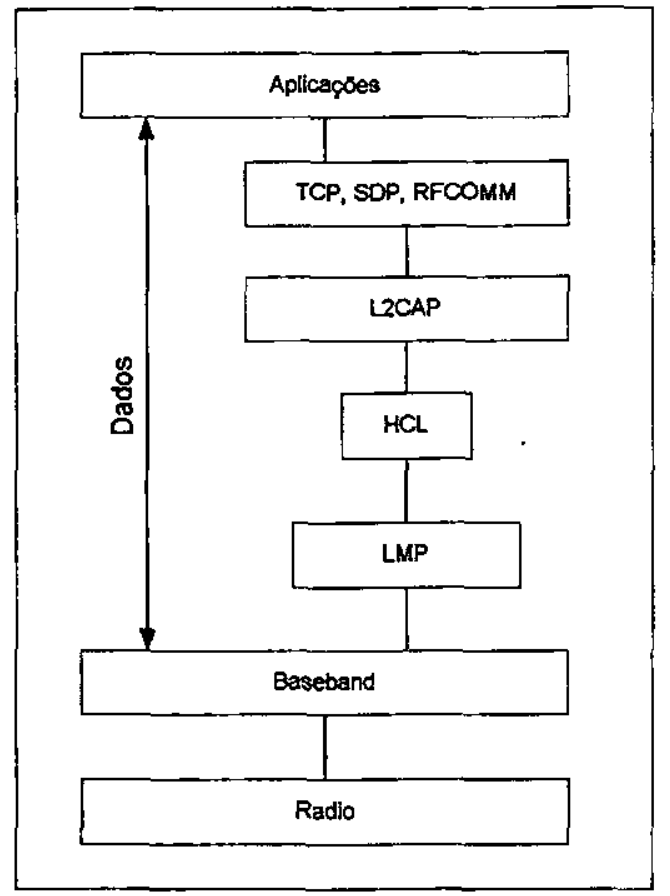

Figura 2.15 - Pilha de Protocolos Bluetooth

Um dispositivo Bluetooth possui uma unidade de rádio, uma unidade para gerenciamento de conexões e funções de interface entre terminais. $O$ rádio opera na faixa de frequêência de $2.4 \mathrm{GHz}$. Suporta no máximo 79 canais de rádio frequêência na banda de 2400 a $2497 \mathrm{MHz}$. Na Espanha, França e Japão o padrão suporta no máximo 23 canais de rádio frequência. $\mathrm{O}$ alcance do rádio Bluetooth está entre $10 \mathrm{~m}$ e $100 \mathrm{~m}$ dependendo da potência do transmissor.

A Camada Baseband é a camada fisica do protocolo entregando pacotes no formato Bluetooth para que a transmissão através de ondas de rádio seja realizada. $O$ 
protocolo situa-se na base da pilha de protocolos Bluetooth e atua como um controlador de conexão, gerencia transmissões de dados síncronas e assíncronas, realiza o tratamento de pacotes e gerencia o acesso aos demais dispositivos Bluetooth. O protocolo Baseband fornece dois tipos de transmissão de dados: transmissão de dados síncrona (SCO) e transmissão nãoorientada a conexão (ACL).

SCO: transmissão síncrona orientada à conexão, ou seja, é uma conexão síncrona chaveada por circuito, por exemplo, transmissão de voz entre dois dispositivos. Este tipo de comunicação periodicamente reserva alguns slots para a transmissão dos dados, os pacotes SCO não possuem correção de erro e nunca são retransmitidos.

ACL:transmissão assíncrona não orientada à conexão, ou seja, é uma conexão chaveada por pacotes sem garantia de entrega. Enquadra-se nesta categoria de transmissão a realização de um multicast de um dispositivo para os demais.

O padrão Bluetooth utiliza o esquema de transmissão Time Division Duplex (TDD) que realiza transmissão de dados em modo full duplex. A transmissão utiliza a modulação de dados Gaussian Frequency Shift Keying (GFSK) [BLU00].

O protocolo LMP realiza o gerenciamento da comunicação entre os dispositivos das piconets, configura conexóes e cuida da segurança na comunicação através do uso de encriptação. $O$ dispositivo que inicia a conexão é o dispositivo mestre da conexão. Um mestre pode estar conectado a no máximo sete dispositivos. O compartilhamento do canal é gerenciado pelo dispositivo mestre.

A Camada HCI situa-se entre as Camadas Baseband, LMP e L2CAP. Este protocolo fornece um método para que a Camada L2CAP tenha acesso a comandos fornecidos pelas Camadas Baseband e LMP, a registradores de estado do hardware, a registradores de controle e a registradores de evento.

A Camada de Controle de Conexão Lógica e o Protocolo de Adaptação (L2CAP) fornecem a camadas superiores dois tipos de comunicação: orientada à conexão e não orientada à conexão. A Camada L2CAP fornece serviços de multiplexação de pacotes provenientes de protocolos superiores, segmentação e remontagem dos mesmos e comunicação de grupo. O comprimento máximo dos pacotes de dados suportado por L2CAP é de 64 kilobytes.

A camada RFCOMM é basicamente um protocolo de transporte simples que emula uma porta de comunicação serial. Suporta até 60 conexões simultâneas entre dois dispositivos. 
O protocolo SDP (Service Discovery Protocol) usa um modelo de requisições e respostas onde cada transação consiste em uma requisição e uma resposta, requisições podem ser enfileiradas em um buffer e as respostas podem chegar fora de ordem. O ponto central do protocolo é permitir que os dispositivos Bluetooth descubram quais serviços os demais podem fornecer. Com esta finalidade o SDP possui alguns serviços internos, tem-se a busca por um determinado serviço (Search) e a navegação por serviços disponíveis (Browser).

Search: permite que um cliente obtenha o controle de um serviço baseado nos atributos registrados para tal serviço. A busca é possível somente para valores cujo tipo é identificador universal único (UUID). Uma busca por um serviço é realizada sobre uma lista de UUIDs que são relacionados com os registros do serviço.

Browser: busca por qualquer serviço disponfvel, este serviço é baseado em atributos compartilhados por classes de serviço. $O$ atributo compartilhado é denominado BrowseGroupList e contém uma lista de UUIDs. Cada UUID representa um grupo com o qual um serviço pode estar associado. 


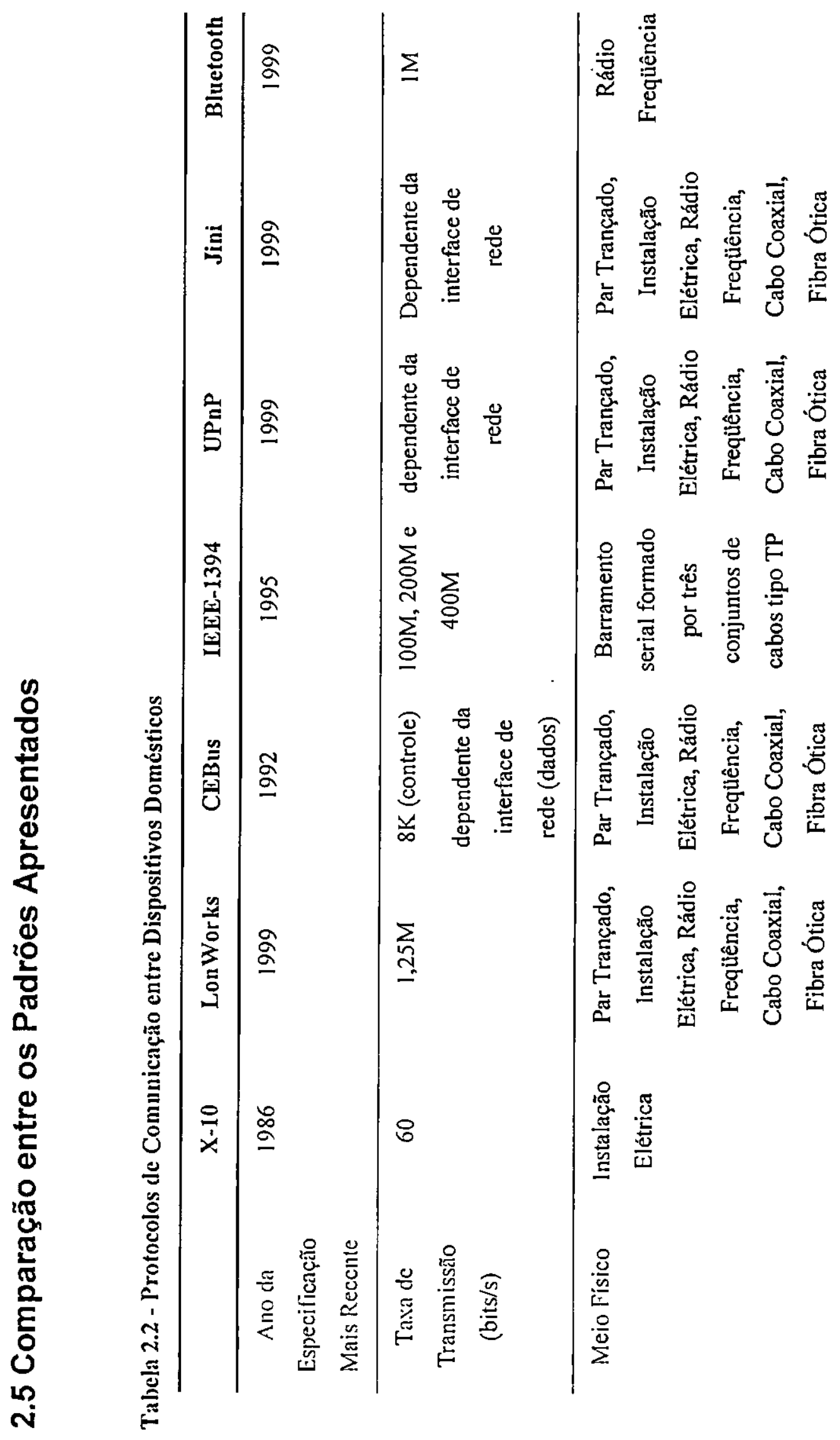




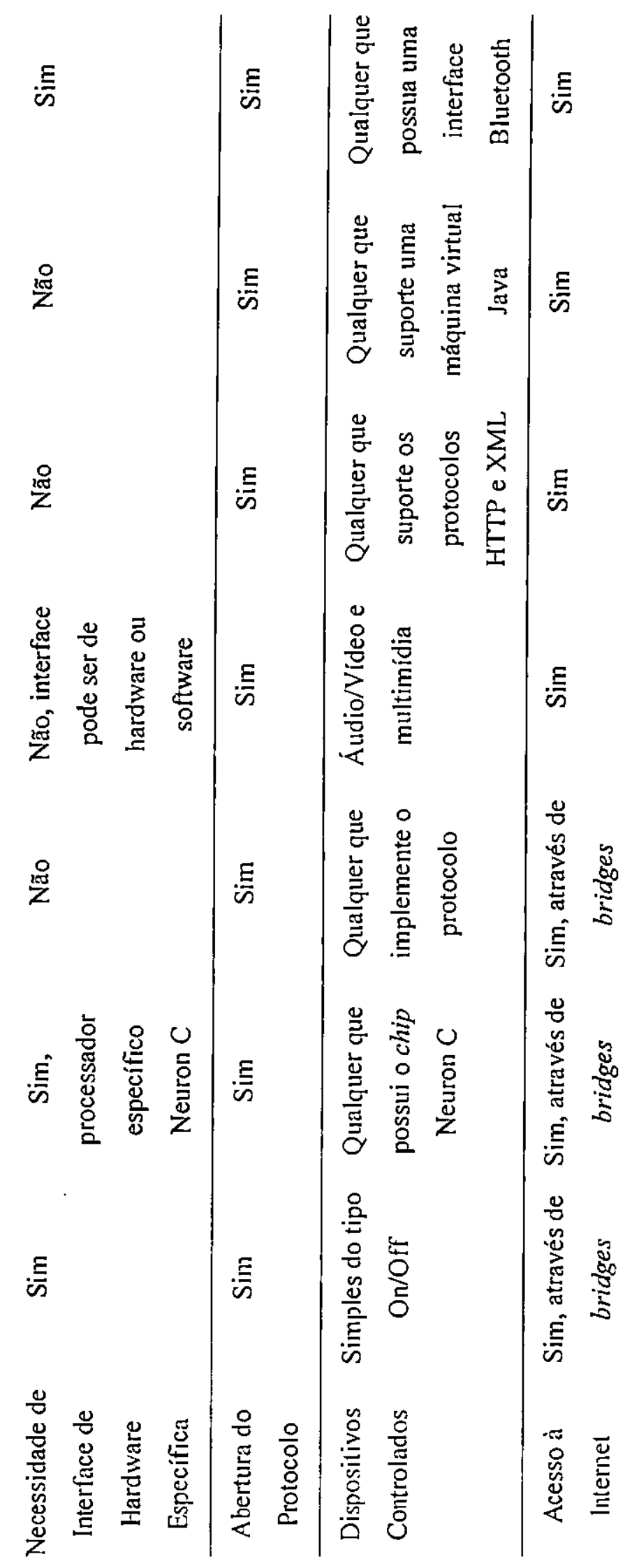




\subsection{Métodos de Identificação Biométricos}

A palavra biometria significa literalmente, a medida da vida. A biometria utilizada em sistemas computacionais se refere aos métodos de identificação de pessoas baseados em suas características físicas únicas ou aspectos comportamentais [SISO1].

A validação de usuários é o aspecto principal quando se fala em segurança da informação. Normalmente, as pessoas obtêm acesso a instalações ou a informações por meio de senhas ou cartões magnéticos. Uma nova forma de permissão de acesso a sistemas seguros pode ser feita utilizando-se a biometria. A biometria funciona porque o ser humano possui características corporais únicas e estáveis. Pode-se citar impressões digitais, traços faciais, características fisicas dos olhos e voz entre outras.

Os dispositivos de aquisição de características biométricas extraem as características-chave do usuário e as convertem em um padrão único. Na prática, o sistema extrai um valor que representa a identidade biométrica do usuário para a característica analisada.

\section{Impressão Digital}

O reconhecimento de impressões digitais é um dos métodos mais simples e baratos de ser integrado a um aplicativo. Por este motivo, os produtos que se baseiam na tomada de impressões digitais são os mais difundidos até o momento.

O método requer um scanner capaz de capturar, com um bom nível de precisão, os traços que definem a impressão dos dedos, além de um programa que trate a imagem capturada e faça o reconhecimento digital da mesma.

\section{Reconhecimento da Face}

Para reconhecer o rosto de uma pessoa, os programas mapeiam a geometria e as proporções da face. O software de reconhecimento registra vários pontos delimitadores da face. Este é capaz de definir proporções, distáncias, tamanhos e formas de cada elemento do rosto, como olhos, nariz, queixo, maçãs do rosto e orelhas. Da mesma forma que nós humanos somos capazes de reconhecer alguém, mesmo que ele esteja mudado sutilmente, o programa de reconhecimento pode prender-se aos detalhes mais marcantes que identificam o rosto da uma pessoa.

\section{Identificação pela Íris}

A íris do olho humano (a parte colorida dos olhos, em torno da pupila) é uma imagem complexa e única para cada pessoa. O reconhecimento da íris é bastante preciso por ser imutável 
com o passar dos anos e pouco suscetível a alterações como sujeira ou machucados que deixam cicatrizes. Lentes e óculos não muito escuros podem ser usados sem comprometer o desempenho do reconhecimento. Para implementar esse tipo de sistema biométrico são necessários uma câmera e um programa de reconhecimento.

\section{Identificação da Retina}

A retina é a parte do fundo do olho, consistindo de uma camada interna composta por vasos sangüíneos que desenham um padrão único e pessoal. $A$ imagem da retina forma um padrão que é o mais preciso dentre todos os métodos biométricos. A captura dessa imagem é difícil e incômoda, é necessário que o usuário olhe fixamente para um ponto até que a câmera focalize os padrōes e os capture.

\section{Reconhecimento da Voz}

Este método realiza uma análise dos padrões harmônicos e não somente a comparação entre reproduções de uma mesma fala. Os sistemas mais recentes solicitam que o usuário fale em voz alta uma sequêencia aleatória de números ou umà frase qualquer, inviabilizando também a tentativa de uso de voz gravada em fita cassete. Ruído no ambiente e o estado emocional do usuário são fatores que limitam a precisão do reconhecimento. É comum que um usuário legítimo seja recusado pelo sistema caso ele esteja rouco, fatigado ou exaltado demais.

\section{Geometria das Mãos, Dedos e Palma}

Trata-se de três sistemas distintos que utilizam um scanner especialmente desenhado para capturar a imagem de cada um desses três elementos biométricos. Em se tratando de reconhecimento da geometria das mãos e dedos, o scanner captura a imagem tridimensional a qual é convertida em um modelo geométrico que é então verificado. No caso da palma da mão, o sistema é focado no desenho das linhas, saliências e outros detalhes, o que o faz muito parecido com os sistemas de reconhecimento de impressões digitais.

\subsection{Dispositivos de Entrada de Dados}

A entrada de dados está relacionada com o registro dos dados e instruções em um sistema computacional. Objetivando interagir de forma efetiva com o sistema, os usuários devem ser capazes de comunicar suas intenções de forma que a máquina possa interpretá-las. Nesta linha de raciocínio, um dispositivo de entrada associado a um software, transforma a informação 
fornecida pelo usuário em dados os quais nesta nova forma podem ser processados por um computador [PRE94].

\section{Teclados, Joysticks, Mouses e Trackballs}

O dispositivo de entrada de dados mais comum e amplamente conhecido é o teclado. Os joysticks operam em duas dimensões e são freqüentemente usados em tarefas onde a direção e a velocidade são mais relevantes que a localização. Um trackball é uma bola que o usuário pode rotacionar em qualquer direção dentro de uma câmara fixa podendo ser movido com os dedos ou com a palma da mão sobre a superfície. O mouse é similar ao trackball, não é fixo e o usuário pode movê-lo sobre uma superfície lisa.

\section{Telas Sensíveis ao Toque (Touch Screen)}

As telas sensiveis a toques permitem ao usuário a entrada de informações simplesmente tocando uma porção apropriada da tela. Transformam o monitor em um periférico bidirecional, entrada e saída de dados. Possui as seguintes vantagens: fácil manipulação, não requer espaço extra, não há partes móveis e durabilidade. Como desvantagens citamos a baixa precisão, taxas de erro consideráveis, dedos sujando e escondendo os detalhes da imagem.

\section{Dispositivos de Entrada de Dados 3D (3D Trackers)}

São dispositivos que podem medir a posição absoluta e a orientação de um sensor em um espaço tridimensional. Os 3D Trackers de alta precisão utilizam sensores magnéticos. As coordenadas resultantes de movimentos nas várias direções são calculadas em relação aos transmissores, por meio da comparação da intensidade do sinal elétrico. Os 3D Trackers de baixa precisão utilizam sensores ultra-sônicos ao invés de magnéticos. Uma imagem que acompanha o movimento real aliada a um software especifico pode ser visualizada em um monitor. Este dispositivo permite que o usuário use a precisão, o controle e a agilidade das próprias mãos como dispositivo de entrada de dados.

\section{Reconhecimento de Escrita a Mão}

Este tipo de interface de sistema permite que o usuário escreva diretamente em um monitor sensivel usando uma caneta (especial ou não). Programas de reconhecimento de escrita traduzem a escrita em caracteres ASCII que podem ser visualizados diretamente na tela do computador. Normalmente neste tipo de sistema o teclado e o mouse são substituídos pela caneta. A principal dificuldade de implementação, denominada segmentação de símbolos, é determinar o término de um caractere e o início do próximo. 


\section{Reconhecimento de Vox}

Os sistemas de reconhecimento de voz podem ser divididos em dois tipos:

- Sistemas de reconhecimento de palavras isoladas: necessitam de intervalos maiores entre as palavras e possuem vocabulário limitado, limitando assim o conjunto de palavras reconhecidas;

- Sistemas de reconhecimento de fala contínua: são capazes de reconhecer palavras isoladas dentro de um fluxo de palavras, apresentando vocabulário limitado. A vantagem é a entrada dos dados mais rápida proporcionando uma velocidade de fala próxima à natural.

Os sistemas de fala contínua são subdivididos da seguinte forma:

- Sistema Dependente do Usuário: requer que o usuário treine o sistema a reconhecer sua voz através da repetição das palavras;

- Sistema Independente do Usuário: acomoda um grande número de características de fala e vocabulário. Devido à grande variabilidade apresentam confiabilidade menor que a de sistemas dependentes do usuário.

Atualmente o reconhecimento de voz apresenta algumas deficiências. Utilizado em sistemas específicos, podem existir falhas no reconhecimento devido a variações de entonação de voz, sotaques e sons parecidos. Os sistemas de reconhecimento de voz estão sujeitos à interferência de ruídos do ambiente. Mesmo após a aquisição do som, a interpretação não é trivial ao computador, requerendo uma elevada capacidade de processamento.

\subsection{Pictografia}

Segundo o Novo Dicionário Aurélio da Língua Portuguesa [FER86], o pictograma é um símbolo utilizado em pictografia, palavra que, por sua vez, é definida como um sistema de escrita de natureza icônica baseada em representações simplificadas dos objetos básicos.

A origem dos pictogramas vem dos tempos pré-históricos, quando o homem imprimia representações gráficas nas paredes das cavernas. Observa-se que no começo, o homem utilizou o desenho para representar o mundo circundante, desenvolvendo formas de obtenção e transmissão do conhecimento e aperfeiçoando a comunicação escrita através da pictografia. Esta forma de representação naturalista e figurativa do mundo visível marcaria profundamente a evolução do 
homem até as formas de escrita ideográfica. Um exemplo que se propaga até os tempos modernos é a escrita chinesa, como apresentado na figura 2.16 .

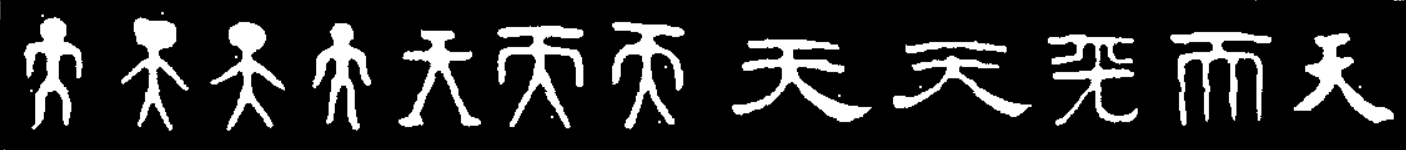

Figura 2.16 - Evoluçâo do símbolo chinês do homem

A velocidade de decodificaçăo da informação e a possibilidade de ocupação de um menor espaço em relação a palavras são diferenciais dos pictogramas. $O$ uso de pictogramas é recomendado na leitura a curta distância e em modelos de comunicação que exigem rápido entendimento [QUA00].

Na década de 50, especialistas da ONU avaliaram a utilização desses sinais gráficos e concluíram que os pictogramas apresentavam uma velocidade de decodificação superior em relação ao uso de palavras. Ou seja, eles podem ser compreendidos mais rapidamente no que diz respeito à identificação da imagem representada e podem ter seu significado extraído em menor tempo.

Um pictograma possui um grau de sintese gráfica que o torna legível e o diferencia de algumas ilustrações mais complexas. Mas seu grau de síntese não pode ser exagerado a ponto de perder a identificação. Por outro lado, o pictograma precisa ser um símbolo e não apenas uma ilustração, ou seja, ele precisa representar um significado para cumprir sua função de elemento de comunicação.

O projeto de pictogramas deve considerar certos requisitos e circunstâncias do meio no qual serão veiculados, consequentemente podendo influenciar suas características básicas. A cultura do público alvo para o qual os pictogramas são projetados é um ponto a ser considerado. Quem recebe a mensagem tem que ter os códigos culturais que o farão entender o significado pretendido pelo emitente da informação. Neste contexto cultural devemos procurar por sinais que já se configurem como símbolo para o público alvo, como é o caso do uso tradicional do garfo e faca para restaurantes ou como no caso da lupa, em uso nos últimos anos, para representar a função de ampliação em diferentes aplicativos de computadores.

O homem possui uma facilidade natural de entendimento de símbolos, resultando em um menor esforço despendido no entendimento da mensagem associado a um acréscimo na velocidade da leitura. Atualmente, são conhecidos alguns sistemas de comunicação pictográficos tais como o sistema Bliss, NOBEL, Pictolabel e as escritas chinesa e japonesa tradicionais. 
$\mathrm{Na}$ seção seguinte são apresentados os conceitos básicos referentes ao sistema de comunicação pictográfica Bliss 41 .

\subsubsection{Bliss 41}

O sistema Bliss 41 foi proposto por Charles $\mathrm{K}$. Bliss e é baseado em um número reduzido de princípios básicos [BLI00]:

- Derivado de um pequeno número de símbolos elementares que são simplificações dos objetos naturais;

- Proposição de um novo símbolo somente quando a idéia não puder ser representada satisfatoriamente com base nos símbolos já existentes;

- A estrutura de uma sentença segue a sequência da ocorrência dos eventos no mundo real, por exemplo:

UMA COISA atua sobre OUTRA COISA.

- Os adjetivos devem aparecer imediatamente após os nomes. Os verbos e advérbios relacionados freqüentemente estão embutidos em um único símbolo.

- Os artigos não adicionam informação a uma sentença e podem ser omitidos sem maiores problemas. Ainda assim existem símbolos Bliss que representem essas palavras;

A maioria das palavras Bliss é formada a partir da associação de símbolos elementares ou símbolos-chave. O ponto fundamental dos símbolos elementares Bliss é a forma como eles se relacionam com o mundo real, ou seja, os elementares são desenhos simplificados dos objetos reais.

\section{Indicadores}

Um símbolo Bliss pode ser um nome, um verbo, um adjetivo ou um advérbio pela adição de indicadores aos símbolos.

Uma "coisa" em notação Bliss é representada por uma caixa em duas dimensões. Esta representação está relacionada com a idéia que qualquer objeto possui uma dimensão. A notação para uma "coisa" é apresentada na figura 2.17. 


\section{$\square$}

Figura 2.17 - Símbolo Bliss Indicador de "Coisa"

O símbolo Bliss para "ação" é derivado da ação primária dos vulcões. Uma outra associação visando a memorização do símbolo é ao crescimento das plantas em direção ao sol, ver figura 2.18.

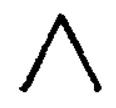

Figura 2.18 - Símbolo Bliss In dica dor de "Ação"

\section{Símbolos Compostos}

Os símbolos no sistema Bliss, compostos ou não, são separados por espaços. Este método de separação de palavras permite saber quando um símbolo é parte integrante de um símbolo composto, como mostrado na figura 2.19 .
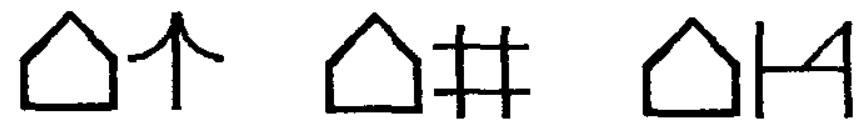

\section{Figura 2.19 - Símbolos Compostos Bliss}

Note que o símbolo "casa" se refere a qualquer tipo de moradia ou construção. O segundo símbolo de cada componente da figura especifica o tipo de moradia ou construção. No exemplo acima os símbolos representam, respectivamente, "casa da árvore" (casa - árvore), "barraca" (casa - fabricada) e "hotel" (casa - com - camas).

\section{Apontadores}

Apontadores são representados por flechas que apontam para partes de símbolos e desta forma adicionam alguma especificidade. Esta técnica permite a representação de várias coisas existentes no mundo real dispensando a necessidade de um novo símbolo específico. 
Para ilustrar o uso de apontadores, primeiramente é apresentado o símbolo elementar "sala", de acordo coma figura 2.20 .

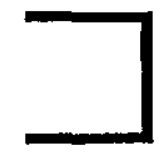

Figura 2.20 - Símbolo Bliss para "sala"

O símbolo elementar sala é modificado por apontadores, conseqüentemente apresenta um novo significado em cada um dos casos, ver figura 2.21 .

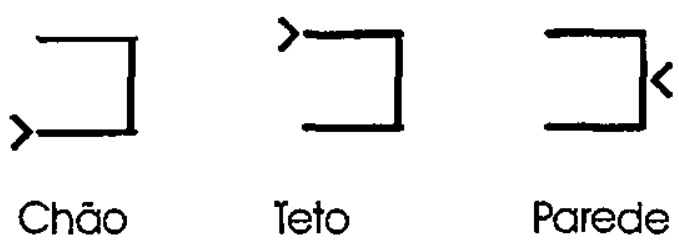

Figura 2.21 - Uso de Apontadores para criação de novas palavras

\section{Sentenças}

Uma sentença completa Bliss possui a seguinte estrutura:

TEMPO LUGAR UMA COISA ATUA SOBRE OUTRA COISA.

Uma representação completa de sentença Bliss é apresentada na figura 2.22 .
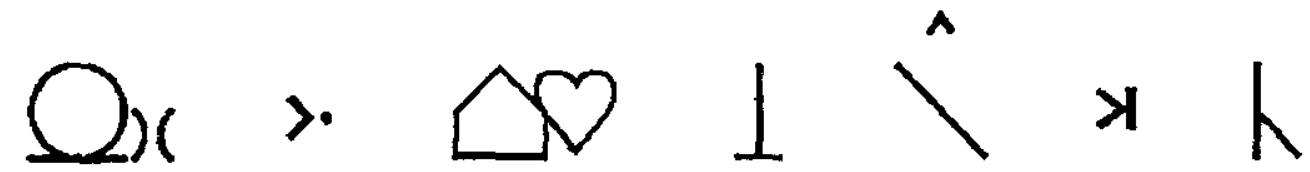

Figura 2.22 - Sentença Bliss "Hoje em casa eu escrevo para você"

Uma vantagem do método é a apresentação visual da ordem de ocorrência dos eventos.

As sentenças variam seu significado da mesma forma que os símbolos, ou seja, através do uso de indicadores. 
Sentenças imperativas são iniciadas pelo indicador "!", assim uma sentença iniciada por "!" representa uma ordem, como mostrado na figura 2.23 .

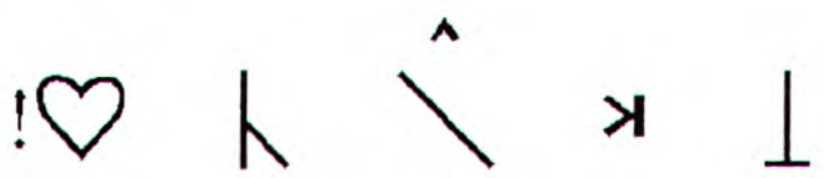

Figura 2.23 - Sentença Imperativa "Por favor escreva para mim!"

As sentenças interrogativas são construídas com base no mesmo princípio, ver figura 2.24.
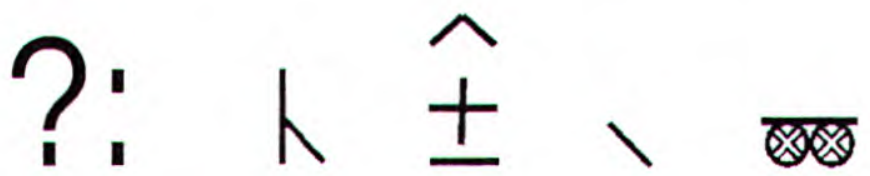

Figura 2.24 - Sentença Interrogativa: "Você tem um carro?"

\subsection{Sistemas de Gerenciamento de Redes Domésticas}

\subsubsection{Classificação das Ferramentas de Gerenciamento}

De acordo com a classificação apresentada em [LEE96] é possível classificar as ferramentas de gerenciamento de redes domésticas em quatro categorias baseadas em quatro modos de interação com os usuários.

A categoria denominada Control Mode é formada por ferramentas que permitem o controle dos dispositivos local ou remotamente. Os usuários podem visualizar as condições do ambiente e possuem um ambiente gráfico para tal.

Na categoria Configuration Mode o usuário pode modificar as configurações do sistema, através de um ambiente visual, escolher aplicações específicas para monitorar o ambiente e tomar decisões com base nas situações identificadas.

Na terceira categoria, Network Management Mode, o usuário pode realizar um ajuste mais elaborado da rede. Nesta categoria são possíveis a análise, a manipulação e a expansão da rede, o 
diagnóstico de falhas, a monitoração das variáveis de rede, a recuperação de erros e o controle de redundância em pontes e roteadores.

Finalmente, o Programming Mode contém um ambiente de programação completo para a implementação de novos aplicativos. Este é o modo que requer o maior grau de conhecimento por parte do usuário.

A maioria dos usuários domésticos não possui um amplo conhecimento em redes de computadores. Conseqüentemente o gerenciamento em Control Mode é o mais utilizado pela maioria dos usuários cujo nivel de conhecimento é mediano.

\subsubsection{Interface de Configuração Home-Net (HCT)}

O objetivo central da automação doméstica é disponibilizar integração e interoperação eficientes entre os eletrodomésticos em uma casa. $O$ software gerenciador deve apresentar uma interface amigável ao usuário que permita a manutenção e controle do sistema em vários níveis [LEE96].

A interface HCT é uma ferramenta de configuração independente da tecnologia da rede e do fabricante, que permite aos usuários especificar as condições do sistema e o funcionamento integrado dos dispositivos, fornecendo serviços a qualquer elemento da rede.

O sistema possui sinais de controle (Control Data) que são interpretados por todos os integrantes da rede, de forma não uniforme, e sinais de dispositivos (Appliance Data) que são dados processados por dispositivos específicos, por exemplor um stream de vídeo.

O gerenciamento da rede é executado através de um conjunto de operações de gerenciamento e operações especiais para controle de uma tecnologia de rede específica. $O$ fabricante deve fornecer o dispositivo com uma interface para a rede, informação suficiente sobre a interface e um módulo de software que representa o dispositivo físico. Este módulo de software realiza o controle do dispositivo e é utilizado da mesma forma que um controle remoto. A ferramenta, através das interfaces de software específicas fornecidas pelo fabricante dos dispositivos, manipula os detalhes técnicos referentes a cada dispositivo da rede.

Os dispositivos são representados graficamente na HCT e os usuários podem combinar a funcionalidade de diversos dispositivos na construção de uma aplicação completa usando uma técnica de programação visual orientada a objetos.

A vantagem deste modelo é que não há programação no sentido tradicional nem há necessidade 
de aprendizado de uma linguagem de programação. O usuário simplesmente escolhe os serviços fornecidos por um determinado dispositivo e graficamente conecta os dispositivos, conforme figura 2.25 .

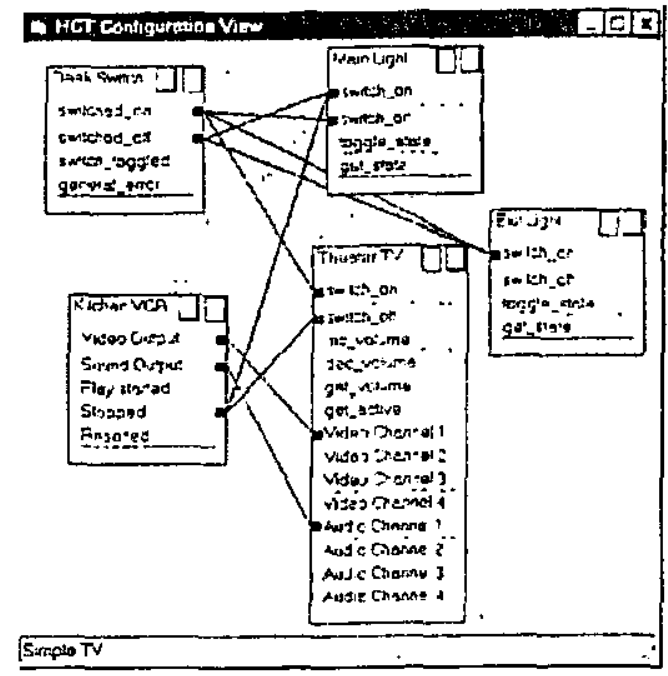

Figura 2.25 - Interface de Programação Gráfica Home-Net

Uma característica importante é a possibilidade de configuração e roteamento da informação através de canais virtuais. Assim, um aparelho de TV é capaz de receber imagens de vídeo enquanto não recebe o som, podendo este ser processado por um equipamento de som $h i$-fi membro da rede.

\subsubsection{Interface Estilo Browser}

Esta interface permite a navegação por uma rede de dispositivos e estruturas de contexto permitindo ao usuário interagir com os dispositivos integrantes da rede. Permite o acesso à rede a partir de qualquer dispositivo microprocessado. Como a interface é implementada usando protocolos utilizados pela Internet, a tecnologia permite o acesso remoto a dispositivos da rede pela rede mundial [COR97].

\section{A Interface do Usuário}

Um Browser, que mostra uma lista de dispositivos registrados em uma base de dados local com o mesmo formato de um sistema de arquivos. Quando um dispositivo é acessado a partir do Browser é carregado um HiPlet (Home-Interactive Programlets) do dispositivo que nada mais é do que a interface do dispositivo com o qual o acesso é desejado. Os HiPlet permite que um gateway Internet/CEBus carregue a interface do usuário para um dispositivo da rede no Browser, satisfazendo desta forma os requisitos dos fabricantes que podem padronizar e diferenciar seus 
produtos. É possível a construção de interfaces padronizadas de acordo com as necessidades do usuário [COR98].

Em seu modo de operação normal, um programa daemon denominado HAL monitora a rede e executa as respostas aos comandos do usuário em nivel de hardware. Săo permitidos o registro e a interação com dispositivos reais e virtuais.

O acesso do usuário aos dispositivos da rede é realizado através da interface mostrada na figura 2.26 .

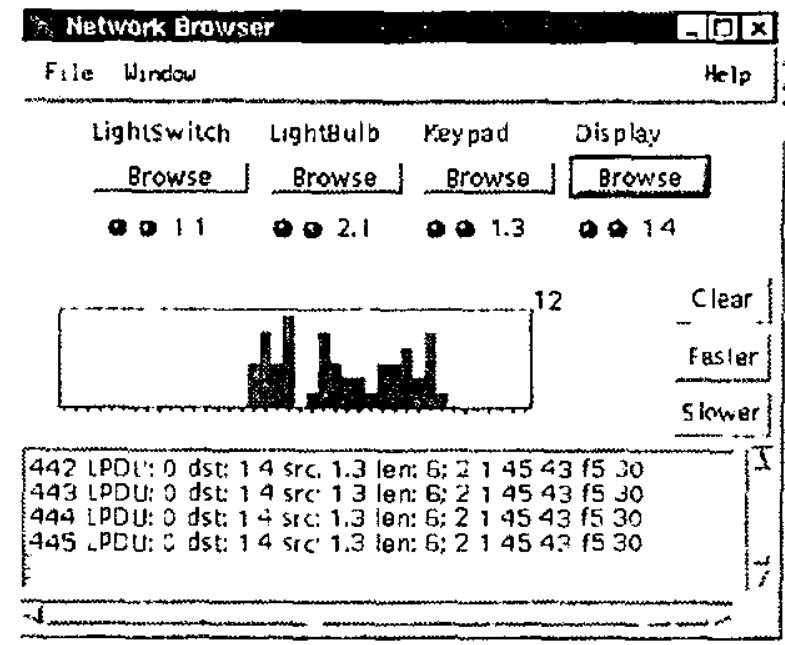

Figura 2.26 - Interface Estilo Browser

\section{Interface do Dispositivo(U1Devs)}

Os elementos de interface do dispositivo foram implementados em Java applets que são carregados como uma URL ligada a um porto fornecido pelo software de gerenciamento de rede. Outra solução possível é a implementação de uma Camada de Interface (DIL).

Foi utilizada a primeira opção, pois a conexão baseada em software permite que a interface do dispositivo esteja em uma máquina virtual Java localizada em um endereço IP distinto do endereço IP do dispositivo da rede doméstica.

\section{Home-Interactive Programlets (HiPlets)}

Para permitir o desenvolvimento de interfaces mais sofisticadas foi criado o conceito de interface de grupo de dispositivos encapsulado em um único objeto, denominado Home-Interactive Programlets ou HiPlets. Este conceito permite que vários dispositivos de rede tenham sua 
funcionalidade combinada podendo ser acessados através de uma interface única. Entretanto, cada dispositivo formador de um HiPlet pode ter sua interface independente.

Cada HiPlet é ligado a um socket específico que é mapeado em endereços locais reais dos dispositivos CEBus pertencentes ao objeto, implementando assim uma chamada "um para muitos" no sistema.

\subsubsection{A Interface Xtension 2.3.8}

A interface Xtension é um software voltado especificamente ao controle de dispositivos domésticos. Inicialmente, quando a interface é executada são apresentadas algumas janelas: uma janela com todos os dispositivos integrantes do sistema, uma com os eventos agendados e outra de registro de $\log$ [TIC01], como apresentado na figura 2.27.

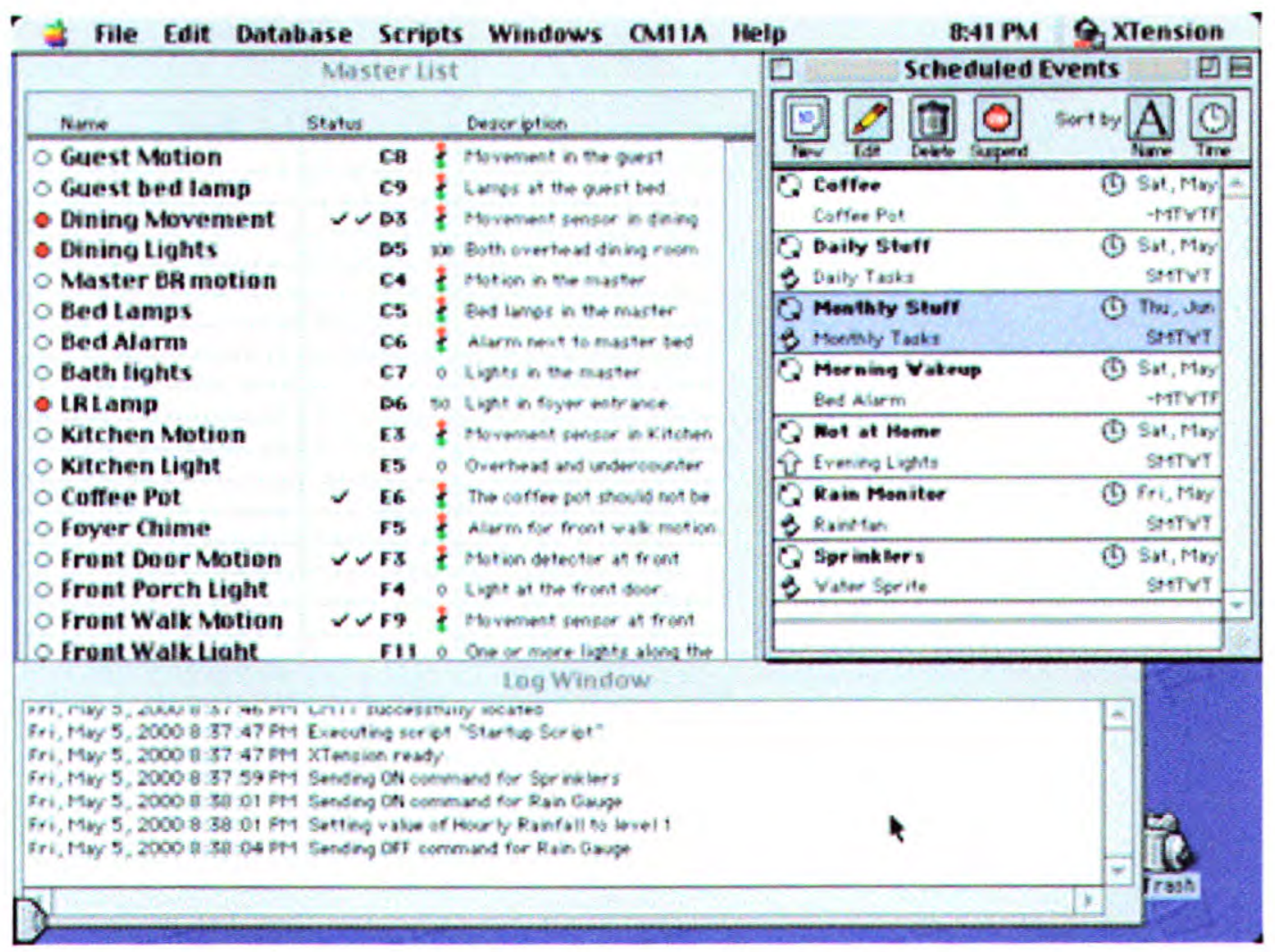

\section{Figura 2.27 - Tela Inicial Xtension}

Outra forma de visualizar os dispositivos controlados é através de uma imagem da planta baixa da casa. Ícones espalhados sobre a imagem representam dispositivos reais na residência. $\mathrm{O}$ 
usuário controla os dispositivos clicando o ícone visualizado na planta. Quando o estado de um item muda, o ícone reflete a alteração. A segunda maneira de controle é apresentada na figura 2.28.

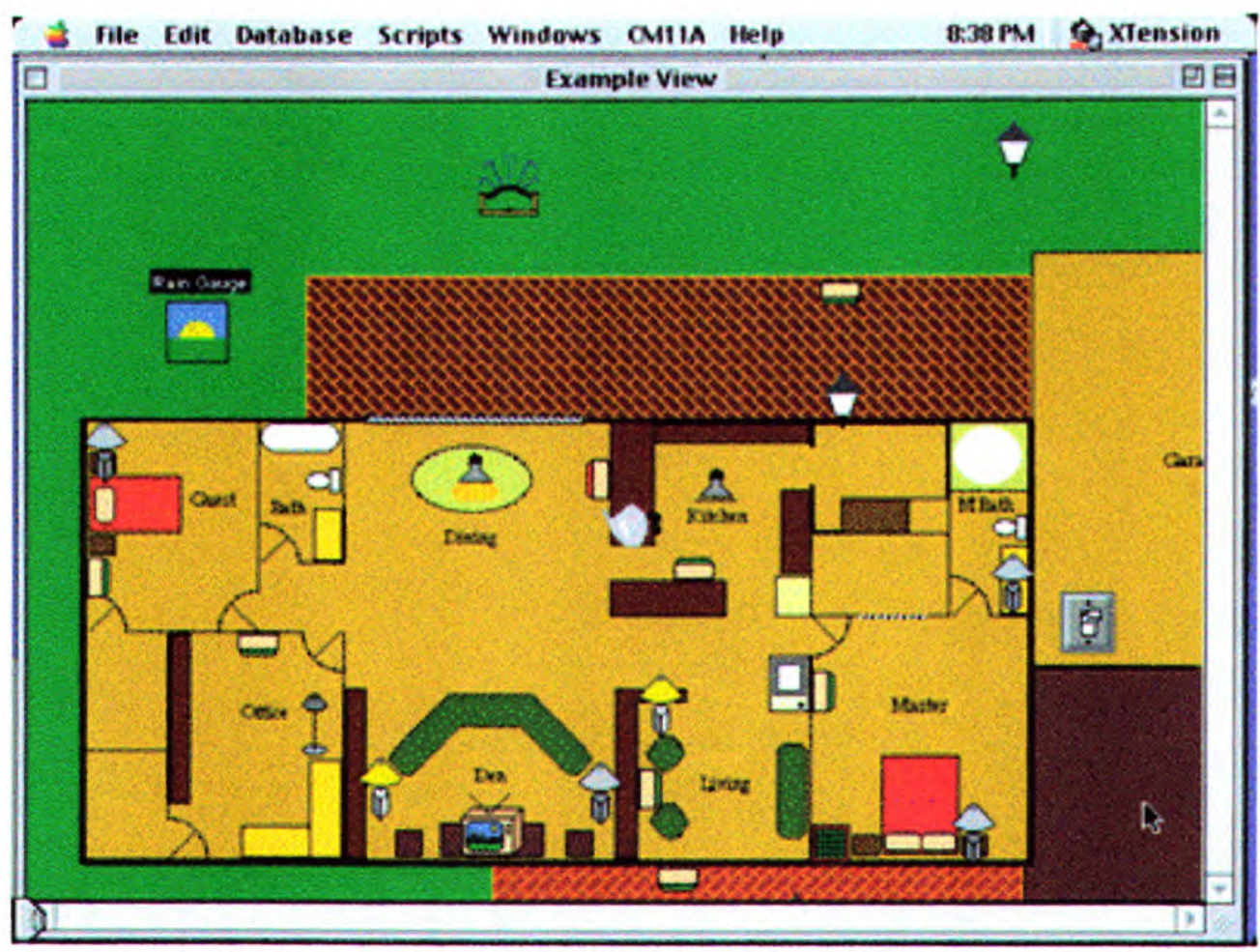

Figura 2.28 - Interface Gráfica XTension

Quando dispositivos são inseridos na área de controle é necessário inserir alguns parâmetros para que a interface possa controlá-los. A interface permite a execução de eventos agendados pelo usuário, como o desligamento das luzes externas em um determinado horário. Um sistema de controle baseado em Xtension pode realizar ações de acordo com sinais enviados por sensores espalhados no ambiente, para tal um script determina as ações a serem executadas no momento da ocorrência de eventos específicos. 


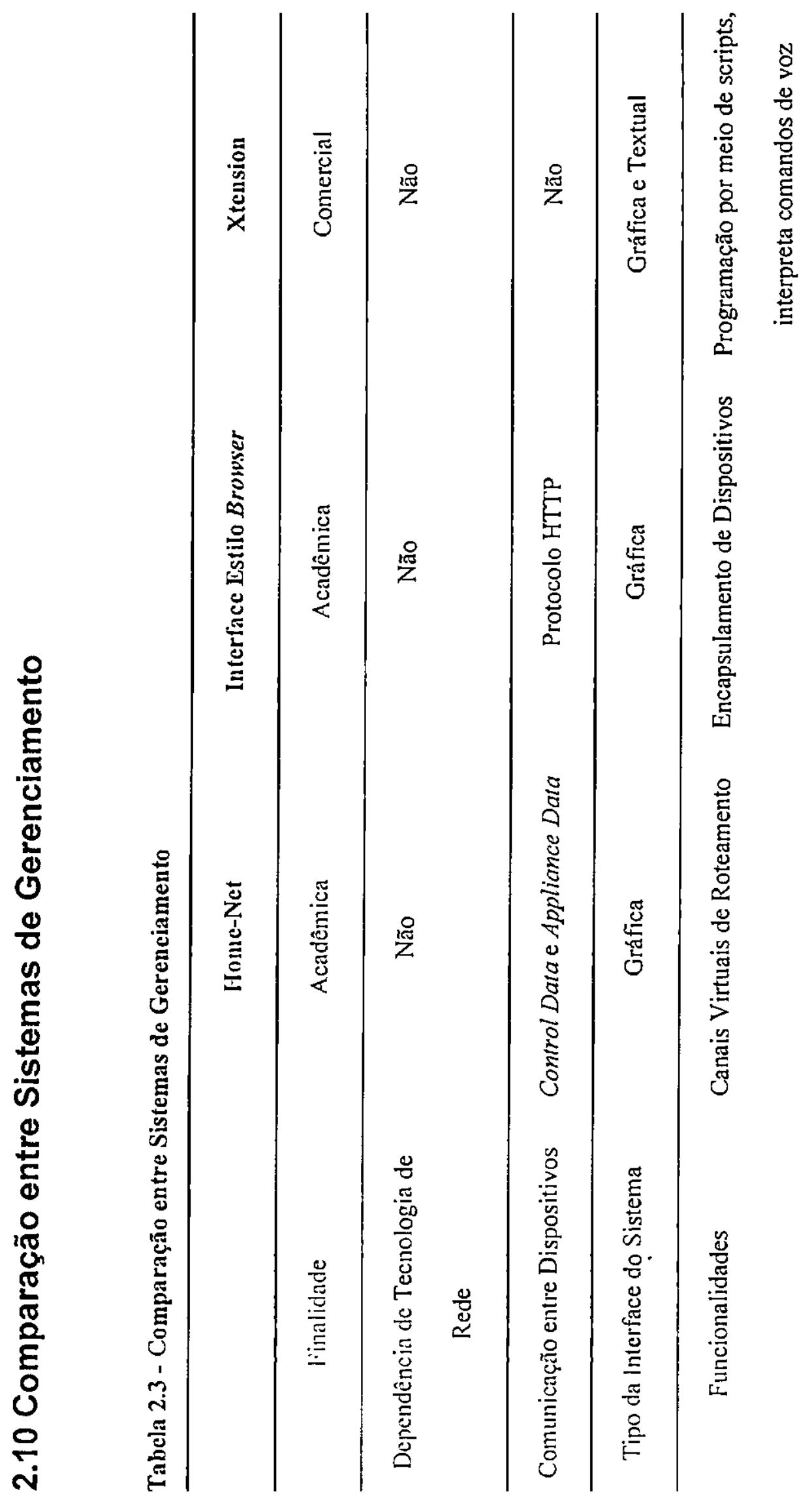




\subsection{Considerações Finais}

Neste capítulo foram revistos diversos conceitos relativos aos meios fisicos e interfaces para a transmissão de dados em redes de computadores. Elaborou-se uma tabela comparativa entre as diversas interfaces apresentadas.

Foram apresentadas as características referentes a alguns padrões de comunicação de dispositivos domésticos incluindo as especificações mais recentes, os elementos básicos de cada arquitetura e as necessidades específicas de cada implementação.

Este capítulo apresentou ainda os principais métodos de reconhecimento baseados em padrões biométricos. Algumas caracteristicas biométricas pessoais podem desempenhar o papel de identificadores únicos para os usuários em um sistema computacional, desta forma contribuindo para a construção de sistemas seguros. Além disso, a identificação pessoal pode ser utilizada pelo sistema de gerenciamento para o estabelecimento de configurações prédefinidas para cada um dos seus usuários.

Preocupou-se em mostrar as principais interfaces e características disponíveis visando a interação homem-computador. O perfil do usuário doméstico padrão e as principais caracteristicas das interfaces apresentadas foram consideradas na definição da interface do sistema de gerenciamento proposto.

Foram apresentados os conceitos relacionados a linguagens pictográficas, que tornam mais natural a interação com o sistema.

Também foram apresentadas as caracteristicas de funcionamento de alguns sistemas de gerenciamento de ambientes domésticos e uma tabela comparativa de pontos importantes referentes aos sistemas apresentados. As idéias apresentadas nesta seção foram utilizados na definição dos requisitos do sistema proposto.

No próximo capítulo é realizado um estudo de caso de como seria um dia comum de uma família em uma residência futurista. São imaginados os diversos dispositivos integrantes da residência e são propostas classificaçoes baseadas em determinadas características intrínsecas aos sistemas de gerenciamento doméstico. 


\section{Capítulo 3}

\section{Estudo de Caso}

\subsection{Introdução}

Este capitulo descreve um ambiente doméstico futurista controlado por um sistema de gerenciamento doméstico. Esse estudo tem como finalidade o levantamento dos requisitos do sistema sem levar em consideração restrições de ordem tecnológica ou a possibilidade de realização prática de alguns dos dispositivos mencionados. O enfoque principal está na funcionalidade da residência e nas atividades típicas dos seus moradores. A seção 3.2 enumera os horários e atividades diárias dos moradores de uma casa do futuro. A seção 3.3 trata dos tipos de subsistemas de controle atuantes no ambiente proposto, suas subseções descrevem os Subsistemas de Controle de Grupo e Individual presentes na residência.

\subsection{A Casa do Futuro}

O ambiente considerado é uma moradia para uma família composta por quatro pessoas, Roberto (marido), Cristina (esposa), Bruno (filho) e Juliana (filha). A casa apresenta-se dividida nas seguintes dependências: escritório, quarto do casal, quarto do filho, quarto da filha, sala de estar, sala de visitas, sala de refeições, sala de jogos e som, sala de reciclagem de residuos domésticos, cozinha, garagem, banheiro do casal, banheiro dos filhos e área de serviço. Objetivando melhorar o entendimento destaca-se que, em todo o texto, as referências a ambiente indicam toda a residência e as referências a cômodo indicam partes específicas da residência.

Em uma residência futurista algumas atividades na residência seriam iniciadas de maneira automática. Abstraindo o dia-a-dia neste ambiente supõe-se a existência de um ente 
monitor que executa tarefas de manutenção do ambiente e atende a requisições dos moradores. A seguir é apresentada uma lista de atividades executadas em um dia comum na residência.

7:00h O sistema de gerenciamento doméstico acorda os moradores com música e informa condições climáticas externas e previsão meteorológica para o dia. $\mathrm{Na}$ cozinha a cafeteira é acionada e o forno aquecido a uma temperatura ideal para torrar pães.

7:15h Cristina entra no banheiro, a região do piso em frente a pia do banheiro é uma balança que obtém seu peso. No banheiro, a interface para o sistema de gerenciamento doméstico possui a forma do espelho sobre a pia. O Dispositivo de Telediagnóstico acoplado à pia colhe informações vitais do morador: temperatura, pressão, pulsação, sons do coração, pulmão e realiza uma préanálise destes dados. A deteç̧ão de sinais anormais é imediatamente enviada para o computador do médico da família. A agenda de compromissos do morador é visualizada na superfície do espelho acima da pia, Cristina pede que uma reunião seja cancelada, o sistema envia um e-mail com aviso de recebimento, informando o cancelamento da reunião. $O$ compartimento de higiene pessoal se auto-ajusta de acordo com as preferências escolhidas previamente. Após Cristina ter feito suas necessidades pessoais o Subsistema de Qualidade do Ar é acionado, tornando assim o ambiente próprio para o uso por outro morador.

8:00h A "faxineira-humana" pede permissão de acesso. O Subsistema de Segurança verifica o padrão de voz da requisitante. Caso não seja possível identificar com segurança o solicitante, são utilizados outros padrões de identificação biométricos, tais como reconhecimento facial, impressão digital e íris. $\mathrm{Na}$ entrada da residência, a pessoa passa por uma inspeção sendo possível detectar armas, substâncias perigosas e tóxicas. Todas as operações do sistema são registradas. Os funcionários possuem horários pré-definidos nos quais o acesso é permitido. No momento em que a "faxineira-humana" entra no ambiente doméstico portando seu PDA (Personal Digital Assistent), este informa ao gerenciador doméstico suas condições de saúde. As informações vitais foram colhidas por um outro sistema de gerenciamento.

8:15h Enquanto a família toma café da manhã, a interface do sistema doméstico exibe a 
lista das tarefas domésticas a serem realizadas. Cristina inclui a limpeza das vidraças da sala de estar e escolhe o cardápio semanal para as refeições da família. O noticiário do dia é disponibilizado na interface do sistema. $\mathrm{Na}$ garagem o carro é ligado, aquecido e a temperatura interna ajustada. A melhor rota para o escritório pode ser visualizada em um monitor no interior do veículo.

8:45h O sistema verifica a disponibilidade dos ingredientes utilizados no preparo do cardápio escolhido por Cristina e realiza a compra daqueles não disponíveis, via Internet. As receitas dos pratos selecionados são verificadas primeiramente no banco de receitas. Caso alguma das receitas desejadas não esteja disponível, o sistema realiza o download da receita e a inclui no banco de receitas do sistema. Cada receita pode receber uma nota de cada morador após ter sido preparada.

9:30h A "empregada-robô" coloca o lixo nos respectivos compartimentos do módulo de reciclagem. O sistema dispara o tratamento do lixo, realiza a cotação de preços e executa a venda do material excedente pelo melhor preço. A água reciclada é utilizada para irrigação e higiene pessoal.

10:00h Toca a campainha, a imagem do visitante e o som externo são disponibilizados no local onde a empregada se encontra. A "faxineira-humana" é informada pelo sistema de que se trata do "entregador-robô" de iogurte. A "empregada-robô" permite a entrada do entregador, o sistema verifica a identidade digital do robô e o registro de $\log$ de acesso ao ambiente é efetuado.

10:30 O sistema informa à "faxineira-humana" que está no horário de tomar o comprimido para controle da pressão arterial, tal informação foi obtida de seu PDA no momento em que ela chegou à residência.

:1:00h A imagem de Cristina é disponibilizada em um monitor onde a "faxineirahumana" se encontra. Cristina informa que um vaso de flores será entregue, o qual deverá ser colocado sobre a mesa da sala de estar.

:1:15 A "empregada-robô" apanha os ingredientes necessários para o preparo do almoço e os coloca em panelas inteligentes, as quais processam as receitas. $\mathrm{O}$ fogão realiza a transferência dos respectivos modos de preparo para cada um dos pratos selecionados.

11:30 Uma imagem do "entregador-robô" de flores é visualizada no monitor da cozinha, a "faxineira-humana" pede que o robô coloque as flores sobre a mesa da sala de 
estar.

12:00h O sistema de gerenciamento avisa à "empregada-robô" que os moradores vão se atrasar para o almoço devido a congestionamento no trânsito, tal mensagem utilizou-se de síntese de voz. Tal mensagem gerada pelo sistema foi obtida da análise dos dados provenientes do GPS (Global Positioning System) do carro e do boletim informativo da companhia de tráfego municipal. As panelas inteligentes mantêm a refeição aquecida. $O$ sistema rastreia o veículo durante $o$ trajeto realizado e infere o horário da chegada dos moradores.

13:00h Os moradores chegam, o almoço está servido, o módulo de som ambiente está tocando uma seleção de músicas. Todas as vezes que os automóveis da residência entram na garagem, o Subsistema de Dados Automotivos se comunica com os sensores a bordo dos automóveis para obter as medições colhidas. Uma troca de pastilhas de freios é agendada para o dia seguinte e o morador é notificado. Quando os PDAs das crianças entram no ambiente residencial o sistema doméstico obtém a lista das tarefas agendadas pelo professor e as mensagens endereçadas aos pais. Roberto é informado que no dia seguinte Bruno realizará prova de Ciências. $\mathrm{Na}$ seqüência, o sistema informa a Bruno que após o período destinado à realização de tarefas agendou uma chamada oral sobre a matéria da prova. Roberto brinca com Cristina dizendo que o casal deve conceder aumento de salário ao gerenciador da residência.

14-16:00h O sistema não permite a exibição de filmes e jogos enquanto as crianças não tenham realizado a contento suas tarefas escolares. Tal restrição pode ser cancelada ou alterada pelas pessoas autorizadas. O sistema informa aos pais caso detecte alguma dificuldade das crianças na realização dos seus deveres escolares.

16:00h Bruno não consegue responder algumas perguntas. Então o gerenciador inicia a exibição de um filme educativo sobre o assunto que contém a deficiência identificada.

16:30h A campainha toca, Juliana é informada que sua amiga Patrícia está no interfone, a imagem da amiga é visualizada em um monitor de plasma no cômodo onde Juliana se encontra. Juliana requisita que o sistema permita a entrada de sua amiga. Patrícia entra na residência, então as duas amigas vão para a sala de jogos e som e Juliana requisita a exibição de um terminal do vídeo 
game, Juliana seleciona o jogo desejado e as duas começam a brincadeira.

17:00h O sistema confere a programação noturna da TV visando identificar bons programas de acordo com as preferências dos habitantes. A TV exibe uma mensagem às crianças informando o horário do banho. No momento que a criança entra no banheiro tem sua jdentidade reconhecida e o compartimento de higiene pessoal se auto-ajusta de acordo com as preferências da pessoa reconhecida.

17:30 Cristina chega em casa, coloca o carro na garagem. Ao entrar na cozinha, o sistema informa sobre os acontecimentos na residência enquanto esteve ausente, inclusive que Bruno se recusou a tomar banho.

18:00h Cristina, enquanto escova os dentes, dá um comando de voz para que o fogão diminua a temperatura de aquecimento da panela no fogão. As alterações da agenda de seu laptop são atualizadas no PC doméstico.

18:30h Roberto chega em casa, o sistema verifica as alterações na agenda de seu laptop e atualiza a agenda do computador doméstico. O sistema gerenciador informa que há cerveja na geladeira e informa as sugestões para programas de TV. Roberto requisita que o sistema encontre Cristina, então a imagem de Cristina é apresentada em um monitor localizado na porta da geladeira.

19:00h Cristina requisita que o sistema faça o pedido de uma pizza de calabreza. O sistema entra em contato com o a pizzaria, executa o pedido e cuida do pagamento.

19:30h O sistema disponibiliza a imagem do entregador no monitor da cozinha, Cristina mantêm um diálogo curto com o entregador e Roberto apanha a pizza.

20:30 Roberto entra no banheiro suas preferências são carregadas. O sistema informa que Roberto está acima do peso ideal e gera um cardápio de bajxa caloria com as devidas quantidades de alimentos a serem ingeridas. Roberto pede uma ligação telefônica para seu irmão e a imagem é disponibilizada no espelho sobre a pia.

21:00h Na sala multimídia, a família escolhe um programa comum e o sistema informa que na residência há pizza, pipoca de microondas, cerveja, refrigerante, suco e frutas; 
21:30h O sistema informa o recebimento de uma chamada telefônica, Roberto pede que o sistema interrompa a exibição do programa e disponibilize a ligação em modo de voz. O sistema automaticamente inicia a gravação do programa para que logo após o término do telefonema o programa recomece do ponto interrompido;

23:00h O sistema aciona todos os módulos do sistema de segurança, travando portas e janelas. Inicia-se o monitoramento da residência com 0 objetivo de detectar invasões.

\subsection{Classificação dos Sistemas de Controle}

Num futuro não muito distante espera-se que toda residência tenha suas atividades cotidianas gerenciadas por um sistema de controle central. Tal sistema gerencia tanto dispositivos individuais quanto grupos de dispositivos. Assim, é proposta uma classificação genérica que leva em consideração características essenciais inerentes ao sistema de controle considerado. De acordo com a característica analisada, tais sistemas encontram-se divididos nas seguintes categorias:

Quanto à forma de atuação sobre o ambiente:

- Automático: usam sensores que fornecem sinais de controle ao sistema;

- Manual: o usuário dispara a execução de tarefas;

- Temporizado: os eventos são disparados em intervalos pré-determinados;

- Miscelaneous: enquadra-se em mais de uma entre as categorias acima.

Quanto ao período de atuação no ambiente:

- Contínuo: monitora e controla o ambiente durante todo o tempo;

- Esporádico: atua no ambiente controlado quando requisitado;

- Periódico: o sistema atua sobre o ambiente em intervalos de tempo.

Quanto à área abrangida

- Amplo: atua em todo o ambiente controlado; 
- Restrito: atua em áreas específicas do ambiente controlado.

Quanto à interface homem-sistema:

- Natural: a interação se dá por meios naturais, como voz, toques e identificação de ondas cerebrais;

- Não natural: meios não naturais de interação como linhas de código e teclas de atalho.

Quanto à forma de acesso ao sistema:

- Local: somente permite acesso interno ao ambiente controlado;

- Remoto: permite acesso externo ao ambiente controlado.

$\checkmark$ Quanto d̀ configuração de novos dispositivos integrantes do sistema

- Auto-configurável: os dispositivos se auto-configuram quando dentro da área de atuação;

- Manual: requer configuração dos dispositivos controlados pelo administrador do sistema.

Quanto a forma de controle dos dispositivos:

- De Grupo: controla conjuntos de dispositivos, como as lâmpadas que fazem parte do sistema de iluminação;

- Individual: controla cada um dos dispositivos isoladamente;

- Misto: controla tanto grupo de dispositivos como dispositivos individuais.

\subsection{Ambiente Controlado}

Este trabalho é baseado em uma residência futurista imaginária e seus eletrodomésticos. O projeto de automação é composto por diversos Subsistemas de Controle de Grupo e Subsistemas de Controle Individual. 
Os Subsistemas de Controle de Grupo gerenciam grupos de dispositivos domésticos que coletivamente realizam tarefas distribuídas, tal como iluminação de ambientes, gerenciamento de energia, controle térmico e segurança. O fato de um determinado dispositivo pertencer a um grupo de controle não impede que o dispositivo aceite requisições individuais. Normalmente os sistemas de controle de grupo monitoram o ambiente e no momento da ocorrência de uma situação anômala o sistema atua.

O Subsistema de Controle Individual controla a execução de tarefas executadas por cada um dos dispositivos, podendo combinar funcionalidades individuais de mais de um dispositivo realizando desta forma uma tarefa mais elaborada. Os controles individuais normalmente são disparados por requisições dos usuários.

A próxima seção e suas subseções descrevem as características de cada um dos subsistemas de controle que integram a residência.

\subsubsection{Subsistemas de Controle de Grupo}

\subsubsection{Subsistema de Controle Térmico}

- Módulo de Gerenciamento de Espaços:

$\checkmark$ ajusta a temperatura ambiente de acordo com a ocupação do cômodo;

$\checkmark$ permite o ajuste de uma temperatura para cada cômodo;

$\checkmark$ permite o ajuste de temperaturas diferenciadas de acordo com as preferências térmicas dos moradores, em caso de conflito de preferências, ou seja, dois moradores em um mesmo ambiente, a escolha é realizada de acordo com a maior prioridade entre os moradores envolvidos;

$\checkmark$ mantém o piso dos banheiros pré-aquecidos .

- Módulo de Absorção de Calor:

$\checkmark$ Ajusta o grau de reflexão dos vidros visando diminuir a quantidade de energia consumida por meio da utilização mais eficiente dos condicionadores de ar. $\mathrm{O}$ objetivo é otimizar a relação entre equilíbrio térmico e consumo de energia.

\subsubsection{Subsistema de Qualidade do Ar}

- Módulo de Grau de Pureza do Ar

$\checkmark$ controla a renovação do ar levando em consideração a quantidade de oxigênio 
no ambiente;

$\checkmark$ controla a umidade do ar;

$\checkmark$ filtra o ar do ambiente eliminando ácaros e outros microorganismos;

- Módulo de Identificação de Odores:

$\checkmark$ identifica as partículas dispersas no ar que sejam prejudiciais ou desagradáveis aos moradores;

$\checkmark$ identifica o odor de substâncias queimadas e notifica o Subsistema de Segurança;

$\checkmark$ monitora odores na cozinha indicando o ponto ideal de cozimento dos alimentos;

$\checkmark$ identifica substâncias deterioradas;

\subsubsection{Subsistema de Segurança}

- Módulo de Acesso:

$\checkmark$ valida requisições de acesso ao ambiente dos ingressantes utilizando um sistema de identificação biométrico, identifica o usuário a partir do cruzamento de informações pessoais provenientes da voz, face, impressão digital e íris;

$\checkmark$ armazena padrões de voz, face, impressão digital e fris dos requisitantes de ingresso no ambiente;

- Módulo Monitor:

$\checkmark$ monitora a casa 24 horas por dia objetivando identificar a ocorrência de situações anômalas, como ocorrência de incêndio, vazamento de gás, eletrodomésticos ligados desnecessariamente, e curto-circuito;

$\checkmark$ valida as alterações ocorridas entre os dados constantes das agendas dos PCs locais, PDAs e laptops no momento que tais dispositivos entram na área gerenciada pelo sistema de gerenciamento doméstico;

$\checkmark$ recebe mensagens contendo a identificação de substâncias queimadas provenientes do Subsistema de Qualidade do $\mathrm{Ar}$ e toma as devidas providências;

$\checkmark$ monitora o ambiente utilizando câmeras de vídeo que periodicamente exibem 
as imagens colhidas. Caso haja requisição específica de um morador estas imagens são exibidas no monitor presente no cômodo onde o morador se encontra;

$\checkmark$ controla a vazão de bicos d'água instalados no teto dos ambientes quando sensores de temperatura identificam a ocorrência de incêndio;

$\checkmark$ "cão-robô" possui comportamento programável, são comportamentos disponíveis: Dog Alemão, Pintcher e São Bernardo. Realiza rondas na residência, a fim de identificar situações anormais. Quando identificada uma situação anômala, o "cão-robô" é enviado para colher evidências in loco, utiliza técnicas de reconhecimento de imagens e por fim envia as informações colhidas ao sistema de segurança. Apresenta características adicionais como: não fazer xixi, ser inteligente e extremamente dócil com os moradores da residência.

$\checkmark$ "empregada-robô" realiza tarefas que dependem de força bruta ou atividades cotidianas para manutenção do ambiente. Na ocorrência de situações anômalas, o sistema de segurança envia a empregada a fim de analisar o problema no local da ocorrência, uma característica importante é sua elevada força. As premissas básicas que norteiam suas atitudes são: manter a residência organizada e limpa, prestar ajuda aos moradores em tudo o que lhe for possível e manter o ambiente familiar livre de intrusões.

- Módulo Invasão de Ambiente

$\checkmark$ trava portas e janelas;

$\checkmark$ envia notificação ao "căo-robô" e à "empregada-robô" para que averiguem o ocorrido in loco;

$\checkmark$ simula a presença de moradores;

$\checkmark$ executa ligações telefônicas pré-ajustadas;

$\checkmark$ dispara sirene;

\subsubsection{Subsistema de Iluminação}

- Módulo de Otimização de Iluminação

$\checkmark$ controla a iluminação do ambiente de acordo com sua utilização, 
$\checkmark$ sensores de ocupação ligam e desligam a iluminação ambiente na entrada ou saída do morador no ambiente;

$\checkmark$ ajusta a intensidade da iluminação de acordo com sensores de luz solar;

$\checkmark$ ajusta a taxa de reflexão dos raios solares pelas vidraças, estas refletem mais ou menos a luz natural de acordo com a orientação das moléculas da vidraça. A orientação das moléculas da vidraça é controlada por meio de uma corrente elétrica que as percorre;

\subsubsection{Subsistema de Gerenciamento de Energia}

- Módulo de Abastecimento

$\checkmark$ sensores de temperatura desligam o abastecimento de gás e o fornecimento de energia elétrica na ocorrência de incêndio;

$\checkmark$ em caso de vazamento de gás o fornecimento de energia elétrica é suspenso;

- Módulo de Consumo de Energia

$\checkmark$ registra de tempos em tempos o consumo de energia por cômodo da residência;

$\checkmark$ determina os valores gastos com eletricidade levando em consideração a quantidade de energia consumida e custo do Kwh;

- Módulo de Gerenciamento de Cargas

$\checkmark$ desloca a utilização de cargas em horários de pico. Os proprietários de casas podem tirar proveito de taxas de energia fora dos horários de pico, o sistema de controle automático se comunica com dispositivos que possuem alto consumo de energia como lavadoras de roupa, ferro de passar roupa, aquecedores de água e controladores térmicos de ambiente desativando os mesmos durante períodos de demanda de pico.

- Módulo de Retorno de Energia

$\checkmark$ Após queda de energia o retorno das cargas da residência se faz em estágios para não sobrecarregar o sistema elétrico que está se recuperando.

- Módulo Gerador

$\checkmark \quad$ Gera eletricidade a partir de reações químicas baseadas na quebra da molécula da água. A energia necessária à quebra da molécula provém de painéis fotovoltaicos instalados sobre o telhado da casa; 
$\checkmark$ Aciona um grupo gerador de energia em caso de falta de energia, abastece os dispositivos essenciais ao funcionamento aceitável da residência;

\subsubsection{Subsistema de Reciclagem de Resíduos Domésticos}

$\checkmark$ recicla e recircula a água doméstica utilizada;

$\checkmark$ recicla lixo doméstico, orgânico e inorgânico.

\subsubsection{Subsistema Gerenciador de Acessos a Intenet}

$\checkmark$ acessa a rede da residência de qualquer visitante obtendo assim informações relacionadas ao visitante. Baseia-se em informações de acesso contidas em dispositivos móveis pertencentes ao visitante, como o PDA, laptop ou telefone celular;

$\checkmark$ em caso de requisição externa para acesso à rede doméstica o sistema verifica as permissões do requisitante;

$\checkmark$ monitora o tráfego de informações com o mundo exterior por meio de um firewall evitando virus e invasões ao sistema.

\subsubsection{Subsistema de Controle Individual}

Um ambiente doméstico é composto por diversos dispositivos e suas respectivas funções. O Subsistema de Controle Individual tem como principal função o controle de cada um dos dispositivos presentes na residência.

No Apêndice A, é apresentada uma lista contendo os dispositivos presentes na residência juntamente com as respectivas funções. Esta lista apresenta alguns exemplos de dispositivos e é baseada nas discussoões realizadas neste capítulo. Não pretende ser completa nem quanto à totalidade dos dispositivos nem quanto à sua funcionalidade. 


\subsection{Considerações Finais}

Este capítulo descreveu um dia comum no ambiente controlado por um sistema de gerenciamento doméstico. Foram descritos vários subsistemas de controle, denominados Subsistemas de Controle de Grupo, que controlam dispositivos que atuam em toda a residência executando uma tarefa distribuída. Outra forma de controle descrita é aquela realizada sobre cada um dos dispositivos, denominada Subsistema de Controle Individual. Foram analisadas as principais características dos sistemas de controle existentes e propostas classificaçoes para os sistemas de controle às quais levam em consideração características essenciais presentes em sistemas de gerenciamento.

O próximo capítulo apresenta a análise de requisitos para o sistema de gerenciamento doméstico proposto. Esta análise encontra-se dividida em requisitos de hardware e software. A seção de requisitos de software apresenta os requisitos funcionais para a interface SmartHome. Adicionalmente, $\hat{e}$ apresentada uma linguagem pictográfica para a representação dos comandos SmartHome. 


\section{Capítulo 4}

\section{Análise de Requisitos}

\subsection{Introdução}

Este capitulo apresenta a análise de requisitos do sistema proposto. Esta análise é fortemente baseada no ambiente hipotético apresentado no capítulo anterior. Informações adicionais são consideradas para tornar a análise mais completa e consistente. A seção 4.2 define um sistema amplo de gerenciamento doméstico e limita o escopo deste trabalho. Requisitos de hardware, funcionais e não funcionais, necessários à implementação do sistema de gerenciamento são discutidos na seção 4.3 e suas subseções. A seção 4.4 e suas subseções tratam dos requisitos do software do sistema de gerenciamento proposto e requisitos da interface. $O$ formato empregado para a construção de sentenças de comando é apresentado na seção 4.5. A subseção 4.5.1 apresenta uma representação dos comandos do sistema de gerenciamento em formato BNF. Uma linguagem pictográfica para a interface SmartHome é definida na seção 4.6. A seção 4.7 apresenta as linhas mestras para a implementação do sistema SmartHome destacando a interação entre atores externos e as funcionalidades do sistema.

\subsection{O Sistema de Gerenciamento Doméstico}

O sistema proposto, denominado SmartHome, é eminentemente baseado na distribuição do poder computacional pelos vários dispositivos que integram o sistema de gerenciamento bem como na delegação de responsabilidades entre os integrantes da rede de comunicação. Todos os dispositivos possuem poder computacional para realizar suas funções. Tal premissa visa diminuir a quantidade de informações transitando pela rede num dado momento. Todas 
as funcionalidades do sistema são implementadas em módulos de hardware, desta forma distribuindo e incrementando o poder de processamento, em última análise, acelerando a velocidade de resposta a eventos.

O sistema SmartHome é composto por vários módulos com funções bem definidas. Tais módulos são agrupados nas seguintes categorias: dispositivos domésticos, sensores, atuadores e interface homem-sistema.

Os equipamentos eletro-eletrônicos, eletrodomésticos e hardware de controle comprem o grupo denominado dispositivos domésticos. Todos os dispositivos domésticos possuem poder computacional suficiente para executar suas tarefas básicas, bem como permite a interligação destes em rede.

Os sensores, continuamente monitoram o ambiente e colhem informaçðes para que os demais dispositivos possam basear suas decisర̋es em tais informações. Os sensores são na sua maioria intensivamente utilizados pelos diversos Subsistemas de Controle de Grupo pertencentes à residência.

O ambiente controlado também utiliza atuadores quando necessita que determinadas ações sejam realizadas em resposta a acontecimentos específicos.

A interface homem-sistema posiciona-se sobre o sistema de gerenciamento, recebendo requisiçōes dos usuários. A seção 4.3 especifica o hardware que serve de base à execução das funções de interface no sistema SmartHome. Os requisitos do sistema SmartHome são apresentados nas próximas seções.

\subsection{Especificação dos Requisitos de Hardware}

\subsubsection{Requisitos Não Funcionais}

- A residência deve utilizar para o gerenciamento do sistema um computador de uso genérico;

- Os dispositivos integrantes do sistema SmartHome devem possuir um circuito integrado capaz de fornecer as coordendas destes com base no sistema GPS.

- Todos os sensores, atuadores e dispositivos domésticos empregados devem ser usuais, ou seja, facilmente disponíveis; 
- O projeto SmartHome propõe a criação de um dispositivo de hardware que integra diversas funcionalidades, a "Janela Virtual". Tal dispositivo pode ser baseado em um monitor de plasma e construído em formatos e dimensões diversos, tornando possível sua inclusão em um dispositivo qualquer. Uma restrição do sistema SmartHome é que um cômodo da residência deve possuir ao menos uma "Janela Virtual". Deve ser possível a qualquer eletrodoméstico hospedar uma "Janela Virtual", podendo esta estar alojada na porta da geladeira ou na porta do forno microondas. Fatores de ordem prática impõem a limitação mecânica de que a espessura da "Janela Virtual" seja reduzida de forma a não descaracterizar o objeto hospedeiro. Em um futuro não muito distante, os dispositivos domésticos de médio e de grande porte devem integrar "Janelas Virtuais". A "Janela Virtual" pode assumir a forma de um objeto qualquer, seja a porta da sala de estar ou o espelho do armário no banheiro.

\subsubsection{Requisitos Funcionais}

- O computador utilizado no gerenciamento do sistema deve hospedar um banco de dados que armazena todas as informações relativas a usuários e dispositivos. Adicionalmente, todas as partes que integram o sistema de gerenciamento, incluindo sensores e atuadores, devem compor uma rede de troca de mensagens e informações;

- O Subsistema de Segurança deve implementar um modo de segurança, no qual todas as portas da residência permanecem normalmente fechadas. Em tal modo as portas somente são abertas por usuários autorizados. No modo de operação normal algumas portas são normalmente fechadas e outras normalmente abertas. Os estados das portas são configurados pelo administrador do sistema;

- Os sensores no sistema SmartHome devem colher informações do ambiente e as enviar a um dispositivo de controle. O resultado do processamento pode então ser enviado a atuadores para que ações sejam executadas em resposta aos eventos identificados;

* Os dispositivos SmartHome devem informar sua localização ao sistema de gerenciamento, as coordendas são fornecidas pelos GPS presentes em cada um dos dispositivos; 
- O dispositivo "Janela Virtual" se propõe a uniformizar a metodologia de acesso aos demais elementos do sistema SmartHome. Este deve ser capaz de apresentar imagens provenientes de fontes diversas, podendo ser da TV, do computador, do vídeo game e do vídeo cassete, entre outras possibilidades. Deve atuar como dispositivo de entrada de dados, quando um usuário compõe comandos tocando sua tela, ou a partir de comandos de voz provenientes dos usuários.

\subsection{Especificação de Requisitos de Software}

\subsubsection{Requisitos Não Funcionais}

- O sistema de gerenciamento SmartHome deve ser executado sobre o sistema operacional Windows;

- A interface do sistema deve ser amigável, possuir elevada usabilidade e utilizar uma linguagem gráfica para construção de sentenças de comando;

* A interface de gerenciamento SmartHome tem como objetivo atender às necessidades de pessoas com algum tipo de limitação física ou mental, devendo ainda ser facilmente utilizada por qualquer outro grupo de pessoas para incrementar a sensação de conforto e comodidade;

- A interface para o sistema SmartHome deve ser exclusivamente gráfica, não possuindo linhas de comando textuais. Os dispositivos controlados e as suas respectivas funçð̃es devem, igualmente, ser representados por ícones.

\subsubsection{Requisitos Funcionais}

- As sentenças de comandos aceitas pelo sistema devem possuir o formato especificado na seção 4.6. Tais comandos devem ser baseados em uma forma de comunicação pictográfica a qual permite ao cérebro humano extrair rapidamente a informação codificada;

- Cada usuário deve possuir um conjunto de permissões no sistema. As permissões podem ser dos seguintes tipos: acesso a cômodo, acesso a dispositivo individual e acesso a grupo de dispositivos. A permissão para o acesso a cômodos está relacionada ao acesso fisico de um morador ou visitante a uma dependência da 
casa. Adicionalmente, não deve ser permitido o controle de nenhum dos dispositivos relacionados a um cômodo com acesso não permitido. A permissão para acesso a um dispositivo individual é relacionada ao controle que um usuário exerce sobre um determinado dispositivo. A permissão de controle de grupo é relacionada à permissão de alteração dos parâmetros necessários aos diversos Subsistemas de Controle de Grupo;

- O sistema deve permitir o controle remoto de um dispositivo real a partir de imagens apresentadas nas "Janelas Virtuais". No futuro todos os fabricantes de dispositivos domésticos com múltiplas funções deverão fornecer módulos de software que desempenham a função de terminal virtual;

- $O$ acesso de pessoas à residência deve utilizar as funcionalidades do sistema de segurança biométrico. A verificação biométrica empregada no sistema deve ser baseada em múltiplos métodos de reconhecimento, como voz, impressão digital, face e/ou íris. O objetivo em verificar características pessoais por diferentes métodos de reconhecimento é incrementar a velocidade e a confiabilidade no reconhecimento;

- As ações de abertura e fechamento das portas devem ser baseadas em permissões de acesso do usuário ao cômodo. Torna-se imprescindivel que o sistema verifique a identidade do requisitante. Uma porta pode prover acesso ao exterior da residência ou realizar a ligação entre dois cômodos interiores da residência. Em ambos os casos, o sistema deve obter a biometria do requisitante e verificar sua identidade. Em seguida, deve recuperar as permissões de acesso. Caso o indivíduo não possua a permissão de acesso necessária, o sistema pode cadastrar o usuário ou negar o acesso;

- A campainha da residência deve apresentar uma interface específica para usuários do sistema que requisitam ingresso à residência ou para visitantes que solicitam diálogo com um dos moradores;

- O sistema SmartHome deve verificar a identidade de um visitante quando requisita acesso à residência. Caso não seja possível a verificação, o sistema deve cadastrar as informações biométricas do requisitante. Adicionalmente o sistema deve dialogar com este visando identificar suas pretensões, à quais servirão de base para o encaminhamento da requisição. Considerando as informações obtidas, deve ser possível para o sistema tomar a decisão de criar um 
canal de comunicação com o morador requisitado ou descartar a chamada do visitante;

- O sistema SmartHome deve realizar a configuração automática dos dispositivos controlados no momento da sua conexão à rede, atribuindo ícones representativos para visualização nas "Janelas Virtuais". Todos os dispositivos devem possuir um circuito integrado capaz de fornecer as coordendas do dispositivo, baseadas no sistema GPS. Quando um dispositivo é transportado, a localização do ícone visualizado nas "Janela Virtuais" devem refletir tal mudança de posição. $\mathrm{O}$ circuito integrado GPS permite que os usuários SmartHome requisitem a informação sobre o local onde se encontra um determinado dispositivo que não esteja sendo encontrado;

- Após um dispositivo ser inserido no sistema deve ser permitido ao usuário adminstrador do sistema alterar algumas das configuraçōes iniciais, como a permissão de acesso ao dispositivo.

\subsubsection{Requisitos Funcionais da Interface}

- A tela inicial da interface de controle deve apresentar uma imagem da planta baixa da residência juntamente com os dispositivos integrantes da residência. $O$ administrador do sistema deve ser capaz de inserir a planta baixa da residência construída a partir de um aplicativo gráfico vetorial. Os cômodos de tal residência, igualmente, devem ser desenhados por meio da associação de traços simples de forma a delimitar a fronteira do cômodo, tais fronteiras guardam informaçōes sobre quais cômodos elas separam. Os dispositivos são representados visualmente por ícones espalhados sobre a planta, a interface deve se encarregar de realizar a conversão das coordenadas da planta baixa para 0 sistema de coordenadas globais. A partir da tela inicial da interface, o administrador do sistema deve poder navegar até uma tela com funçōes restritas. A tela inicial deve conter uma região destinada à visualização e interpretação das sentenças de comando pictográficas. A sentença visualizada deve ser convertida em uma sentença executável que finalmente deve ser enviada ao dispositivo;

- A partir da planta baixa da residência, deve ser possível representar o ambiente controlado tridimensionalmente, permitindo a navegação pela residência utilizando técnicas de realidade virtual. No interior de um cômodo, o usuário 
poderá visualizar e interagir com os dispositivos. Deve também ser permitido ao usuário simular uma nova arrumação do ambiente alterando a disposição dos móveis e dispositivos visualizados.

- Ao usuário deve ser possível requisitar a exibição de uma tela do interior de cômodo onde somente devem ser visualizados os ícones relacionados ao cômodo em questão;

- As interfaces gráficas do software de gerenciamento doméstico devem possuir uma região destinada à exibição do mapa da residência com indicadores da localização das pessoas presentes na residência;

- A interface deve permitir que a "Janela Virtual" exiba um terminal virtual para um determinado dispositivo, apresentando a imagem real do dispositivo a ser controlado. Toques realizados sobre a imagem visualizada devem ser capazes de controlar o dispositivo. $O$ efeito obtido deve ser o mesmo que toques realizados no painel do dispositivo considerado;

- Requisições de apresentação de ícones ampliados e com diferentes níveis de detalhamento devem ser possíveis a um usuário. Essa funcionalidade introduz o conceito de família de ícones para um determinado objeto. Os ícones de uma família são ordenados em ordem crescente quanto a seu grau de detalhamento. $O$ último ícone da familia deve consistir em uma imagem real do dispositivo de forma a suprimir toda e qualquer dúvida sobre a identidade do objeto representado;

* Comandos de voz devem ser reconhecidos pela interface SmartHome. À medida que as sentenças de comando são interpretadas pela interface as respectivas sentenças pictográficas devem ser visualizadas na área destinada à interpretação de comandos. De outro modo, sentenças de comando podem ser elaboradas tocando ícones em um repositório e arrastando-os até a posição desejada na sentença. 


\subsection{Linguagem de Representação de Comandos}

A interface SmartHome utiliza linhas de comando estruturadas de acordo com o formato abaixo:

O "sujeito" realiza uma "ação" sobre um determinado "objeto".

O "sujeito" consiste em um dispositivo que integra a rede de controle ou o próprio sistema de gerenciamento. Uma "ação" é uma tarefa realizada por um "sujeito". Quando uma "ação" necessita de um complemento este é denominado "objeto".

Ambos, "sujeitos" e "objetos", são identificados por substantivos e pela posição que ocupam em uma sentença de controle. De acordo com a definição, um substantivo que inicia uma sentença é identificado como "sujeito", caso esteja localizado no final da sentença é identificado como "objeto".

As "Janelas Virtuais" capturam sentenças de comando em formato pictográfico e as processam com o intuito de extrair os termos essenciais da sentença de controle.

\subsubsection{Representação de Comandos em Backus-Naur Form (BNF)}

A sintaxe de uma linguagem é formada por um conjunto de símbolos e regras de construção de sentenças de comando. A representação BNF é constituída de declarações não ambíguas, matemáticas, que definem a sintaxe correta das instruções na linguagem em questão [BAC01].

Simbologia básica BNF:

- $\quad<>$ indica que seu conteúdo será substituido por um termo relacionado;

- ::= significa é uma instância de;

- | significa a operação lógica ou;

- \& significa a operação lógica e;

- [ ] significa que o termo interior é opcional;

- \{ $\}$ significa que o termo interior pode repetir-se zero ou mais vezes.

Com o intuito de representar sem ambigüidades os comandos suportados pelo sistema SmartHome, foi elaborada a representação baseada no modelo de representação BNF:

$<$ sentençaSH $>::=<$ sujeito $><$ ação $>\{<$ objeto $>\}$ 
$<$ sujeito $>::=<$ sujeito $>\mid<$ sujeito $><$ cômodo $>$

$<$ sujeito $>:=\{$ lista de dispositivos descritos no apêndice $A\}$

$<$ cômodo $>::=<$ cômodo $>\mid<$ cômodo $><$ número $>$

<cômodo>::=quarto | sala | banheiro | escritório | cozinha | garagem | área de serviço

$<$ número $>::=1|2| 3|4| \ldots$

<ação >::= abrir | acessar | acionar | agendar | ajustar | anterior | atender | aumentar | avançar | capturar | coletar | desabilitar | desligar | despertar | diminuir | discar | disparar | encontrar | enviar | executar | exibir | gerar | gravar | imprimir | ligar | mostrar | parar | paralisar | procurar | preview | próximo | receber | reciclar | salvar | selecionar | validar | secar | sugerir | realizar | realizar | verifiçar

<objeto>::= <sujeito> $\mid$ <alimento> $\mid$ alarme $\mid$ AM $\mid$ atração $\mid$ <atração> $\mid$ arquivos $\mid<$ arquivo> $\mid$ arquivos adquiridos | auto-diagnóstico $\mid<$ automático $\mid$ manual $>\mid<$ bolo $>$ caixa de correio | câmera de vídeo | campainha | canal $\mid<$ canal $>\mathrm{CD} \mid$ compras $\mid$ computador $\mid$ controle de contas $\mid$ dados $\mid<$ data $>$ dispositivo $\mid<$ dispositivo $>1$ DVD | ecocardiograma | entrada de dados | fax | fax enviados | fax recebidos |FM | filme $\mid$ fotos $\mid<$ foto $>$ <hora : minutos $>$ imagem | imagens $\mid$ interface SmartHome | Internet | <jogo> | jogos | lista de canais | lista de compras | lista de imagens | lista de jogos | lista de receitas $\mid$ mail | <endereço eletrônico> | $<$ minutos $>\mid$ modo $\mid$ modo de voz $\mid$ mural de lembretes $\mid$ nível $<1 . .10>\mid<$ número de telefone $>$ | preparo | visualizar $\mid$ produtos $\mid$ produtos disponíveis $\mid$ projetor $\mid$ proteção de tela | <queimador> | receitas disponíveis | <receita> | <serviço automotivo $>$ | som ambiente $\mid$ sons $\mid$ teclado $\mid$ temperatura $\mid$ timer $\mid$ TV $\mid$ velocidade $\mid$ vídeo $\mid$ vídeo game $\mid$ volume $\mid$ voz $|<1 . .3>|<1 . .5>|<1 . .10>|<+\mid->$ 


\subsection{Linguagem Pictográfica SmartHome}

Os termos que compõem uma sentença de controle são representados graficamente por ícones. O conjunto de ícones do SmartHome tem como objetivo único transmitir uma mensagem sem se preocupar com a complexidade das formas utilizadas.

\section{Indicadores}

Um ícone pode representar um "sujeito", uma "ação" ou um "objeto" dependendo do indicador associado ao ícone e sua posição na sentença.

Um indicador de que o ícone proposto pode ser interpretado como um "sujeito" ou "objeto", de acordo com a notação adotada, é uma caixa em duas dimensões, adicionada no lado direito inferior do ícone proposto. $\mathrm{O}$ ícone apresentado na figura 4.1 representa uma geladeira:

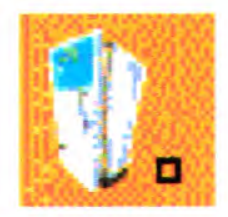

Figura 4.1- Ícone representativo de "sujeito" - Geladeira

O símbolo indicador de "ação" é uma cunha associada ao ícone. Quando se deseja representar uma função de um dispositivo ou do sistema de gerenciamento associa-se o indicador de "ação" no lado inferior direito do ícone. A figura 4.2 apresenta um ícone de "ação" construído segundo a diretiva SmartHome.

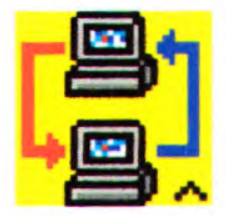

Figura 4.2 - Ícone representativo de "ação" - Conectar

\section{Sentenças}

Uma sentença completa na linguagem SmartHome é composta de uma associação de ícones de representação individual, a seção 4.6 apresentou a estrutura para uma sentença de comando no sistema SmartHome. A figura 4.3 apresenta uma sentença pictográfica baseada na especificação proposta. 

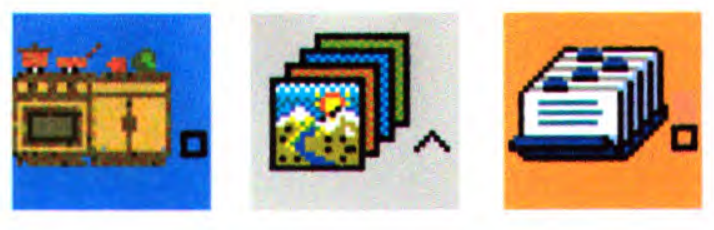

Figura 4.3 - Sentença SmartHome - "Fogão Exibir Lista de Receitas"

\subsection{Diagramas de Software}

O sistema proposto foi projetado utilizando a notação UML (Unified Modeling Language) seguindo uma metodologia de desenvolvimento orientada a objetos [RAU98]. Durante a fase de especificação e projeto foi utilizado o software de modelagem de sistemas Rose 98. O produto final produzido pela ferramenta de modelagem Rose 98 inclui documentos específicos da fase de implementação [RAT01].

$\mathrm{Na}$ notação UML, um ator externo é qualquer elemento que requisita para o sistema a realização de uma tarefa, podendo ser uma pessoa, outro sistema, um computador ou um dispositivo. Um diagrama de Use Case é uma seqüência de transações realizadas pelo sistema em resposta a um evento gerado por um ator externo. Um diagrama de Use Case representa as ações permitidas a um ator externo no sistema modelado.

\subsubsection{Diagrama Ambiental}

O diagrama ambiental mostra o comportamento do sistema na visão de um ator externo. O sistema SmartHome interage com os seguintes atores externos: "AtorAdmSH", "AtorUsuario", "AtorDispositivo" e "AtorVisitante".

$\mathrm{O}$ "AtorAdmSH" representa o administrador do sistema doméstico. Na modelagem do sistema SmartHome os diversos usuários do sistema são representados pelo "AtorUsuario". Os vários dispositivos domésticos são representados pelo “AtorDispositivo". O "AtorVisitante" representa pessoas que interagem com os moradores da residência.

O diagrama apresentado na figura 4.4 apresenta todos os atores externos que de alguma forma interagem com o sistema SmartHome. 


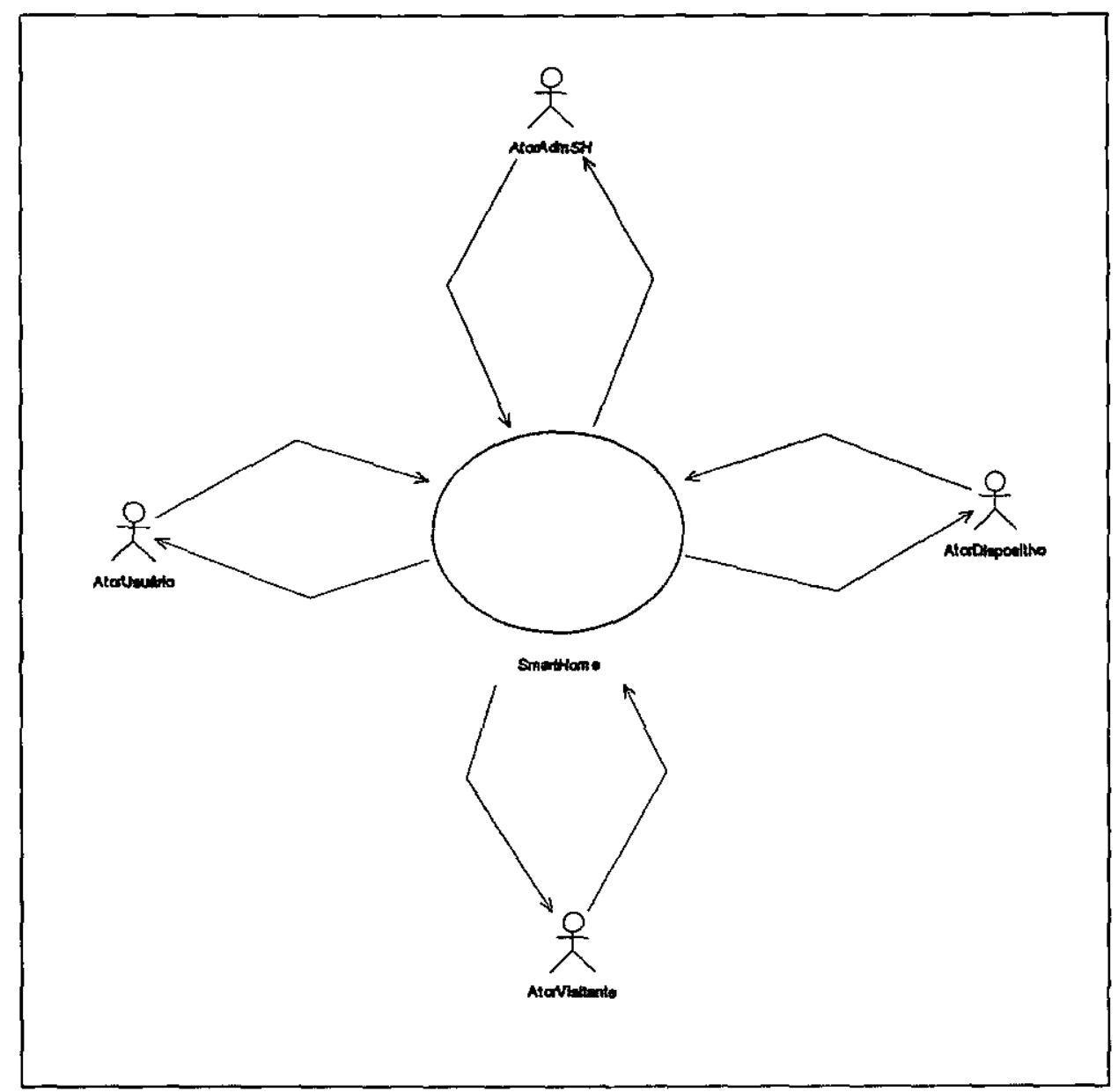

Figura 4.4 - Diagrama Ambiental do Sistema SmartHome

A figura anterior é uma representação bastante genérica para o sistema proposto. Prosseguindo a especificação, o sistema SmartHome apresenta-se dividido nas seguintes funcionalidades básicas: execução de sentenças de comando, cadastro de preferências do usuário, configuração automática de dispositivos, gerenciamento do sistema e atendimento a visitantes. Os Use Cases que compz̃em o sistema SmartHome são apresentados na figura 4.5. 


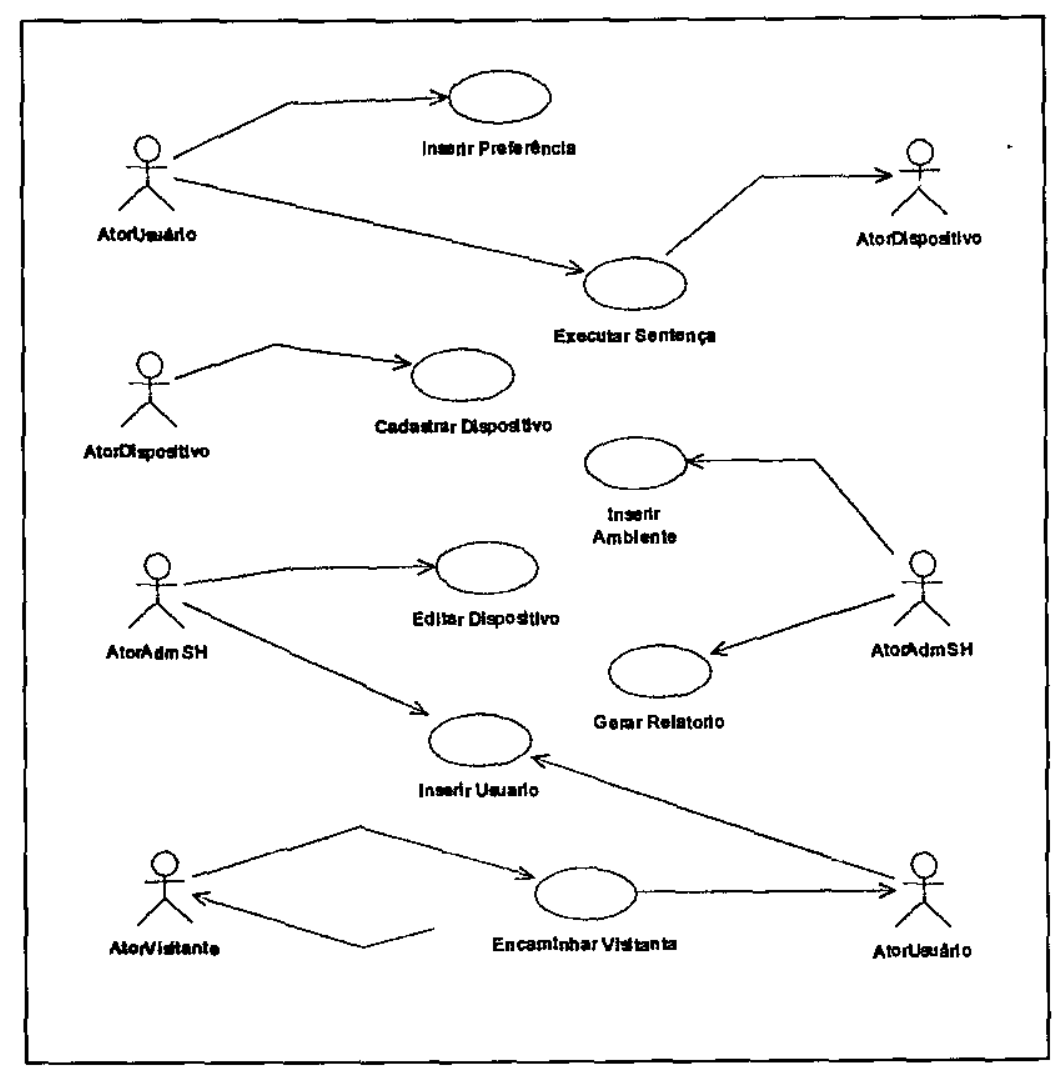

Figura 4.5 - Use Cases SmartHome

A funcionalidade "Executar Sentença" processa requisiçőes provenientes de um morador e atua sobre um dispositivo da residência. Um morador pode cadastrar suas preferências no sistema utilizando o Use Case "Inserir Preferência". É possível inserir preferências como a temperatura da água para o banho, músicas prediletas, gêneros de programas de TV preferidos, entre outras. O Use Case "Cadastrar Dispositivo" realiza a inserção automática de um dispositivo no momento que este se conecta à rede de dispositivos domésticos. A configuração dos ambientes controlados e respectivos cômodos é realizada pelo Use Case "Inserir Ambiente". Um dispositivo controlado pelo sistema SmartHome pode ter algumas de suas configurações alteradas pelo "AtorAdmSH". Tal tarefa é realizada pelo Use Case "Editar Dispositivo". A inserção de usuários no sistema SmartHome é realizada pelo Use Case "Inserir Usuário". O Use Case "Encaminhar Visitante" recebe chamadas de visitantes e realiza uma triagem para identificar suas intenções e definir o encaminhamento dado à chamada. Ressalta-se que no momento que o sistema SmartHome recebe uma chamada de um visitante não cadastrado, o cadastro deste é realizado. Após a realização do cadastro, o visitante imediatamente torna-se um usuário SmartHome com permissões limitadas. O Use Case "Gerar Relatório" formata e emite relatórios administrativos. 


\subsection{Consideraçöes Finais}

Neste capítulo foram analisados requisitos de hardware e software para o sistema de gerenciamento proposto. As tarefas realizadas pelo sistema foram especificadas utilizando-se a linguagem de representação de comandos BNF. Propôs-se uma linguagem pictográfica para a construção de sentenças de comando as quais deverão ser interpretadas pela interface do sistema. Finalmente, foram apresentados alguns diagramas de uso do sistema. Tais diagramas seguem as especificações da notação UML.

No próximo capítulo são apresentados diagramas mais detalhados para os Use Cases do sistema, diagramas de classes funcionais e não funcionais e o diagrama de hardware do sistema. Finalmente é apresentado um protótipo para a interface do sistema SmartHome. 


\section{Capítulo 5}

\section{Projeto e Implementação}

\subsection{Introdução}

Este capítulo é dividido em seçōes que tratam de assuntos relacionados às fases de projeto e implementação do sistema SmartHome. Em relação à implementação, é apresentado um protótipo da interface do sistema.

A seção 5.2, e suas subseções, apresentam diagramas detalhados para os Use Cases do sistema SmartHome. Na seção 5.3 são apresentados os diagramas de classes para o sistema SmartHome, particionadas em classes funcionais e do tipo interface. A seção 5.4 apresenta os módulos de hardware que compõem o sistema SmartHome. A seção 5.5 apresenta os elementos utilizados na implementação do protótipo da interface SmartHome, suas subseções apresentam as tabelas utilizadas pela base de dados as as telas que compõem a interface SmartHome.

\subsection{Use Cases do Sistema SmartHome}

A notação UML permite a criação de um diagrama, denominado diagrama de interação, que enfatiza a interação e a sequêtncia de colaboração entre os objetos que fazem parte do sistema. Adicionalmente, identifica as mensagens trocadas entre os objetos. Este tipo de diagrama evidencia a forma como os objetos cooperam entre si para atingir um objetivo comum.

Nas próximas subseções são apresentados Use Cases mais detalhados para cada uma das funcionalidades apresentadas na figura 4.5. Tal figura foi denominada Use Cases SmartHome. 
Complementarmente, cada subseção apresenta o respectivo diagrama de interação entre as classes utilizadas.

\subsubsection{Use Case "Executar Sentença"}

O diagrama para o Use Case "Executar Sentença" é apresentado na figura 5.1.

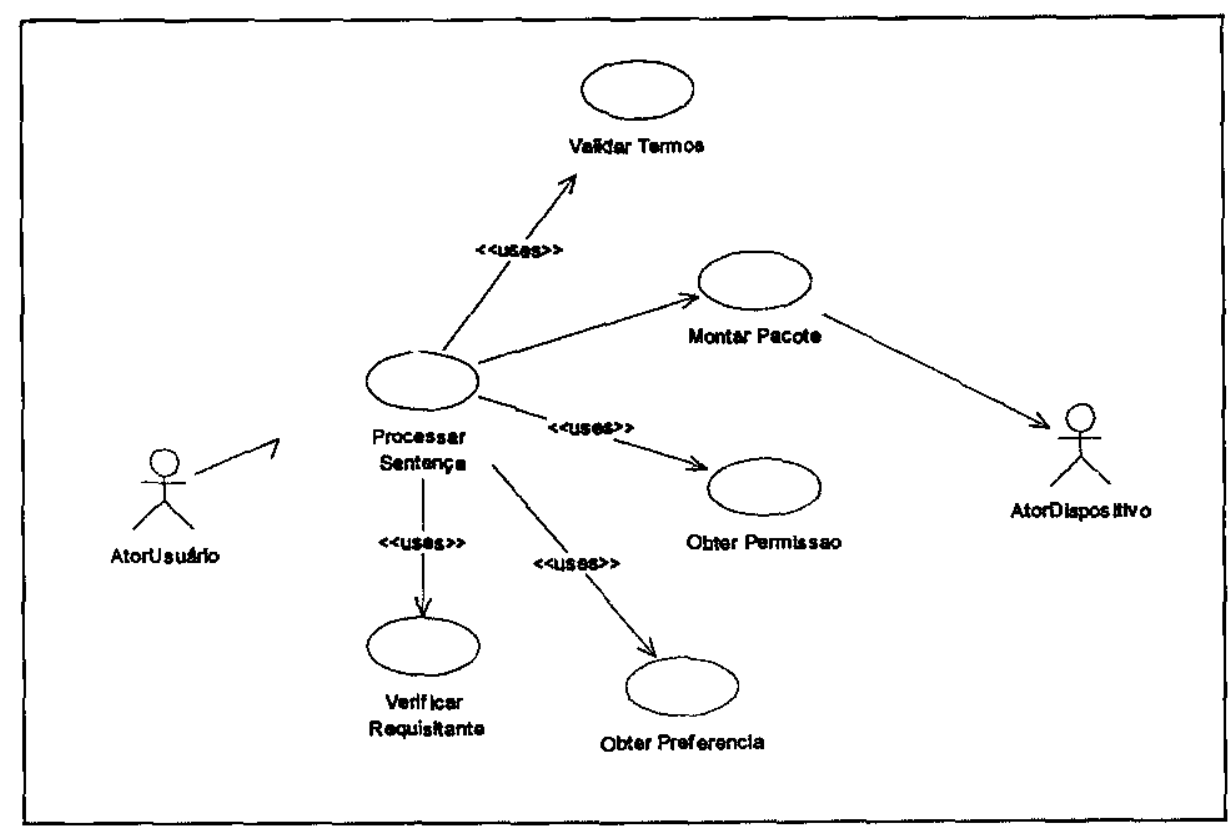

Figura 5.1 - Use Case "Executar Sentença"

Este Use Case cuida da execução dos comandos requisitados por um usuário. O Use Case "Processar Sentença" recebe requisições de tarefas por parte dos usuários. O Use Case "Verificar Requisitante" obtém dados de biometria do "AtorUsuário" visando identificá-lo. Caso a identificação seja realizada com sucesso, as permissões do usuário são verificadas pelo Use Case "Obter Permissão". O Use Case "Validar Termos" verifica a validade da sentença. Os termos da sentença são validados em um banco de comandos. As preferências do "AtorUsuário" são recuperadas pelo Use Case "Obter Preferência". Finalmente, um pacote executável é montado e enviado ao dispositivo alvo da requisição. Esta funcionalidade é executada pelo Use Case "Montar Pacote".

A funcionalidade "Executar Sentença" tem seu diagrama de interação apresentado na figura 5.2. No diagrama apresentado podemos evidenciar a maneira como os objetos do sistema interagem entre si, bem como o momento em que estas interaçőes ocorrem. 


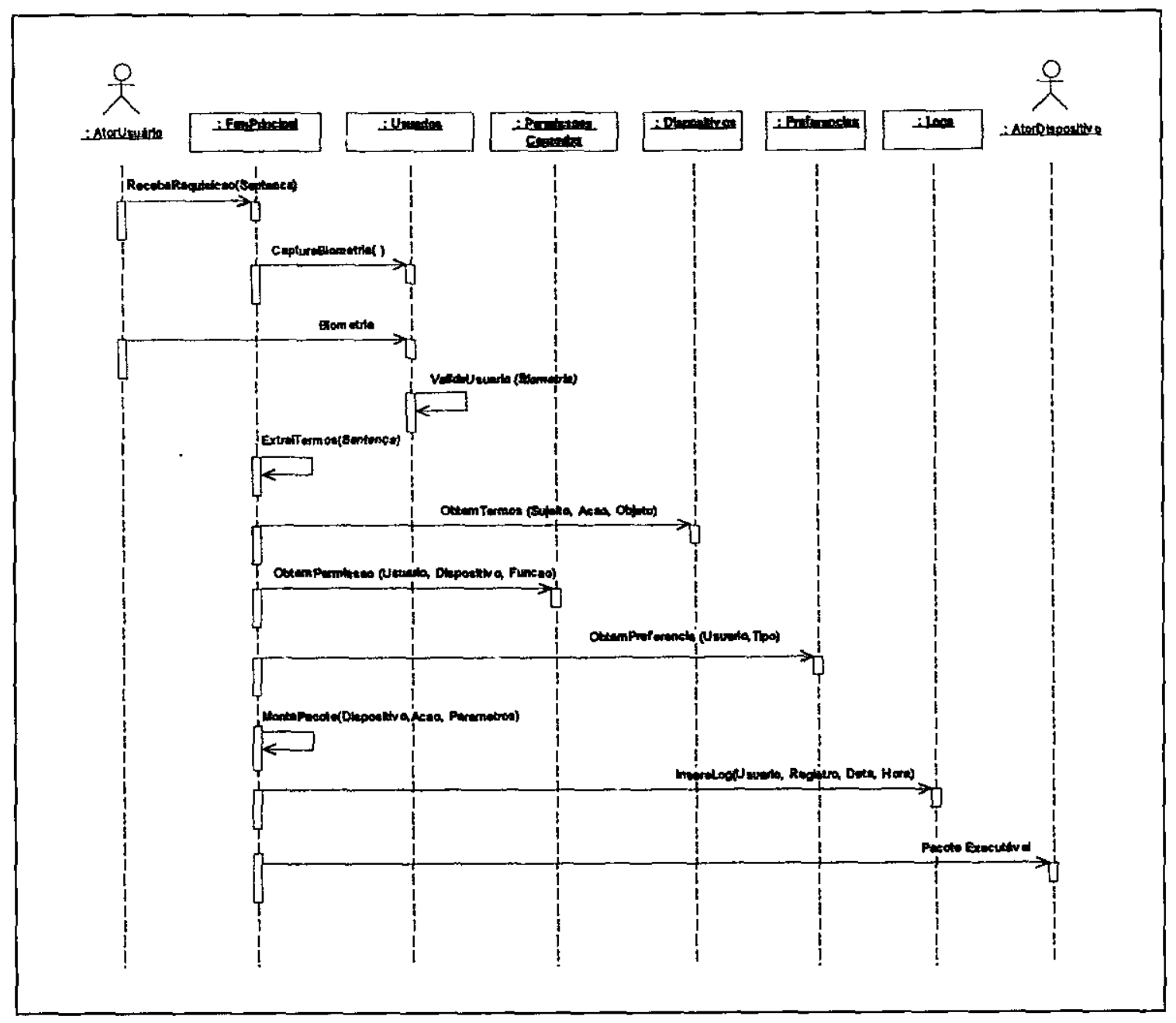

\section{Figura 5.2 - Diagrama de Interaçăo - Use Case "Executar Sentença"}

Na região superior dos diagramas de interação, são apresentados retângulos com preenchimento. Estes evidenciam os objetos que participam do Use Case. As linhas tracejadas verticais evidenciam a ordem na qual os objetos executam seus métodos. As setas horizontais representam mensagens trocadas entre os objetos. Tais setas também apresentam os métodos chamados. Os retângulos sem preenchimento, localizados sobre as linhas tracejadas verticais, representam o tempo gasto na execução dos métodos. As definições contidas neste parágrafo são válidas para todos os diagramas de interação apresentados neste documento. $O$ apêndice $B$ apresenta um relatório que contém todas as classes do sistema SmartHome, incluindo os respectivos atributos e métodos. O relatório apresentado foi produzido automaticamente pela ferramenta de modelagem Rose 98. 


\subsubsection{Use Case "Cadastrar Preferência"}

A figura 5.3 apresenta o diagrama para o Use Case "Cadastrar Preferência".

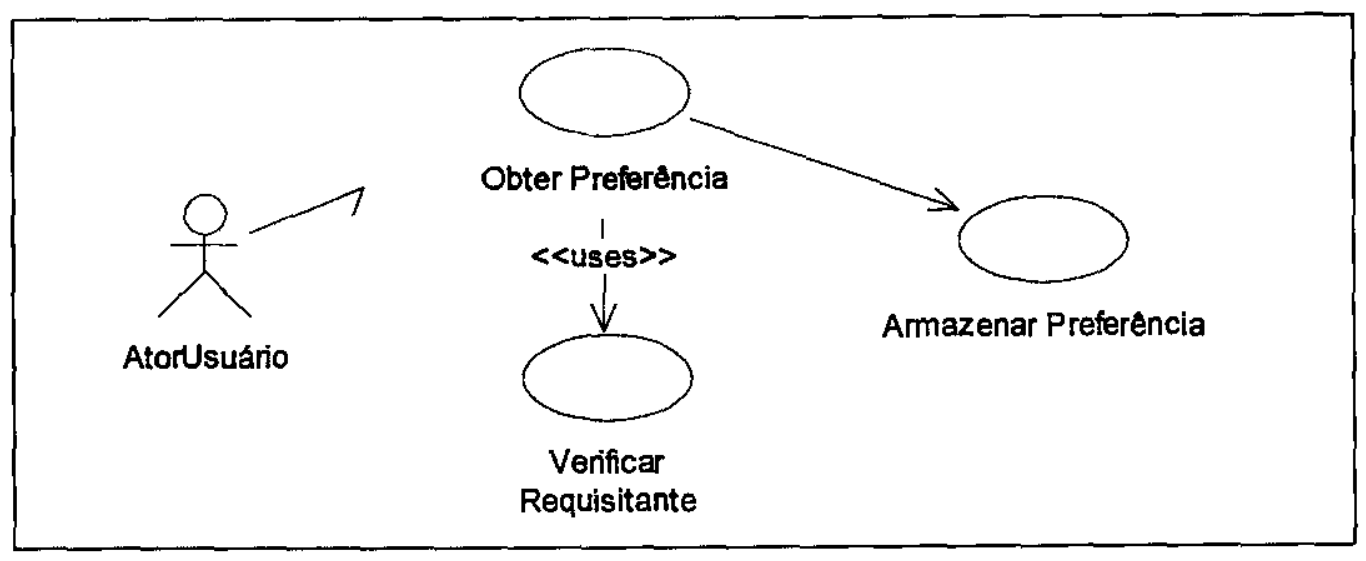

Figura 5.3 - Use Case "Cadastrar Preferência"

O Use Case "Cadastrar Preferência" permite ao usuário cadastrar suas preferências no sistema SmartHome. Uma função que necessita receber um parâmetro pode utilizar uma preferência previamente cadastrada desde que o parâmetro e a preferência sejam de mesmo tipo, considerando que o usuário não tenha fornecido um outro valor para o parâmetro.

O Use Case "Obter Preferênica" recebe as preferências de um usuário. A identidade de tal usuário é verificada pelo Use Case "Verificar Requisitante". Caso este usuário esteja cadastrado no sistema de gerenciamento a preferência é armazenada pelo Use Case "Armazenar Preferência".

A figura 5.4 apresenta o diagrama de interação para a funcionalidade que realiza o cadastro das preferências dos usuários. 


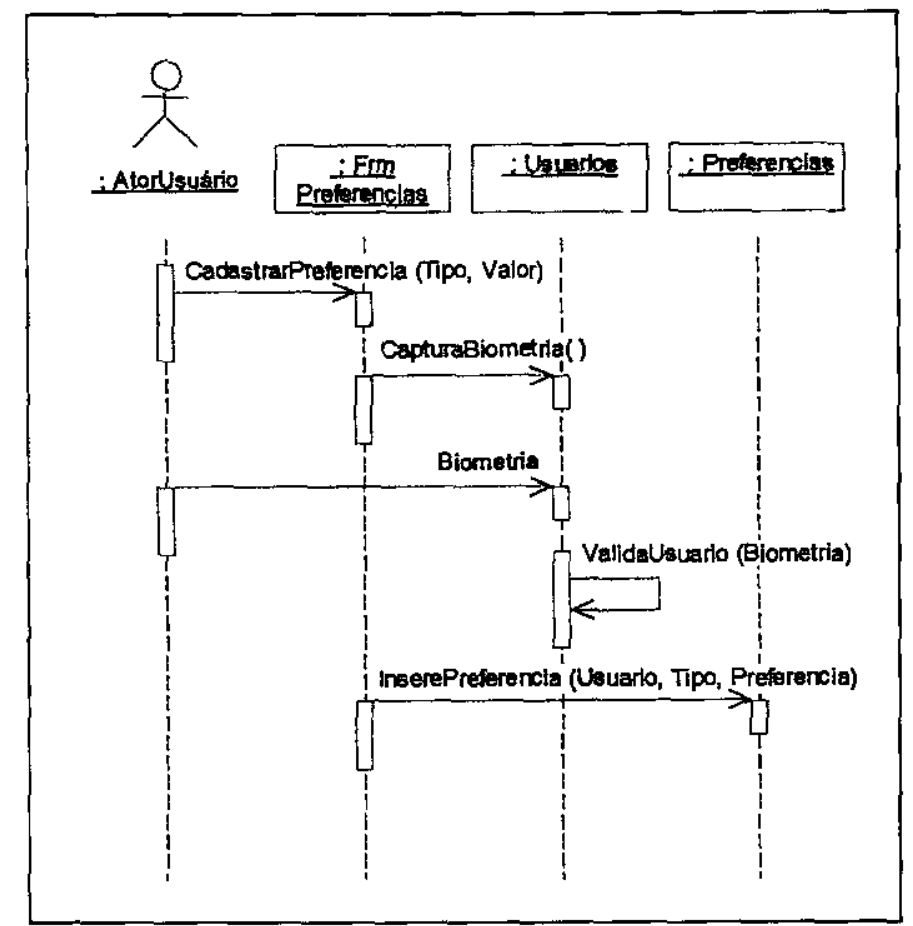

Figura 5.4 - Diagrama de Interação - Use Case "Cadastrar Preferência"

\subsubsection{Use Case "Configurar Dispositivo"}

O Use Case "Configurar Dispositivo" trata da inclusão automática de dispositivos que estejam na área controlada pelo sistema SmartHome, de acordo com o apresentado na figura 5.5 .

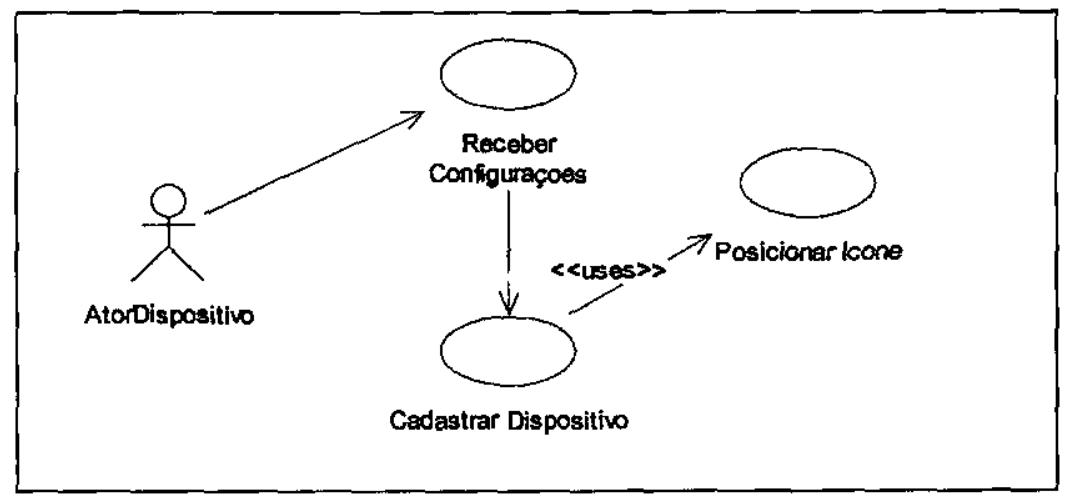

Figura 5.5 - Use Case "Configurar Dispositivo" 
O Use Case "Receber Configurações" permanece monitorando a rede com a intenção de identificar pacotes que possuam pedidos de configuração. Quando pacotes de configuração são identificados, o Use Case "Cadastrar Dispositivo" insere o dispositivo no sistema de gerenciamento, permitindo assim que usuários do sistema possam controlá-lo. Assim que o dispositivo foi cadastrado, o sistema SmartHome apresenta o respectivo fcone nas "Janelas Virtuais" com a utilizaçăo do Use Case "Posicionar Icone". Todo dispositivo possui um chip GPS que fornece a localização geográfica do dispositivo so sistema SmartHome. Desta forma, o ícone visualizado em uma "Janela Virtual" localiza-se em posição equivalente a localização fisica do dispositivo.

A figura 5.6 apresenta o diagrama de interaçăo para o Use Case "Configurar Dispositivo".

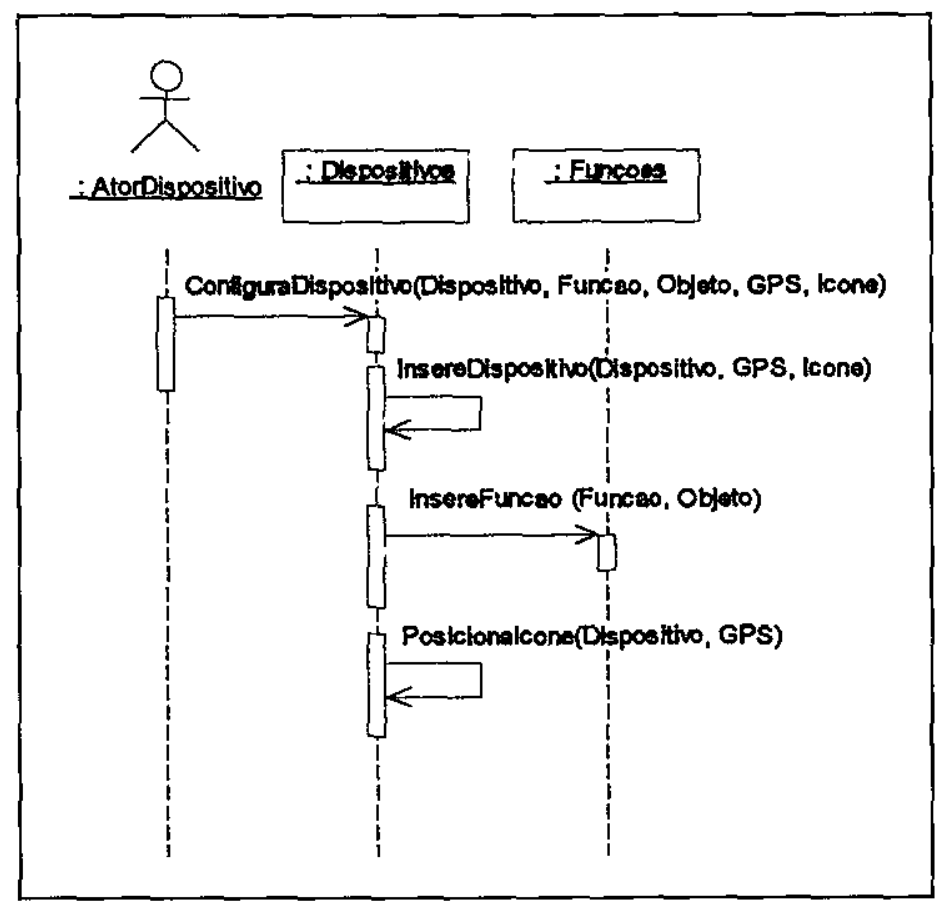

Figura 5.6 - Diagrama de Interaço - Use Case "Configurar Dispositivo"

\subsubsection{Use Case "Configurar Ambiente"}

Este Use Case realiza a configuração do ambiente a ser controlado pelo sistema de gerenciamento SmartHome, conforme a figura 5.7. 


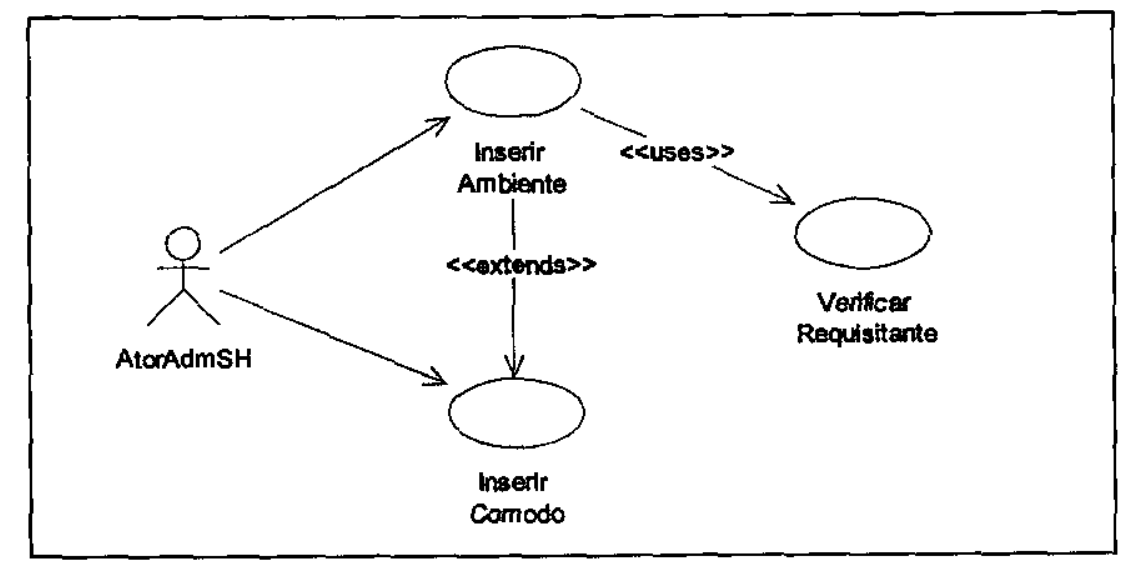

Figura 5.7 - Use Case "Configarar Ambiente"

O Use Case "Inserir Ambiente" recebe uma requisição para configuração do ambiente a ser gerenciado. Em seguida o requisitante tem sua identidade verificada pelo Use Case "Verificar Requisitante". Caso o requisitante possua permissão de administrador sua requisição é atendida. A planta baixa do ambiente a ser gerenciado deve ser gerada a partir de um ambiente de desenhos vetoriais. As coordendas vetoriais da planta são internamente convertidas e armazenadas no formato de coordenadas globais. Após um ambiente de gerenciamento ser inserido o Use Case "Inserir Comodo" realiza a configuração lógica das dependências do ambiente, os desenhos relativos a cômodos também devem ser gerados a partir de um ambiente de desenho vetorial. Novamente, as coordendas vetoriais do cômodo são convertidas e armazenadas em formato de coordenadas globais.

A figura 5.8 apresenta o diagrama de interação para a funcionalidade "Configurar Ambiente". Ressalta-se que a execução das funcionalidades do Use Case "Configurar Ambiente" possui acesso restrito ao administrador do sistema ou a usuários que possuam as mesmas permissões deste. 


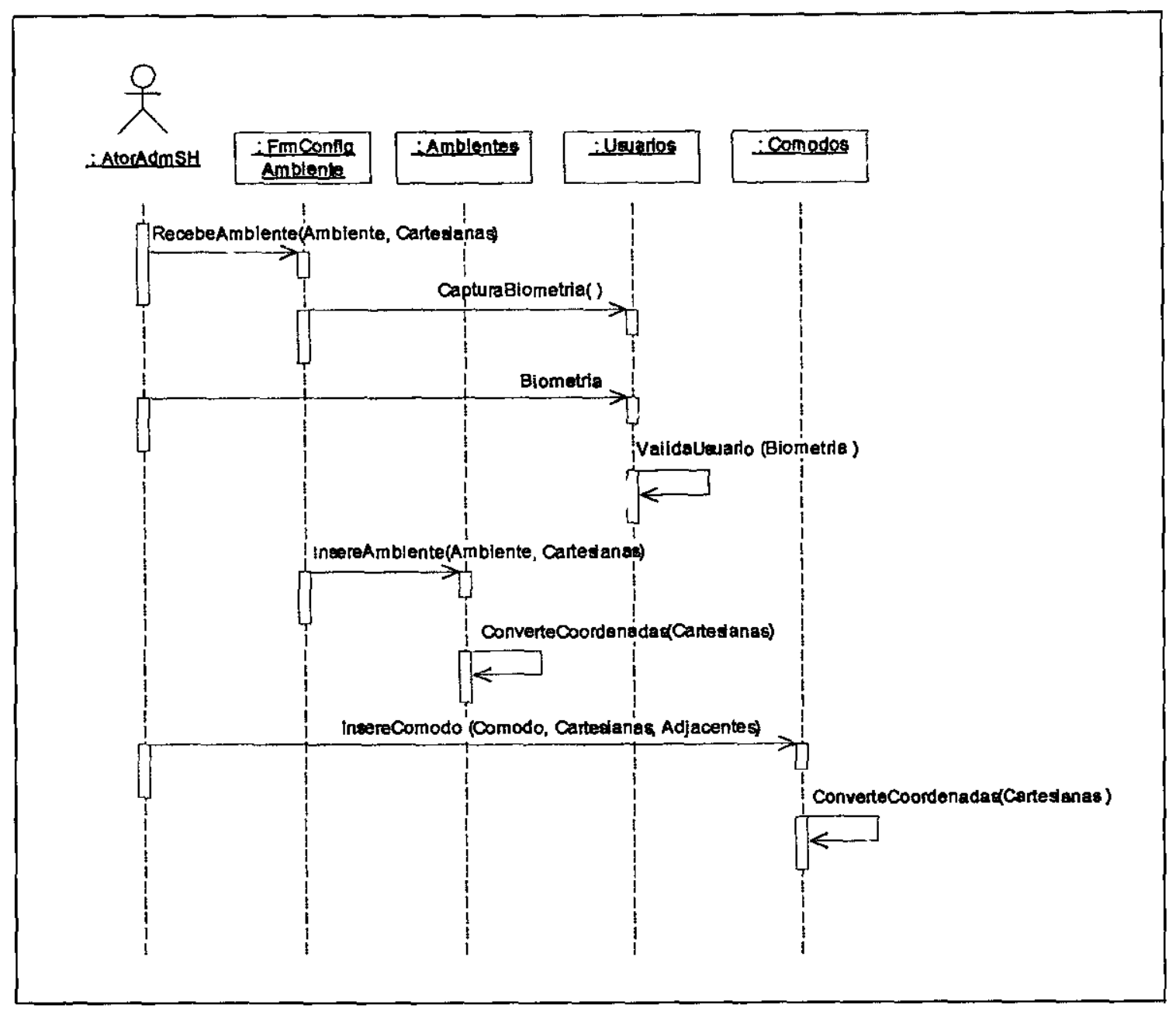

Figura 5.8 - Diagrama de Interaçăo - Use Case "Configurar Ambiente"

\subsubsection{Use Case "Gerar Relatório"}

A figura 5.9 apresenta o diagrama para o Use Case "Gerar Relatório". O Use Case "Gerar Relatório" gera relatórios textuais e estatísticos tomando por base os registros armazenados nos arquivos de $\log$ do sistema. São relatórios possíveis de serem gerados: acessos de um determinado usuário, usuários cadastrados, dispositivos cadastrados, além de relatórios de acesso a um determinado dispositivo em um periodo. 


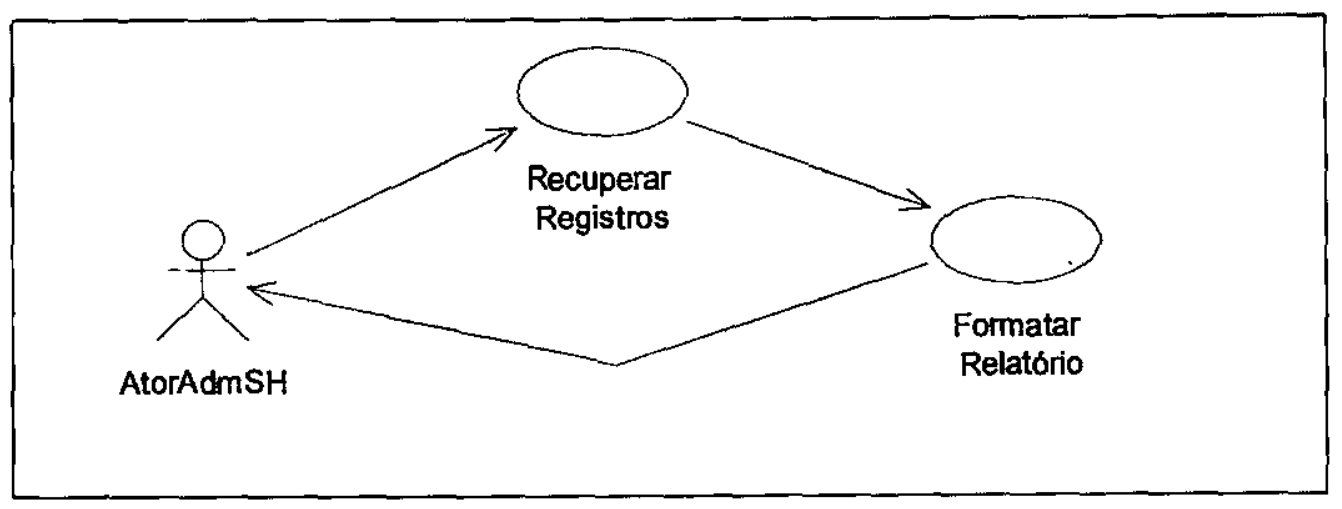

Figura 5.9 - Use Case "Gerar Relatório"

O Use Case "Recuperar Registros" recupera os registros do sistema de acordo com o relatório requisitado. Adicionalmente, o Use Case "Formatar Relatório" realiza a formatação dos dados obtidos e emite o relatório.

A figura 5.10 apresenta o diagrama de interação entre as classes empregadas na arquitetura do Use Case "Gerar Relatório".

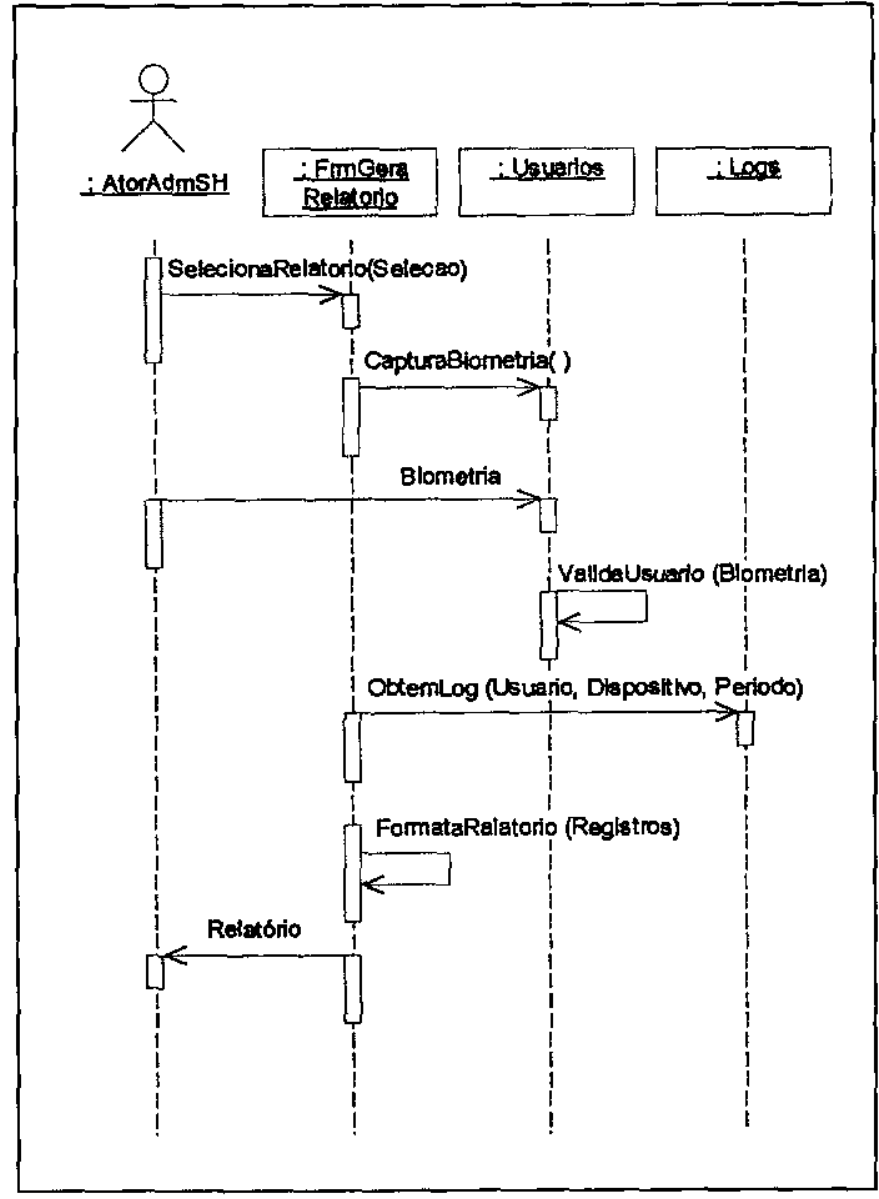

Figura 5.10 - Diagrama de Interação - Use Case "Gerar Relatório" 


\subsubsection{Use Case "Editar Dispositivo"}

O Use Case "Editar Dispositivo" é mostrado de forma detalhada na figura 5.11.

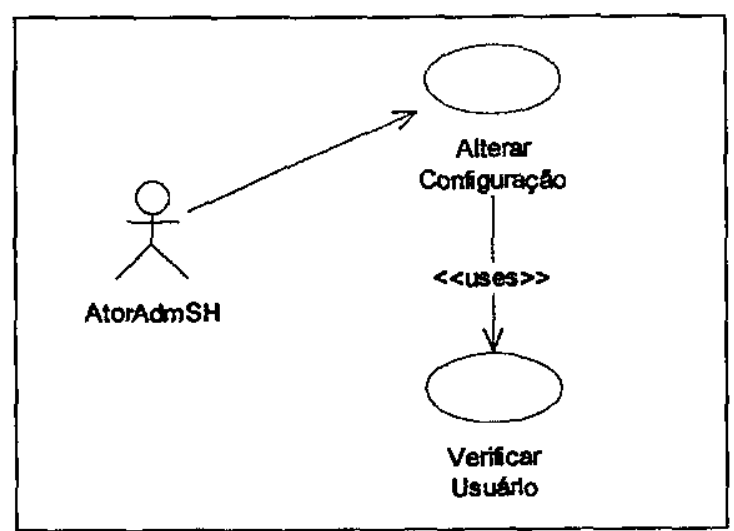

Figura 5.11 - Use Case "Editar Dispositivo"

O Use Case "Editar Dispositivo" permite que o "AtorAdmSH" altere algumas das configurações que o sistema realizou automaticamente quando o dispositivo foi inserido no sistema.

No momento que o administrador requer a edição dos parâmetros de configuração de um dispositivo, o Use Case "Verificar Requisitante" verifica a identidade do requisitante e suas permissões. O Use Case "Alterar Configuração" prepara os valores a serem modificados armazenando-os no banco de dados que registra as configurações dos dispositivos pertencentes ao sistema SmartHome.

A figura 5.12 mostra o diagrama de interação para o Use Case "Editar Dispositivo". 


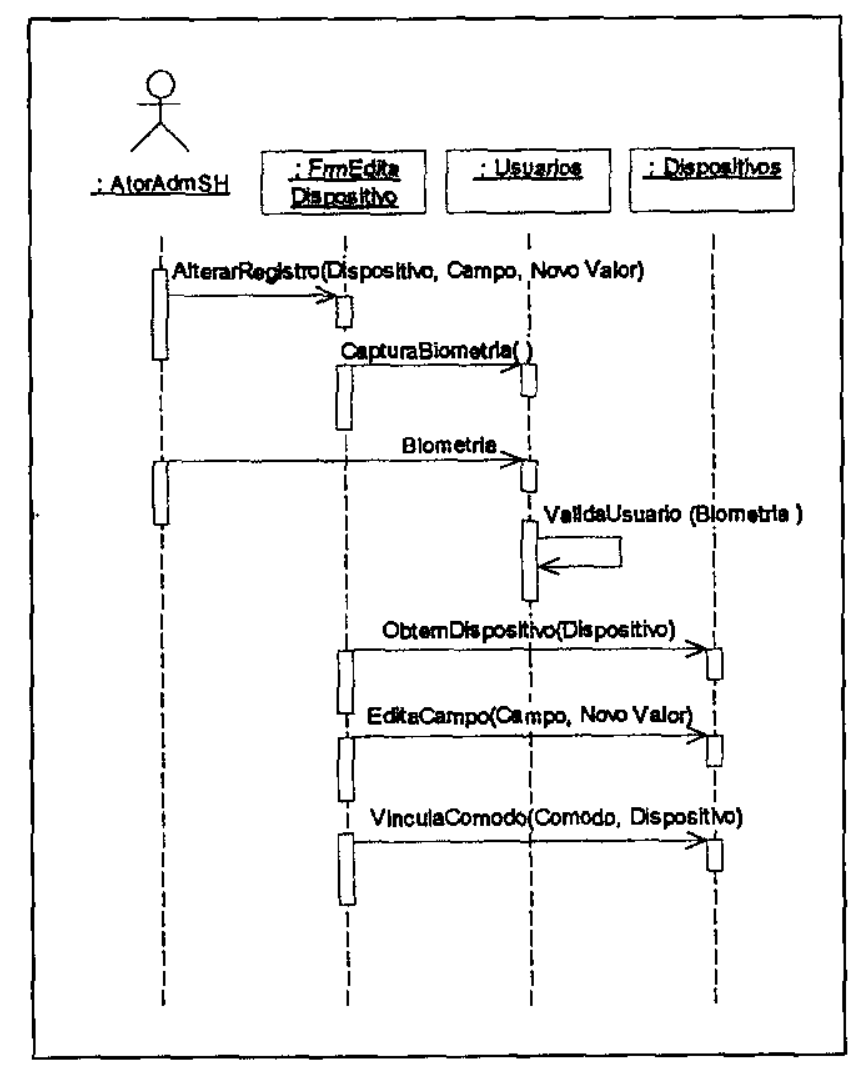

Figura 5.12 - Diagrama de Interação - Use Case "Editar Dispositivo"

\subsubsection{Use Case "Cadastrar Usuário"}

O Use Case "Cadastrar Usuário" realiza a inserção de novos usuários e suas permissões no sistema SmartHome. Este Use Case também é de utilização exclusiva do "AtorAdmSH". A figura 5.13 apresenta o diagrama detalhado para o Use Case "Cadastrar Usuário".

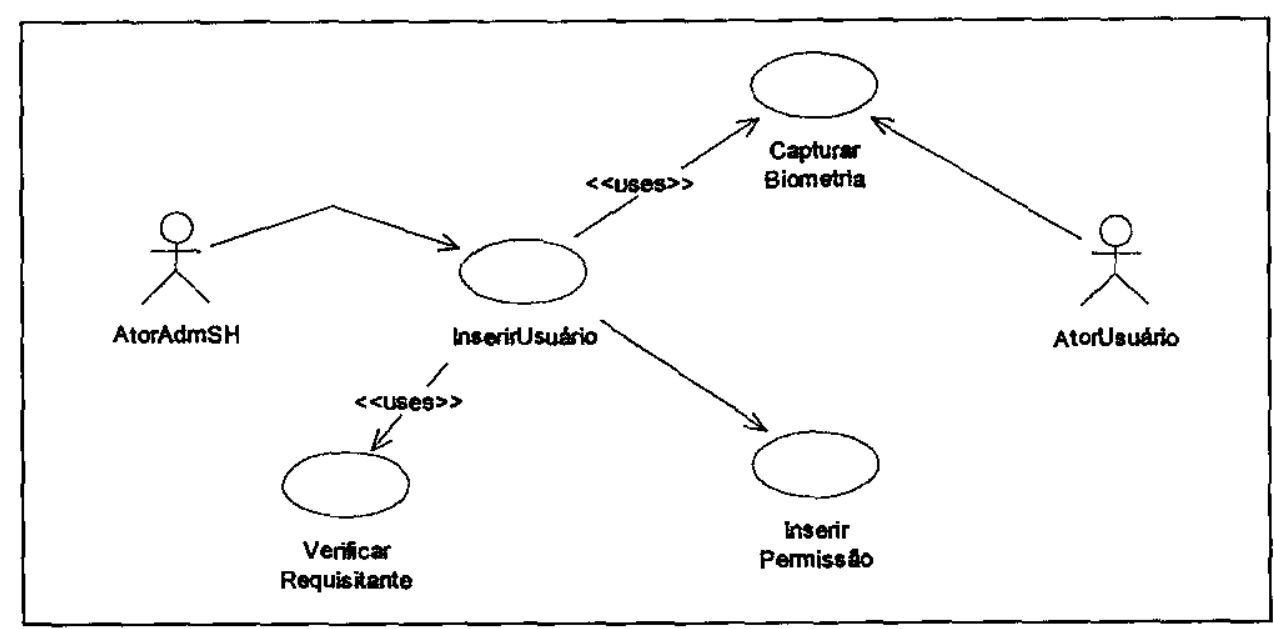

Figura 5.13 - Use Case "Cadastrar Usuário" 
O Use Case "Inserir Usuário" recebe requisiçōes de inserção de novos usuários. O requisitante tem sua identidade verificada pelo Use Case "Verificar Requisitante". Caso o requisitante possua permissão de administrador, o novo usuário é cadastrado. O Use Case "Inserir Permissão" realiza a atribuição de permissões ao usuário recém-criado. Posteriormente o Use Case "Capturar Biometria" recebe os dados da biometria do novo usuário. Desta forma, tornando o usuário apto a interagir com o sistema SmartHome.

Na figura 5.14 é apresentado o diagrama de interação para a funcionalidade de inserção de novos usuários no sistema.

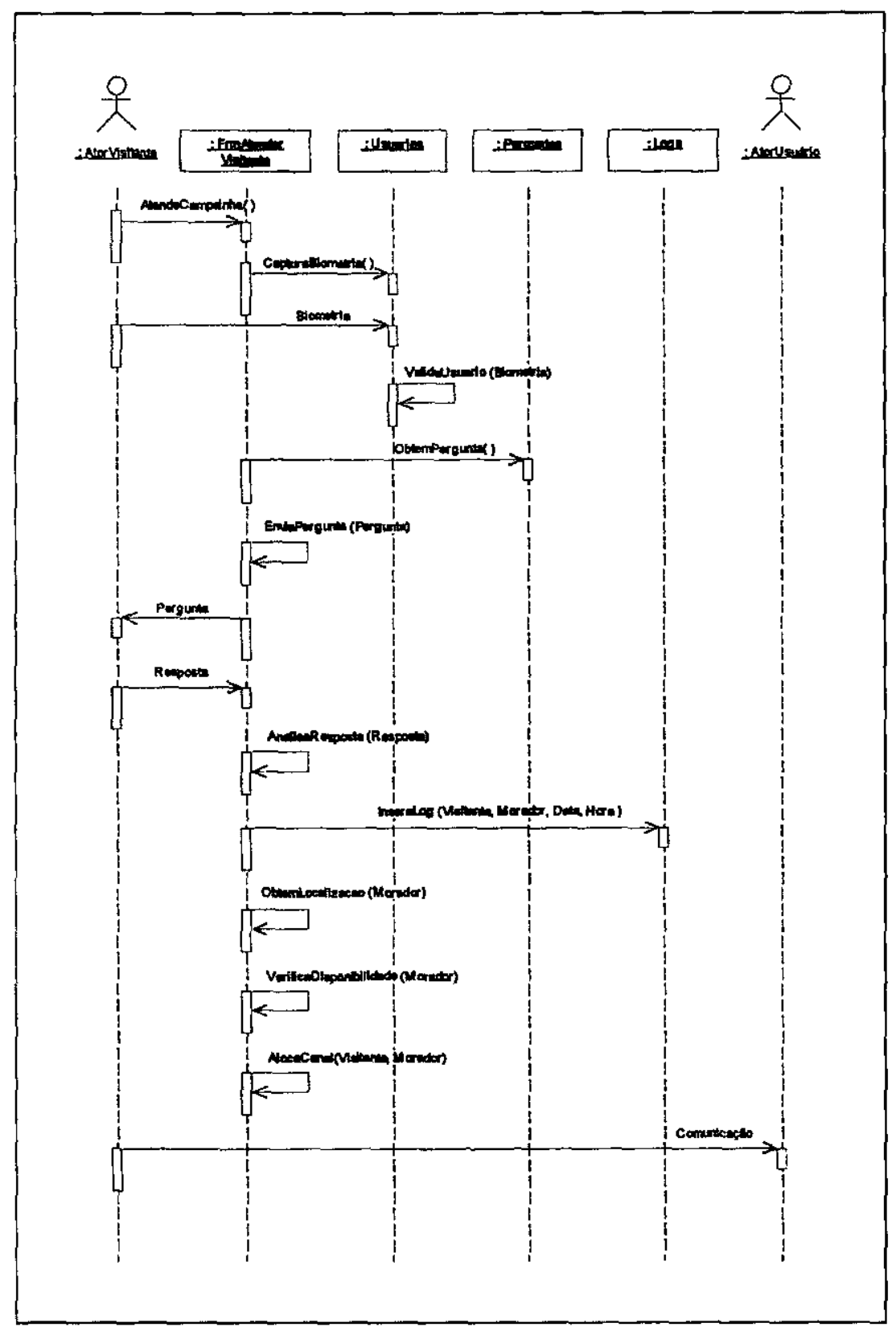

Figura 5.14 - Diagrama de Interação - Use Case "Cadastrar Usuário" 


\subsubsection{Use Case "Atender Visitante"}

A figura 5.15 apresenta o diagrama detalhado para o Use Case "Atender Visitante". Este Use Case trata do encaminhamento de chamadas de visitantes em portas que fazem a comunicação com o exterior da residência.

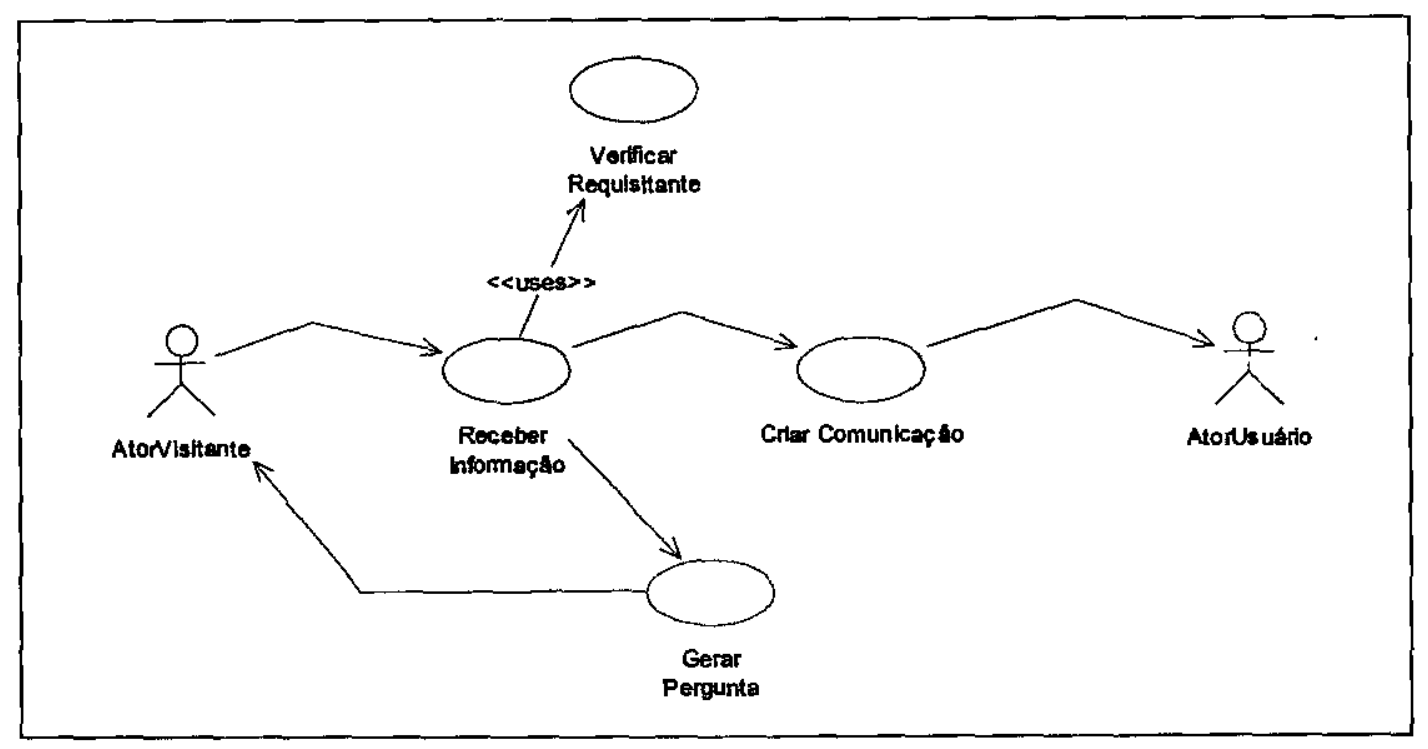

Figura 5.15 - Use Case “Atender Visitante”

O Use Case "Receber Informação" recebe chamadas de um visitante e analisa as informações obtidas com a intenção de encaminhar tal chamada a um dos moradores. Em seguida, o Use Case "Verificar Requisitante" verifica se o visitante é cadastrado no sistema, caso não seja, o sistema realiza o cadastro do visitante. Ressalta-se que o cadastro de um visitante o torna um usuário com permissőes mínimas. Algumas perguntas são realizadas ao "usuário-visitante" objetivando auxiliar a tomada de decisões, o Use Case "Gerar Pergunta" possui tal função. Após tomada a decisão para quem encaminhar a chamada, o Use Case "Criar Comunicação" aloca um canal para a transmissão de voz e imagem do visitante até o "morador-alvo" da requisição.

Visando mostrar a interação entre os vários objetos que integram a funcionalidade "Atender Visitante", elaborou-se o diagrama de interação apresentado na figura 5.16. 


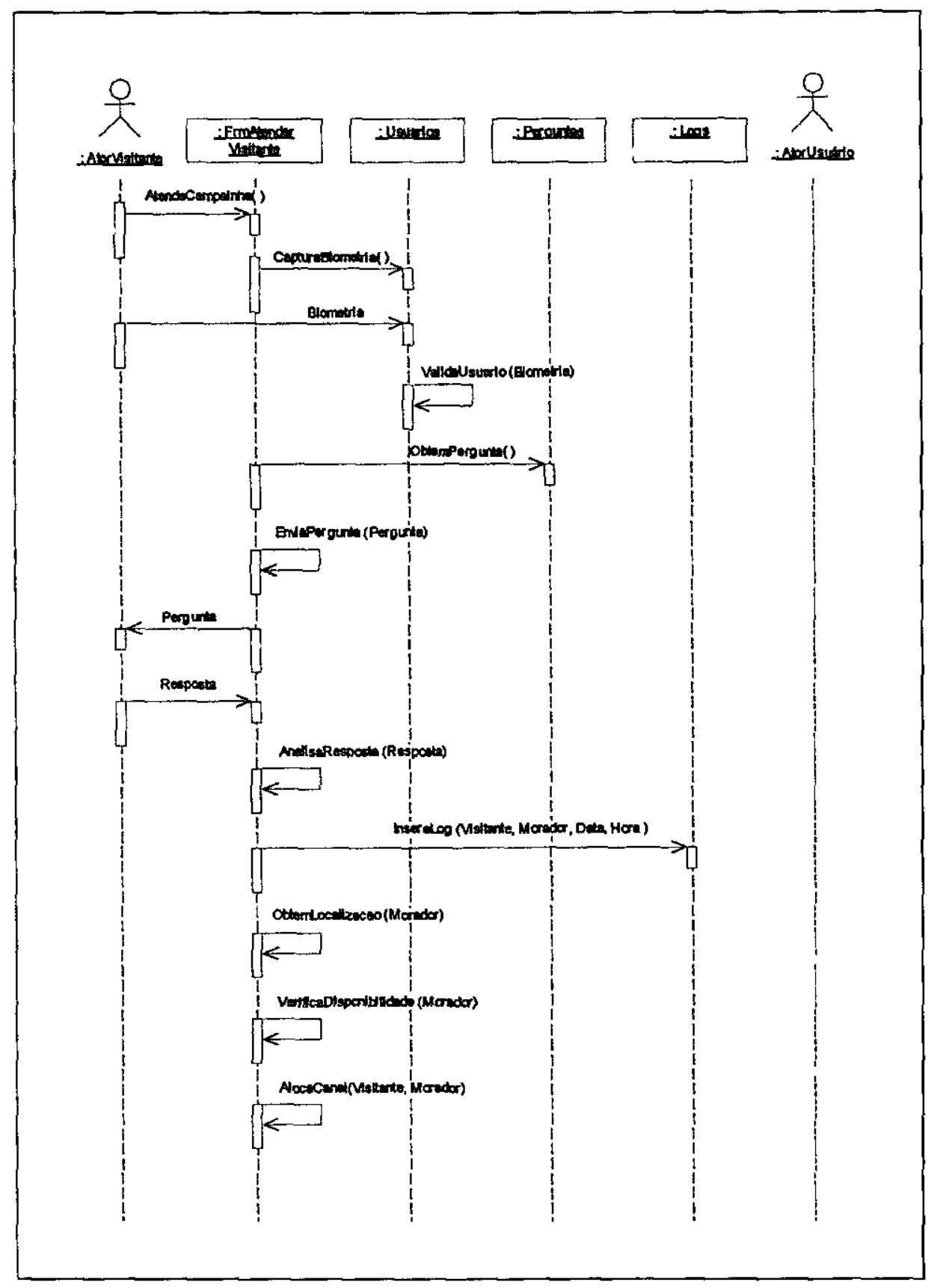

Figura 5.16 - Diagrama de Interaçâo - Use Case “Atender Visitante"

\subsection{Diagramas de Classes do Sistema}

Um diagrama de classes, denominado Logical View na notação UML, modela os relacionamentos entre Use Cases em um determinado escopo, evidenciando as classes que fazem parte do sistema em questão [RAU98]. 
Com a intenção de melhorar o entendimento do sistema SmartHome foram elaborados dois diagramas lógicos: o primeiro referente a classes funcionais e o segundo referente somente a classes que desempenham funções de interface no sistema.

A figura 5.17 apresenta o diagrama de classes funcionais do sistema SmartHome. Podese observar que atributos e operações pertinentes às classes do sistema já se encontram especificadas.

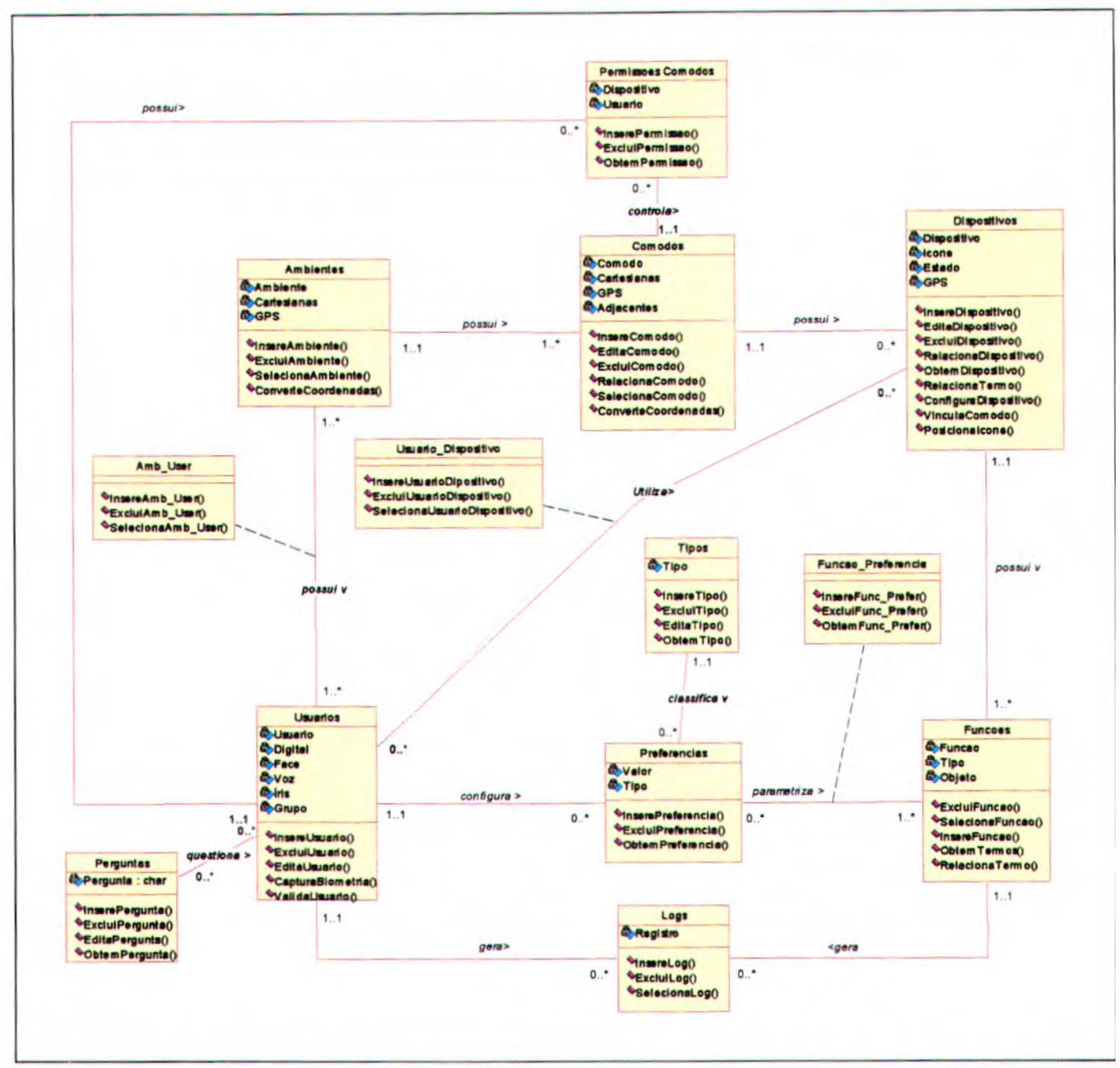

Figura 5.17 - Diagrama de Classes SmartHome - Classes Funcionais

Durante a fase de especificação, observou-se que algumas classes desempenham suas funções posicionadas entre as entidades externas e as classes funcionais internas ao sistema SmartHome. Classes regidas por esta propriedade são denominadas classes do tipo interface. Visando diminuir a complexidade visual do diagrama gerado, todas as classes do tipo 
interface foram representadas em um segundo diagrama. Tal diagrama de classes pode ser visualizado na figura 5.18 .

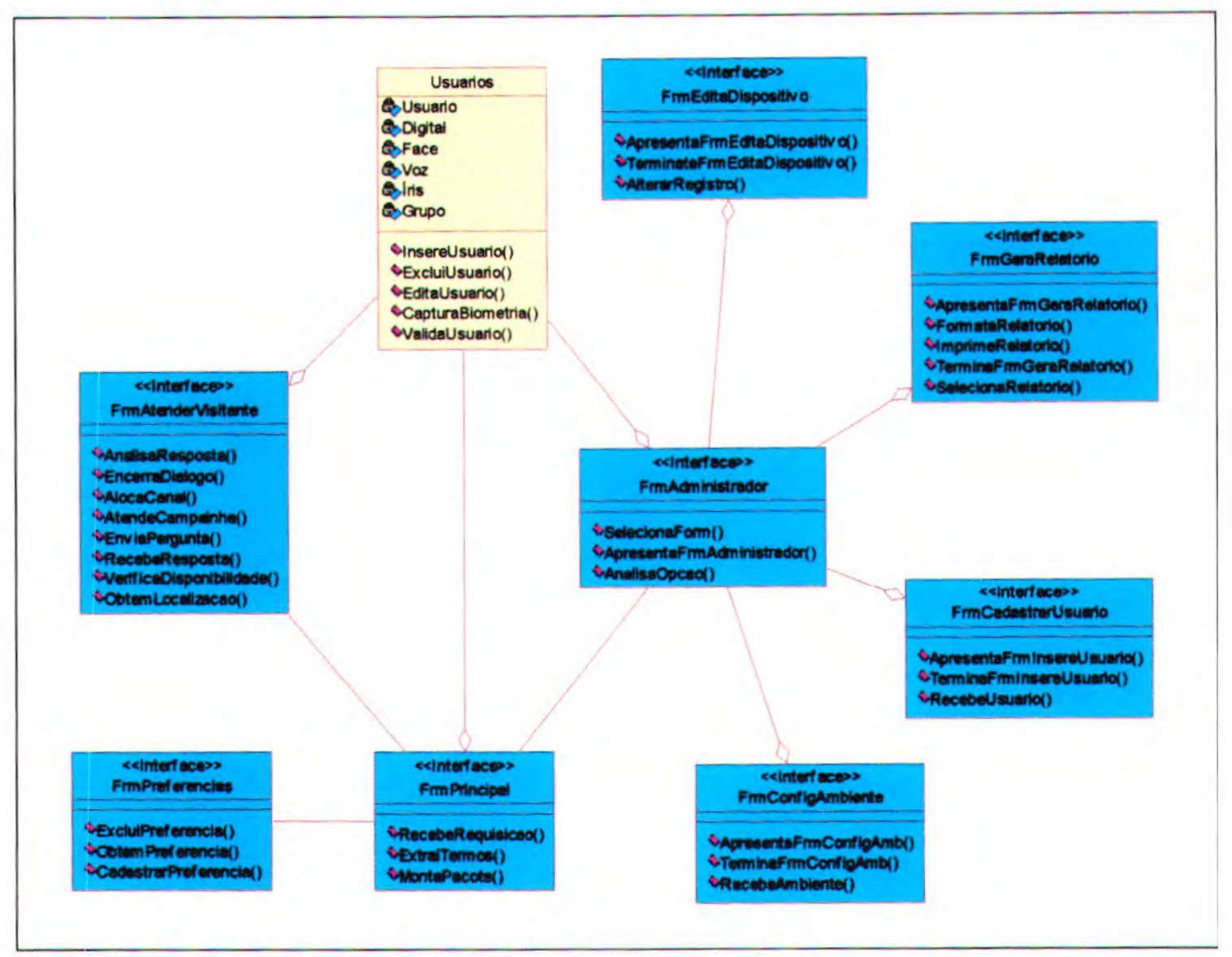

Figura 5.18 - Diagrama de Classes SmartHome - Classes Tipo Interface

\subsection{Hardware do Sistema SmartHome}

Os módulos de hardware componentes do sistema de gerenciamento SmartHome estão representados na figura 5.19. Adicionalmente, estão representadas as interações permitidas entre tais módulos.

Diversos sensores integram o sistema SmartHome. Os dados provenientes destes sensores embasam a tomada de decisão pelos diversos subsistemas de controle da residência. Os sensores do sistema possuem poder computacional para permitir a conexão em rede e processar os dados colhidos no ambiente monitorado.

O sistema possui uma classe de dispositivos que agem sobre o ambiente para modificálo, estes são denominados atuadores. Os atuadores possuem poder de processamento 
para comunicação em rede e monitoramento da execução de suas tarefas, podendo receber sinais de controle do computador gerenciador ou da rede de dispositivos. A título de exemplo, um elemento que integra o grupo denominado de atuadores pode ser uma porta que controla o trânsito de pessoas com o exterior da residência.

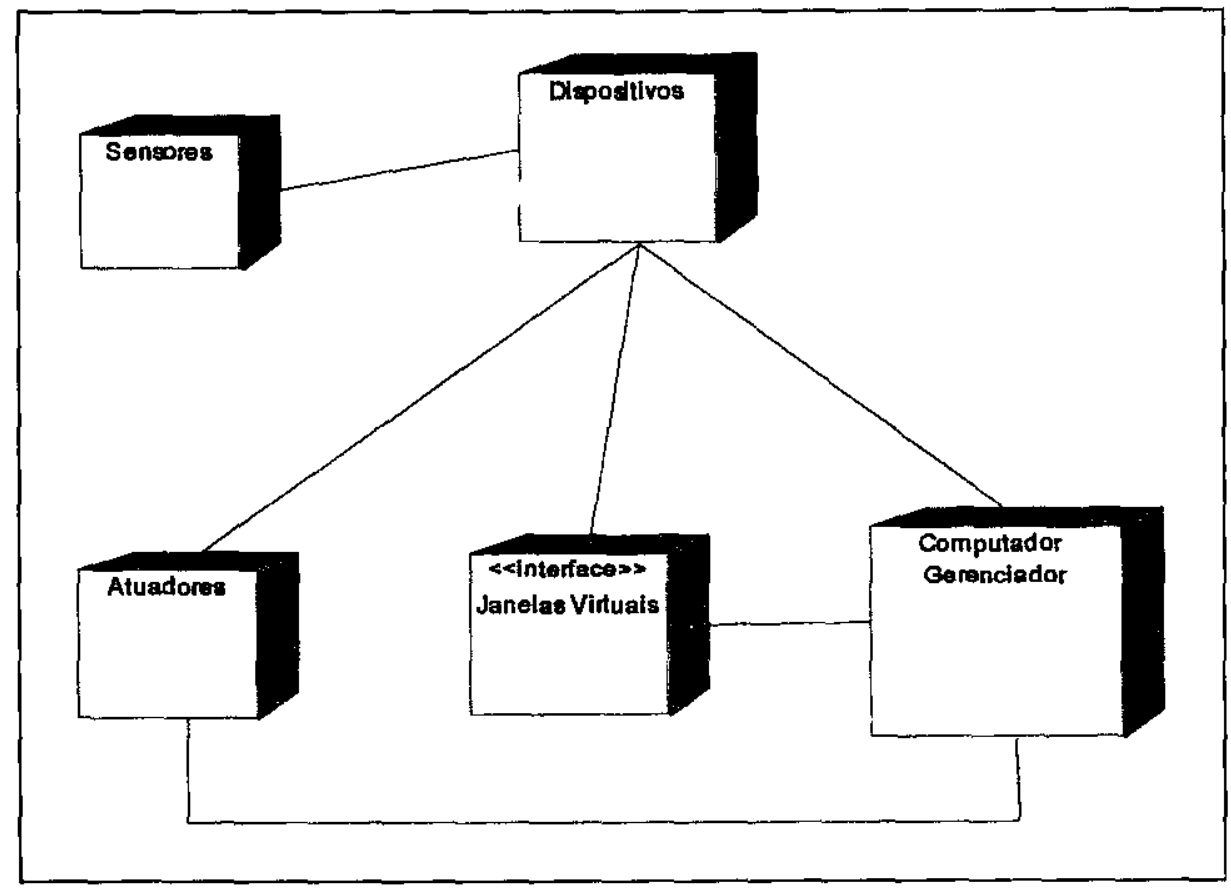

Figura 5.19 - Diagrama de Hardware SmartHome

O computador gerenciador é um computador de uso geral que realiza tarefas relativas à administração e manutenção do sistema, inclusão automática de novos dispositivos e manutenção da integridade dos dados necessários ao sistema SmartHome.

O sistema SmartHome considera dispositivo todo eletrodoméstico, eletro-eletrônico ou hardware de controle em uma residência. O hardware denominado "Janela Virtual" é a interface padrão para o sistema de gerenciamento SmartHome. A "Janela Virtual" realiza processamento de comandos de voz ou de sentenças de comando pictográficas objetivando compor um comando executável a um dispositivo ou a um grupo de dispositivos. Uma funcionalidade essencial realizada pela "Janela Virtual" é a verificação da identidade e das permissões das pessoas que interagem com o sistema doméstico.

\subsection{Implementação de um Protótipo de Interface}

O software do sistema SmartHome é executado sobre o sistema operacional Windows 
98. A interface de controle foi implementada utilizando-se o ambiente de programação Delphi 5. A Opção por esse ambiente é devida à facilidade de aprendizado e desenvolvimento de aplicações gráficas.

A facilidade de desenvolvimento de aplicações gráficas decorre da elevada disponibilidade de bibliotecas gráficas, denominadas VCL (Visual Component Library) [CAN00]. A facilidade de desenvolvimento decorre do ambiente de programação ser amigável e bastante intuitivo. A linguagem de programação adotada permite a implementação baseada no paradigma de programação orientada a objetos, o que vai de encontro à especificação apresentada para o sistema SmartHome.

Para a implementação da interface de reconhecimento de comandos de voz utilizou-se o pacote de reconhecimento de voz Dtalk 3 e o kit de desenvolvimento de aplicações de voz Microsoft Speech SDK 4.0.

O pacote Dtalk 3, distribuído pela O\&A Productions [O\&A01], possui vários componentes para reconhecimento de voz, alguns classificados como de baixo nivel e outros como de alto nível. Estes componentes fazem a conexão entre a aplicação desenvolvida e 0 software de processamento de voz. Na interface em questão optou-se por utilizar somente componentes de baixo nível, os quais proporcionam ao programador uma maior liberdade na implementação, como permitir a criação de gramáticas de reconhecimento específicas e a escolha das ações realizadas após o reconhecimento de uma determinada sentença.

O processador de reconhecimento de voz, Microsoft Speech SDK 4.0 que é distribuído pela Microsoft Corporation [MIC01], é o software utilizado para converter o sinal digital proveniente da placa de som em fonemas. Os fonemas são então processados pelos componentes de reconhecimento de voz e, finalmente, fornecidos em formato texto para a aplicação SmartHome. O reconhecedor utilizado neste projeto identifica somente termos e sentenças em inglês, devido ao kit de desenvolvimento utilizado somente permitir o desenvolvimento de aplicativos em tal idioma.

\subsubsection{Base de Dados}

Para armazenar os dados necessários no protótipo implementado foi utilizada a base de dados Paradox 7. Tal escolha se deve ao fato desta base estar disponivel no pacote de instalação do Delphi 5, apresentar facilidade de utilização e permitir o armazenamento de imagens em suas tabelas. 
Como o Delphi não possui acesso direto a bases de dados, faz-se necessário o uso de um gerenciador de base de dados, no caso o Borland Database Engine (BDE). O BDE utiliza um driver específico para cada tipo de base de dados. Todas as versões do Delphi possuem um driver padrão para ser utilizado com o Paradox.

O protótipo da interface SmartHome utiliza três tabelas para armazenar os dados referentes aos dispositivos que fazem parte da residência, d̀ funções desempenhadas por dispositivos e aos complementos que especificam a função a ser realizada por um dispositivo. Foram criadas as seguintes tabelas:

$>$ Tabela Dispositivos: armazena dados referentes aos dispositivos presentes na residência, são eles:

- Identificador do dispositivo;

- Descrição;

- Ícone.

Tabela Funções: armazena os dados referentes à função a ser realizada pelo dispositivo. Esta tabela possui um campo que a relaciona com a Tabela Dispositivos. Os dados de cada função são:

- Identificador da função;

- Identificador do dispositivo;

- Descrição;

- Ícone.

Tabela Complementos: armazena os dados necessários aos complementos possiveis a uma função. Esta tabela possui um campo que a relaciona com a Tabela Funções. Os dados de cada complemento são:

- Identificador do complemento;

- Identificador da função;

- Descrição;

- Ícone. 


\subsubsection{Tela Inicial}

Esta seção mostra o protótipo da tela inicial do sistema SmartHome. O objetivo do protótipo é mostrar algumas das principais funcionalidades do sistema. A figura 5.20 mostra a tela inicial da interface SmartHome.

A interface inicialmente apresenta uma imagem que representa a planta baixa do ambiente controlado e seus dispositivos. A imagem da planta baixa utilizada foi construída em um aplicativo de editoração de imagens qualquer. Quando um dispositivo é selecionado os ícones das funções associadas ao dispositivo selecionado são mostrados na barra de ferramentas no lado esquerdo da tela. Selecionando-se uma das funções permitidas, a interface exibe os objetos relacionados à função selecionada na barra de ferramentas à direita. Finalmente, selecionando-se um dos objetos tem-se a exibição da sentença pictográfica na barra de ferramentas localizada na base da interface gráfica apresentada.

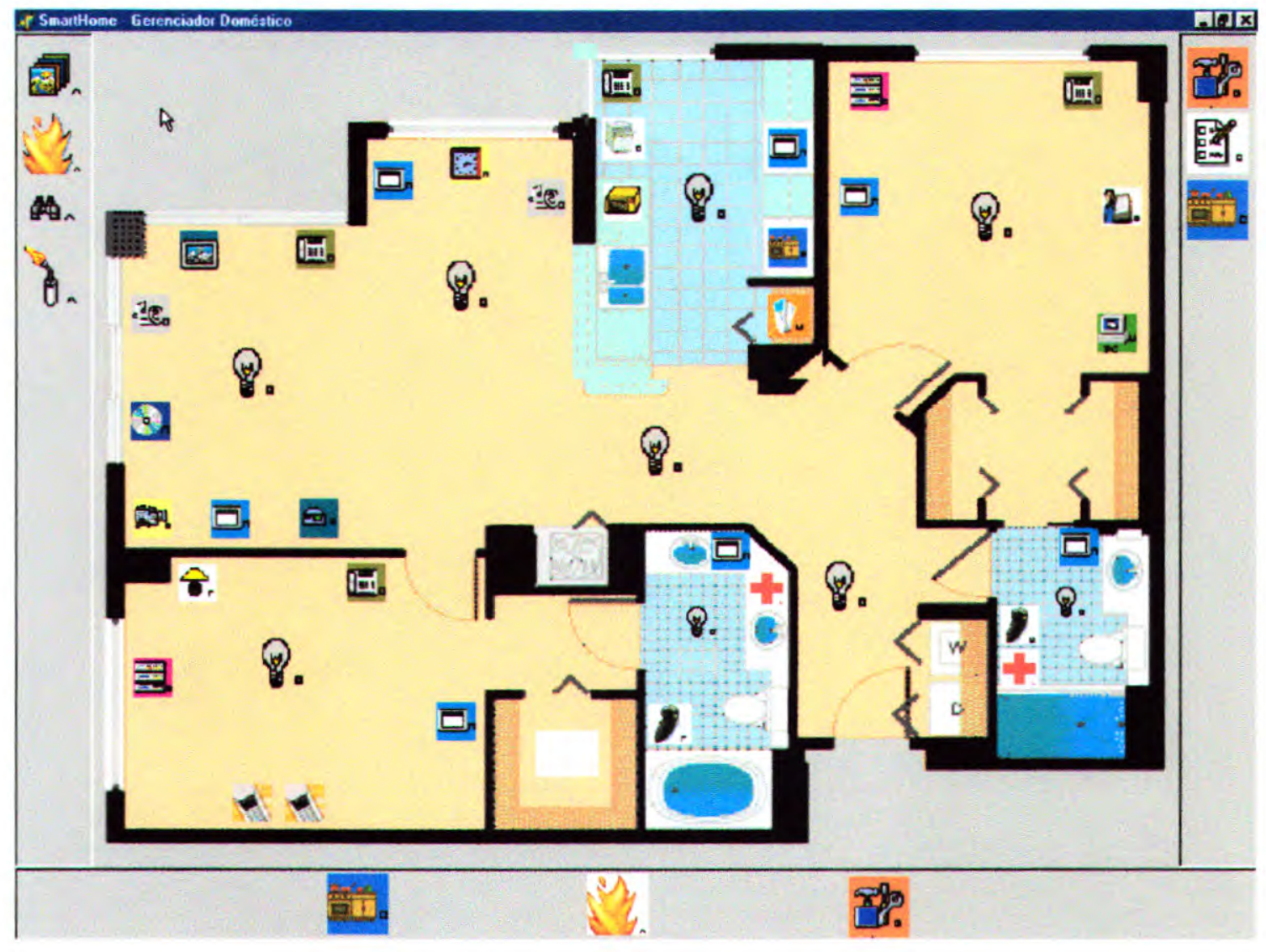

Figura 5.20 - Interface Inicial - SmartHome

A sentença pictográfica visualizada na barra de ferramentas inferior da interface, apresentada na figura 5.20, pode ser obtida de duas maneiras: comando de voz ou toques sobre os ícones visualizados na interface. Para obter a sentença utilizando comando 
de voz, um usuário deve pronunciar a sentença "microwave run self diagnosis". O segundo meio é selecionar primeiramente o ícone "microwave", em seguida o ícone "run" e finalmente o ícone "self diagnosis". Finalmente o sistema processa a sentença e o forno de microondas executa a ação requisitada.

\subsubsection{Tela de Interior de Cômodo}

Esta seção mostra a tela exibida pelo sistema quando o usuário entra em um cômodo. Somente as imagens de dispositivos pertencentes ao cômodo são apresentadas. A figura 5.21 apresenta a interface gráfica do interior da cozinha. A exibição da interface de interior de cômodo apresentada pode ser obtida pela pronúncia da sentença "SmartHome enter kitchen" ou por um toque na região da tela da "Janela Virtual" referente à cozinha.

É permitido ao usuário selecionar um dispositivo apresentado o qual fará parte de uma sentença de controle pictográfica. Apesar desta interface apresentar somente os dispositivos relacionados ao cômodo apresentado, aceita também requisições de voz endereçadas a qualquer dispositivo da residência.

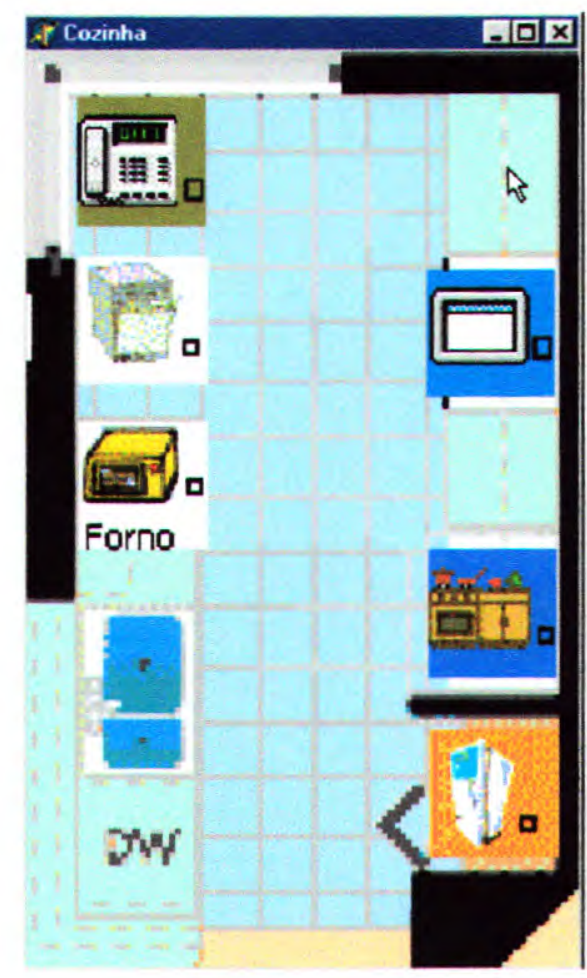

Figura 5.21 - Interface de Interior da Cozinha - SmartHome

O objetivo deste tipo de interface é apresentar ícones com um grau de detalhamento e dimensões superiores aos apresentados na interface gráfica inicial, bem como restringir a 
visualização dos demais dispositivos controlados pela interface SmartHome.

\subsubsection{Tela de Controle de Dispositivo}

A tela de controle de dispositivos exibe a imagem real do dispositivo selecionado, desta forma permitindo que um dispositivo seja controlado diretamente por meio de toques sobre determinadas áreas da imagem ou também por meio de comandos de voz. Este tipo de interface implementa um controle remoto de dispositivos sobre uma rede de comunicação. $\mathrm{O}$ efeito obtido é o mesmo de tocar os botões do painel de controle do dispositivo real. A figura 5.24 ilustra a forma da interface de controle de uma televisão.

A tela de controle apresentada na figura 5.22 é capaz de mudar o canal da televisão pela pronúncia da sentença "TV up channel". Outra forma de requisição consiste no usuário tocar a região do painel relativa ao botão de troca de canal.

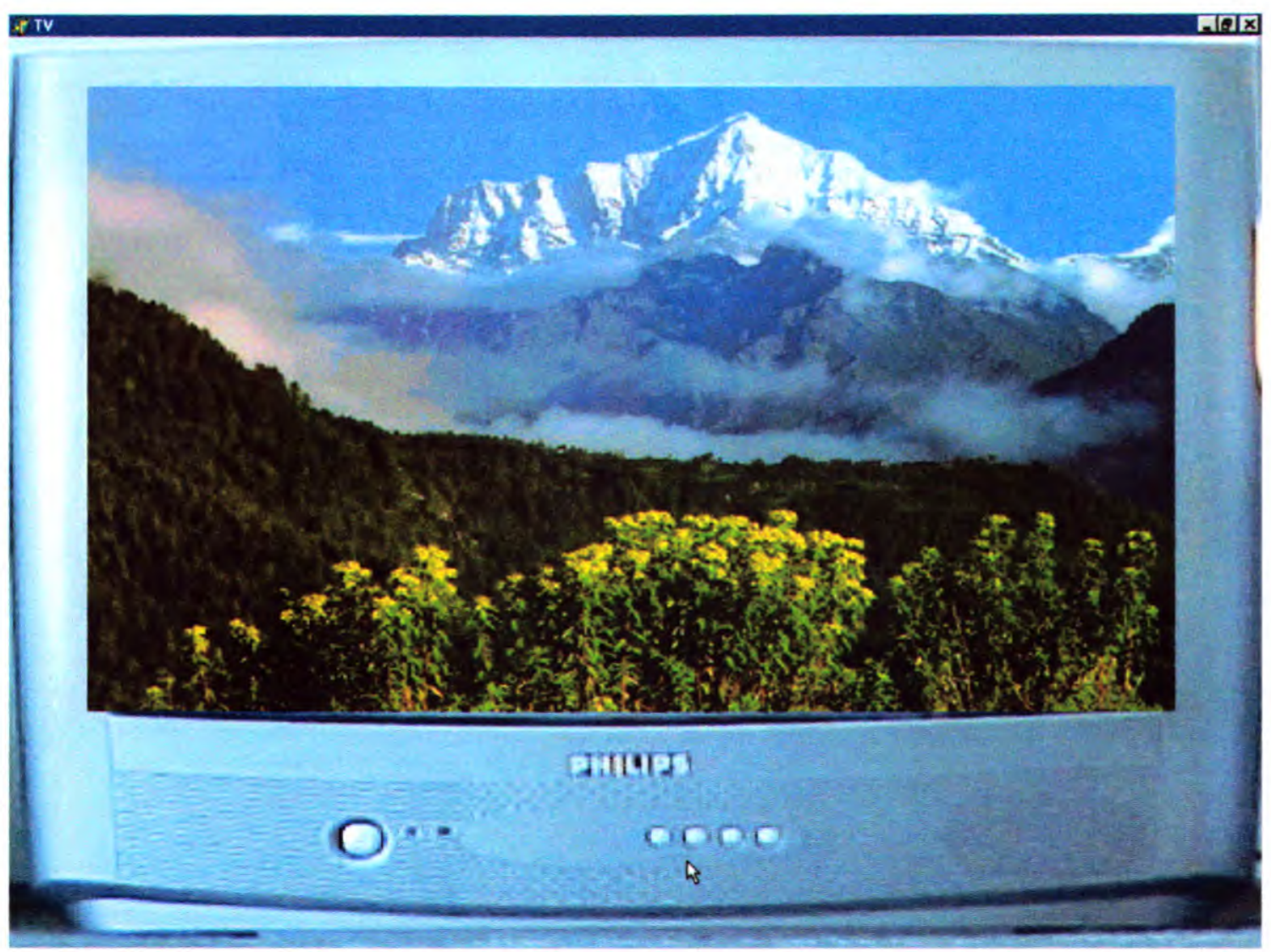

Figura 5.22 - Tela de Controle da TV - SmartHome 


\subsection{Resultados Obtidos}

Levando em consideração que a área de automação doméstica é bastante ampla e é reduzida a uniformidade dos padrões existentes, especificar um sistema de gerenciamento doméstico que fosse ao encontro dos desejos dos usuários domésticos e abrigasse um conjunto amplo de comandos consistiu em um desafio neste trabalho.

$\mathrm{Na}$ identificação dos requisitos foi necessária uma pesquisa ampla para identificar as principais possibilidades de operação do sistema. Elaborou-se as regras de formação de sentenças de representação de comandos dando origem à linguagem de representação de comandos do sistema SmartHome. Adicionalmente, esta linguagem foi transposta para um formato gráfico e definida como a linguagem pictográfica SmartHome. Os objetos que fazem parte de uma linguagem gráfica possuem papel fundamental na transmissão da informação.

O protótipo da interface implementado utiliza duas formas naturais de interação homemsistema: reconhecimento de voz e toques na superficie de um monitor. Durante o desenvolvimento do trabalho foram testados dois reconhecedores de voz: Microsoft Speech SDK 4.0 e IBM Via Voice SDK 7.0. Os dois reconhecedores de voz apresentaram caracteristicas e eficiência semelhantes. Os dois reconhecedores disponiveis apresentam deficiências relacionadas à língua portuguesa, à baixa eficiência em ambientes ruidosos, dicção e entonação do usuário.

A forma de interação baseada em toques na tela de um monitor foi simulada utilizandose o ponteiro do mouse do computador. A inclusão de reconhecimento de voz em um programa depende basicamente de dois componentes: o reconhecedor de voz e componentes para a linguagem de programação utilizada. Durante o projeto, foram pesquisados componentes gratuitos de reconhecimento de voz para a linguagem Delphi 5. O único que atendeu aos requisitos apresentados foi o componente denominado Dtalk 3. Optou-se por utilizar o reconhecedor de voz da Microsoft pois é o mais indicado para utilização com o componente Delphi selecionado.

A interface proposta reconhece sentenças no idioma Inglês, apesar da existência de um reconhecedor para a lingua portuguesa. Tal deficiência decorre do componente de reconhecimento Dtalk 3 necessitar de um identificador (langid) o qual define o idioma a ser utilizado. Foram enviados alguns e-mails ao fornecedor do componente a fim de obter esclarecimentos sobre como alterar o idioma de reconhecimento, não foram obtidas respostas esclarecedoras. Finalmente, optou-se por implementar o protótipo com reconhecimento de 
voz para a língua inglesa.

A interface implementada reconhece sentenças completas, não sendo capaz de reconhecer palavras isoladas. Em um dado momento, foi proposta a implementação de um segundo protótipo que realizasse o reconhecimento de palavras isoladas. Essa atividade foi deixada como trabalho futuro devido à escassez de tempo para o desenvolvimento de outras estapas do projeto.

Com relação ao reconhecimento de voz, identificou-se a necessidade da pronúncia das sentenças SmartHome ser realizada de forma ritmada. Identificou-se que a utilização de aplicativos para reconhecimento de voz requer o uso de computadores com elevada capacidade de processamento. Adicionalmente, ressalta-se que o desempenho do microfone e da placa de som são determinantes na eficiência do processo de reconhecimento.

Acredita-se que um projeto gráfico bem elaborado para os ícones que fazem parte da linguagem pictográfica e a familiarização dos usuários com a metodologia possa incrementar o entendimento e a usabilidade da interface.

A utilização da interface baseada no protótipo desenvolvido apresenta como vantagem principal a interação usuário-sistema através de meios naturais de comunição humana. Como principal desvantagem foi identificada a necessidade de grande capacidade de processamento e a baixa eficiência de reconhecimento de comandos de voz, que é bastante dependente da pronúncia e da velocidade da fala.

\subsection{Considerações Finais}

Este capítulo apresentou o projeto do sistema SmartHome utilizando-se um paradigma de modelagem orientada a objetos, representado através dos diagramas de Use Cases e de Classes. Apresentou-se também um modelo de hardware para a rede de comunicação do sistema proposto. Foram apresentadas as telas de um protótipo de interface baseadas em algumas das especificações propostas. Finalmente, elaborou-se uma seção que apresenta os resultados obtidos durante o projeto.

No próximo capítulo serão apresentadas algumas contribuições do trabalho, conclusões e propostas para trabalhos futuros. 


\section{Capítulo 6}

\section{Conclusões}

\subsection{Introdução}

Este trabalho trata de automação residencial, também denominada domótica. Foram pesquisadas as literaturas disponiveis sobre interfaces e meios fisicos empregados na interligação de dispositivos em redes domésticas, protocolos de rede destinados à implementação de sistemas de automação doméstica, métodos de identificação biométricos, dispositivos de entrada de dados em sistemas computacionais, comunicação baseada em pictogramas e alguns sistemas de gerenciamento domésticos existentes.

Durante o desenvolvimento do projeto SmartHome foi realizado um estudo de caso baseado em uma residência fictícia. Deste estudo de caso, foram propostas classificações para os dispositivos integrantes de uma residência e para os sistemas de controle doméstico.

Foi realizada uma análise de requisitos de um sistema de gerenciamento doméstico levando-se em consideração as necessidades dos moradores. Foram considerados os requisitos de hardware, de software e da linguagem de representação de comandos no formato pictográfico.

Durante a fase de projeto e implementação foi utilizada a ferramenta de modelagem de sistemas orientada a objetos Rose 98. Foram gerados os seguintes diagramas: Diagrama de Hardware, Diagrama de Classes, Diagrama de Use Cases e Diagrama de Interação. Finalmente, implementou-se um protótipo da interface com a finalidade de mostrar algumas telas que evidenciam algumas das suas funcionalidades principais.

A seção 6.1 deste capítulo cita as principais contribuições deste trabalho. Na seção 6.2 são apresentadas as conclusões finais e na seção 6.3 são sugeridos alguns trabalhos futuros decorrentes deste. 


\subsection{Contribuições do Trabalho}

O desenvolvimento deste trabalho resultou nas seguintes contribuições:

- Estudo das diversas tecnologias que podem ser utilizadas na implementação de um sistema distribuído doméstico;

- Proposição de formas de classificação dos sistemas de controle doméstico existentes. A classificação proposta é baseada em características essenciais do sistema classificado;

- Definição de uma linguagem gráfica de comandos que é capaz de representar o conjunto de tarefas que podem ser executadas pelo sistema de gerenciamento doméstico;

- Implementação de um protótipo da interface de gerenciamento doméstico, baseada na interpretação de sentenças pictográficas, que executa as tarefas solicitadas pelo usuário. As requisições também podem ser feitas utilizando-se comandos de voz. Adicionalmente, a interface permite a construção de sentenças de comando através de toques sobre as imagens exibidas nas "Janelas Virtuais";

\subsection{Conclusões Finais}

O sistema de gerenciamento proposto, o SmartHome, apresenta duas formas de comunicação bastante usuais para os seres humanos: a fala e o toque sobre um determinado f́cone. Estas formas de comunicação permitem uma melhor usabilidade da interface por parte dos usuários.

Uma inovação ê a ausência de linhas de comando textuais para a execução das tarefas. Desta forma, pode-se imaginar uma interface universal onde podem ser eliminadas as dificuldades relativas ao idioma utilizado. Conseqüentemente, pode-se inferir que o sistema apresenta uma redução significativa do período de aprendizado da sua utilização, devida principalmente ao elevado grau de intuição na interface para a execução dos comandos. Um ponto importante na interface de um sistema de gerenciamento doméstico é a uniformidade de utilização em função da grande diversidade de fabricantes e de dispositivos. 
O reconhecimento e síntese de voz utilizados pelo sistema SmartHome contribui de forma marcante em sua usabilidade. Apesar dos pontos favoráveis à utilização da voz humana em aplicações computacionais, tal utilização necessita de uma elevada capacidade de processamento, o que até pouco tempo atrás tornava inviável essa utilização em larga escala. Em decorrência da diminuição do custo dos processadores e do aumento da capacidade de processamento, a tendência é que surjam as mais diversas aplicações utilizando essa tecnologia, principalmente em dispositivos portáteis.

\subsection{Sugestões para Trabalhos Futuros}

Alguns trabalhos futuros podem ser propostos em continuidade ao desenvolvido até o presente momento. Enquanto alguns são adequados para novos programas de mestrado, outros apresentam menor complexidade sendo recomendados para programas de iniciação cientifica. Entre tais trabalhos pode-se citar:

- Desenvolvimento de um conjunto de imagens, utilizando técnicas de representação por ícones, para representar mais adequadamente os dispositivos de uma residência bem como as sentenças de controle do sistema SmartHome;

- Desenvolvimento de drivers modulares para realizar a interação entre os dispositivos domésticos e o sistema SmartHome;

- Implementação de uma interface de controle para o sistema Smarthome que possa ser executada em dispositivos portáteis, como PDAs, celulares e palmtops;

- Implementação completa do sistema SmartHome com o objetivo de colher dados sobre a usabilidade da interface e a praticidade do uso da linguagem de comando pictográfica por pessoas com algum tipo de limitação, possivelmente pessoas idosas, pessoas doentes e deficientes físicos e mentais; 


\section{Referências Bibliográficas}

[ALL00] ALLEN, B. et al. Design Guidelines on Smart Homes. April 19, 2000. http://www.stakes. fi/cost219/smarthousing.htm\#Type of media

[AXE98] AXELSON, J. Control and Automation Interfaces Overview. October 21, 1998. http://homeautomationtimes.com/tech-19980721-interfaces.html

[BAC01] BACKUS-Naur Form (BNF). January 12, 2001

http://nerv-un.net/ nak/bnf.htm

[BLI00] BLISSIMBOLIC tutorial. June 06, 2000.

http://www.symbols.net/blissdi/tutorial.htm

[BLU00] BLUETOOTH Tutorial. July 18, 2000.

http://www.softtooth.com/tech/tutorial/bluetooth/intro.html

[BLU01] BLUETOOTH non-commercial tutorial page. July 20, 2001

http://www.ee.iitb.ernet.in/uma/_aman/bluetooth

[CAN00] CANTÚ, M. Dominando o Delphi 5. São Paulo. Makron Book, 2000. 860 p.

[COM01] COMPLETE Bluetooth Tutorial. August 03, 2001

http://www.palowireless.com/infotooth/tutorial/complete.asp

[COR97] CORCORAN, P. M., DESBONET, J. Browser-Style Interfaces to a Home Automation Network. IEEE Transactions on Consumers Electronics, V.44, N. 4, p.1063-106, 1997.

[COR98] CORCORAN, P. M., PAPAI, F., ZOLDI, A. User Interface Technologies for home Appliances and Networks. IEEE Transactions on Consumer Electronics, V. 44, N. 3, p. 679-685 August. 1998.

[EIA00] EIA - Electronic Industries Association. Introduction to the CEBus Stand ard. March 07, 2000.

Http://integrasoft/ro/ bani/EIA600\%20Specification/index.htm 
[FEN00] FENG, X.. Home Networking. March 01,2000

Atp://netlab.ohiostate.edu/pub/jain/courses/cis78899/home nets/index.htm!\#ta g 332

[FER86] FERREIRA, H. B. A. Novo Dicionário da Língua Portuguesa. Rio de Janeiro. Editora Nova Fronteira, 1986. 2 ed. 1838 p.

[FUN00] FUNDAMENTALS of Firewire. March 03, 2000. http://204.33.180.24/1999/9906/9906feat2.htm

[HOF00] HOFFMAN, G. A. IEEE-1394, the A/V Digital Interface of Choice. March 28, 2000. Http://www.1394ta.org/Techninology/About/digital_av.htm

[IEE00] IEEE-1394 High Performance Serial Bus. March 29, 2000. http://www.unisys.com/marketplace/aquanta/tech-library/brief-ieee.html

[IEE98] IEEE-1394 Standard for High Speed Data Transfer. March 2, 1998. Http://www.tm.agilent.com/tmo/newsrelease/English/PRTM0960802-A.html

[INT00] INTELLON Products. Intellon Unveils PowerPacket, The Fastest Working Silicon for Power Line Networking Technology. March 01, 2000. http://www.intellon.com/press/releases/020700.html

[JIN99] The JINITM Architecture Specification (AR), V. 1.1. November, 1999. http://www.sun.com/jini/specs/jini101.html

[KIN99] KINGERY, P. Digital X-10. March 15, 1999. http://actsolutions.com/kingery13.htm\#digital-10.coml

[LEE00] LEE, C. IEEE Standard 1394 Serial Bus. March 29, 2000. http://calab.cs.pusan.ac.kr/TechnicalReport/1394/1394.html

[LEE96] LEE, G. et al. A configuration Tool for Home-Net. IEEE Transactions on Consumers Electronics, V. $42, N .3$, p. 387-393, 1996.

[MED00] MEDIA Fusion - Confidential Information Package. April,2000.

[M1C01] MICROSOFT Corporation. Microsoft Speech SDK. May 26, 2001. http://www.microsoft.com/downloads/release.asp?ReleaselD $=26299$

[O\&A01] O\&A Productions. Voice Packet Dtalk 3. May 25, 2001

Download em: http://www.o2a.com/dtalk.htm 
[PRE94] PREECE, J., ROGERS, Y., SHARP, H., BENYON, D., HOLLAND, S., CAREY, T. Human-Computer Interaction Addison-Wesley Publishing Company, 1994.

[QUA00] QUANDO a Síntese Gráfica é Mais Eficiente. Maio 31, 2000.

http://www.carioca.br/design/croni_pi.htm

[RAT01] RATIONAL Software Corporation. Rational Rose 98. April 25, 2001

Download em: http://www.rational.com/tryit/rose/index.jsp

[RAU98] RAUMBAUGH, J., JACOBSON, I., BOOCH, G. The Unified Modeling Language - Reference Manual ed.01 Addison Wesley Longman Inc. December, 1998.

[RYE00] RYE, D. My Live at X-10. April 26, 2000.

http://www.hometoys.com/resources.htm

[SAL99] SAUNDERS, A. Universal Plug for Net Appliances. EETimes, ed. 1060, 10 May 1999. http://www.techweb.com/se/directlink.cgi?EET19990510S0056

[SHW96] SHWEHDI, M. H., KHAN, A. Z. A Power Line Data Communication Interface Using Spread Spectrum Technology in Home Automation. IEEE Transactions on Power Delivery, V. 11, N. 3, p. 1232-1237, 1996.

[SIS01] SISTEMAS Digitais de Reconhecimento de Voz-Biometria. April 25, 2001. http://www.fieo.br/revista/rev2000/trabalhos/trab biometria.htm

[TIC01] TICKTIN, N. Home Automation: The Geeks Holy Grail. MacTech Magazine. Volume 16. Issue Number 6. August 04, 2001. http://www.mactech.com/articles/mactech/Vol.16/16.06/HomeAutomation/

[UN199] Universal Plug and Play Device Architecture Reference Specification. ver. 0.9. Nov 10. 1999. http://microsoft.com/spec

[VEN99] VENABLES, W. Nouveau Networking: Introducing Jini. Hello World, I. 1, V. l, March 1999.

http://helloworld.nexus.carleton.ca/1999/03-mar/nouveau networking.html 
[WAC00] WACKS, P. K.. Introduction to the CEBus Comunications Protocol. March $07,2000$.

http://www.hometoys.com/htinews/aug97/articles/kwacks/kwacks.htm

[WAD00] WADE, W. Power-line networks seek outlet for standards. EE Times,

January 14, 2000. http://www.edtn.com/story/tech/OEG20000114S0022

[X-100] X-10 Technology Transmission Theory. March 15, 2000. http://www.evonet.globe.nl/projects/X10/X10tech.html 


\section{Apêndice A}

\section{Subsistema de Controle Individual}

Os dispositivos que compõem o Subsistema de Controle Individual são os considerados na tabela abaixo, juntamente com exemplos de suas funções principais.

Dispositivo: Computador Pessoal (PC) - $\quad$ ID(PC) exibir < dispositivo $>$

Localização: Escritório, Quarto do casal, - ID(PC) exibir SmartHome Quarto do filho

- $\mathrm{ID}(\mathrm{PC})$ selecionar mute

- ID(PC) realizar auto-diagnóstico

Dispositivo: Teclado sem fio (TW) - $\quad$ ID(TW) conectar $<$ PC $\mid$ PDA $\mid$ Celular $\mid$ SP $>$

Localização: Portátil

- ID(TW) realizar auto-diagnóstico

Dispositivo: "Janela Virtual" (JV)

- ID(JV) selecionar mute

Localização: Todos os cômodos

- ID(JV) exibir <proteção de tela | TV | vídeo | DVD | computador | vídeo game | câmera de vídeo $\mid$ mural de lembretes $>$

- ID(JV) exibir < dispositivo $>$

- $\quad \mathrm{ID}(\mathrm{JV})$ realizar auto-diagnóstico

Dispositivo: Máquina Fotográfica Digital - ID(MF) disparar

- ID(MF) salvar foto

Localização: Portátil

- ID(MF) imprimir <foto $>$

- $\quad$ ID(MF) realizar auto-diagnóstico 
Dispositivo: Scanner

Localização: Escritório
- $\operatorname{ID}($ Scanner $)$ capturar <imagem | preview>

- ID(Scanner $)$ salvar imagem

- ID(Scanner $)$ exibir lista de arquivos scaneados

- $\quad \mathrm{ID}($ Scanner $)$ imprimir <imagem>

- ID(Scanner) realizar auto-diagnóstico

Dispositivo: Impressora

Localização: Escritório
- ID(Impressora) exibir lista <arquivos | fotos | imagens>

- ID(Impressora) imprimir <arquivo | foto | imagem $>$

- ID(Impressora) realizar auto-diagnóstico

Diapositivo: Slide Show (SS)

- ID(SS) exibir lista de imagens

Localização: Escritório, Quarto do filho, - $\mathrm{ID}(\mathrm{SS})$ selecionar <imagem>

Quarto da filha, Sala de estar, Sala de visitas

Dispositivo: Screen-phone (SP)

- ID(SP) telefonar <número de telefone>

Localização: Escritório, Quarto do casal, - ID(SP) ajustar campainha nível $<1 . .3>$ Quarto da filho, Quarto da filha, Sala de

- ID(SP) exibir lista de fax recebidos jogos e som, Sala de estar, Cozinha

- ID(SP) enviar fax <número $>$

- ID(SP) acessar Internet

- ID(SP) verificar caixa de correio

- ID(SP) enviar mail <endereço eletrônico>

- ID(SP) exibir interface SmartHome

- ID(SP) realizar auto-diagnóstico 
Dispositivo: Som Ambiente (SA)

- $\mathrm{ID}(\mathrm{SA})$ ligar

Localização: Escritório, Quarto do casal, - ID(SA) desligar

Quarto do filho, Quarto da filha, Sala de

- ID(SA) ajustar volume $<1 . .10>$

estar, Sala de visitas, Sala de refeições,

Cozinha, Banheiro

- ID(SA) selecionar <AM | FM | CD>

Dispositivo: Telefone Celular (Celular) - ID(Celular) telefonar $<$ número de telefone $>$

Localização: Portátil

- ID(Celular) exibir SmartHome

- ID(Celular) verificar caixa de correio

- ID(Celular) enviar mail <endereço

eletrônico>

- ID(Celular) realizar auto-diagnóstico

Dispositivo: Pesonal Digital Assistent - ID(PDA) acessar Internet

(PDA)

- ID(PDA) exibir interface SmartHome

Localização: Portátil

- ID(PDA) realizar auto-diagnóstico

Dispositivo: Módulo Multimídia (MM) - ID(MM) exibir lista de dispositivos

Localização: Quarto do Casal

- ID(MM) selecionar <FM | CD | DVD | Filme | Som Ambiente >

- ID(MM) exibir lista de atrações

- ID(MM) selecionar <atração>

- $\quad$ ID(MM) ajustar timer $<$ minutos $>$

- $\quad \mathrm{ID}(\mathrm{MM})$ realizar auto-diagnóstico

Dispositivo: Receptor de TV (Rec. TV) - ID(Rec. TV) exibir lista de canais

Localização: Sala de estar

- $\quad$ ID(Rec. TV) selecionar canal $<0$ a 99>

- ID(Rec. TV) realizar auto-diagnóstico 
Dispositivo: DVD/CD Player

Localização: Sala de estar
- ID(DVD/CD Player) exibir lista dispositivos

- ID(DVD/CD Player) selecionar <DVD / CD >

- ID(DVD/CD Player) exibir lista atrações

- ID(DVD/CD Player) selecionar < executar | para $\mid$ congelar $\mid$ próximo | prévio >

- ID(DVD/CD Player) realizar auto-diagnóstico

Dispositivo: ReplayTV

- ID(ReplayTV) gravar. <horário> <data>

Localização: Sala de estar, $<$ canal $>$

- ID(ReplayTV) gravar

- ID(Replay TV) realizar auto-diagnóstico

Dispositivo: Filmadora Digital (Filmadora)

Localizaçaõ: Portátil
- ID(Filmadora) gravar

- ID(Filmadora) selecionar < executar | parar | paralisar >

- ID(Filmadora) zoom $<+\mid->$

- ID(Filmadora) realizar auto-diagnóstico

- $\mathrm{ID}(\mathrm{RM})$ ajustar alarme <hora : minutos>

- ID(RM) ajustar timer <minutos>

- ID(RP) ajustar alarme <hora : minutos>

- ID(RP) ajustar timer <minutos $>$

- $\mathrm{ID}(\mathrm{HT})$ ligar/desligar

- ID(HT) exibir lista de dispositivos

- ID(HT) selecionar <Rádio |CD | DVD | Filme | Internet >

- ID(HT) exibir lista de atrações

- ID(HT) selecionar <atração>

- ID(HT) ajustar timer <minutos>

- ID(HT) realizar auto-diagnóstico 
Dispositivo: Telão

Localização: Sala de jogos e som
- ID(Telão) acionar projetor

- ID(Telão) exibir lista de dispositivos

- ID(Telão) selecionar < dispositivo >

- ID(Telão) exibir lista de atrações

- ID(Telão) selecionar <atração>

- ID(Telão) realizar auto-diagnóstico

- ID(VG) exibir lista de jogos

- ID(VG) selecionar <jogo>

- ID(VG) realizar auto-diagnóstico

Dispositivo: Módulo de Reciclagem de

- $\quad$ ID(MRL) selecionar < automático | manual > Lixo (MRL)

- $\quad \mathrm{ID}(\mathrm{MRL})$ reciclar

Localização: Sala de resíduos domésticos

- $\quad \mathrm{ID}(\mathrm{MRL})$ pesar

- $\mathrm{ID}(\mathrm{MRL})$ realizar auto-diagnóstico

Dispositivo: Módulo de Reciclagem de Água (MRA)

- $\quad$ ID(MRA) selecionar < automático | manual >

- ID(MRA) reciclar

Localização: Sala de resíduos domésticos

- ID(MRA) realizar auto-diagnóstico

Dispositivo: Geladeira/Freezer (G/F)

- $\quad \mathrm{ID}(\mathrm{G} / \mathrm{F})$ exibir lista de receitas

Localização: Cozinha

- $\mathrm{ID}(\mathrm{G} / \mathrm{F})$ procurar receita de <alimento $>$

- $\quad \mathrm{ID}(\mathrm{G} / \mathrm{F})$ sugerir receita

- $\quad \mathrm{ID}(\mathrm{G} / \mathrm{F})$ realizar auto-diagnóstico

Dispositivo: Fogão

- ID(Fogão) procurar receita <alimento>

Localização: Cozinha

- ID(fogão) sugerir receita

- ID(fogão) acender <queimador>

- ID(Fogão) realizar auto-diagnóstico 
Dispositivo: Microondas

Localização: Cozinha
- ID(microondas) exibir lista de receitas

- ID(microondas) procurar receita de $<$ alimento $>$

- ID(microondas) sugerir receita

- $\mathrm{ID}$ (microondas) realizar auto-diagnóstico

Dispositivo: Lavadora de Louça (LL) - ID(LL) selecionar modo

Localização: Cozinha

- ID(LL) iniciar

- ID(LL) realizar auto-diagnóstico

Dispositivo: Cafeteira

- ID(Cafeteira) iniciar

Localização: Cozinha

- ID(Cafeteira) selecionar modo

- ID(Cafeteira) realizar auto-diagnóstico

Dispositivo: Batedeira de Bolo (BB)

- ID(BB) exibir lista de receitas

Localização: Cozinha

- $\mathrm{ID}(\mathrm{BB})$ procurar receita $<$ bolo $>$

- $\quad \mathrm{ID}(\mathrm{BB})$ sugerir receita

- $\mathrm{ID}(\mathrm{BB})$ selecionar velocidade

- $\quad \mathrm{ID}(\mathrm{BB})$ iniciar

- $\quad$ ID(BB) realizar auto-diagnóstico
Dispositivo: Processador de Alimentos (PA)

Localização: Cozinha
- ID(PA) exibir lista de receitas

- ID(PA) procurar receita de <alimento $>$

- ID(PA) ajustar velocidade

- $\quad \mathrm{ID}(\mathrm{PA})$ sugerir receita

- $\quad \mathrm{ID}(\mathrm{PA})$ iniciar

Dispositivo: Relógio de Cozinha (RC) - $\quad \mathrm{ID}(\mathrm{RC})$ ajustar timer $<$ minutos $>$

Localização: Cozinha 
Dispositivo: Analista de Dados Automotivos (ADA)

Localização: Garagem

Dispositivo: Dispositivo de Telediagnóstico Portátil (DTP)

Localização: Banheiros do casal, dos filhos, da empregada
- ID(ADA) confirmar agendamento <serviço>

- ID(ADA) realizar auto-diagnóstico
- ID(DTP) coletar dados

- ID(DTP) enviar dados para <médico>

Dispositivo: Compartimento de

- ID(CHP) selecionar temperatura

Higienização Pessoal (CHP)

- ID(CHP) selecionar modo

Localização: Banheiros do casal, dos

- ID(CHP) ajustar timer $<$ minutos $>$

filhos, da empregada

- ID(CHP) iniciar

- ID(CHP) realizar auto-diagnóstico

Dispositivo: Barbeador Elétrico (BE) - $\quad \mathrm{ID}(\mathrm{BE})$ ajustar lâminas

Localização: Banheiros do casal, dos - ID(BE) iniciar

filhos, da empregada

- $\quad \mathrm{ID}(\mathrm{BE})$ realizar auto-diagnóstico

Dispositivo: Lavadora de Roupas (LR) - ID(LR) iniciar

Localização: Área de serviço

- ID(LR) terminar

- ID(LR) selecionar modo de lavagem

- ID(LR) secar

- ID(LR) realizar auto-diagnóstico

Dispositivo: Ferro de passar roupa (FPR) - ID(FPR) selecionar temperatura

Localização: Área de serviço

- $\quad$ ID(FPR) ligar

- ID(FPR) desligar

- ID(FPR) realizar auto-diagnóstico 


\section{Apêndice B}

\section{Relatório de Classes SmartHome}

O relatório apresentado neste apêndice foi gerado pela ferramenta Rose 98 , o conteúdo deste é baseado nos dados fornecidos durante a modelagem do sistema. Ao contrário do diagrama de classes, o relatório é totalmente descritivo. As classes que compõem o sistema SmartHome, juntamente com seus atributos e métodos, fazem parte do documento apresentado.

- Ambientes

$/ /$ Classe de ambientes gerenciados.

- Private Attributes:

- Ambiente: // Atributo que identifica o ambiente gerenciado.

- Cartesianas: // Atributo que registra as coordenadas cartesianas.

- GPS: // Atributo que registra coordenadas no formato GPS.

- Public Operations:

- InsereAmbiente (): // Método que insere ambiente a ser gerenciado.

- ExcluiAmbiente (): // Método que exclui um ambiente gerenciado.

- SelecionaAmbiente (): // Método que seleciona um ambiente para gerenciamento.

- ConverteCoordenadas(): // Método que converte coordenadas cartesianas em coordenadas GPS.

- Amb_User $\quad / /$ Classe que relaciona os diversos usuários aos diversos 
ambientes.

- Public Operations:

- InsereAmb_User (): //Insere Amb_User

- ExcluiAmb_User (): //Exclui Amb_User

- SelecionaAmb_User (): //Seleciona Amb_User

- Comodos // Classe de cômodos relacionados a um ambiente.

- Private Attributes:

- Comodo : //Atributo que identifica um cômodo.

- Cartesianas: //Atributo que registra coordenadas cartesianas.

- GPS: // Atributo que registra coordenadas GPS.

- Adjacentes: // Atributo que identifica cômodos adjacentes.

- Public Operations:

- InsereComodo (): // Método que insere um cômodo em um determinado ambiente.

- EditaComodo 0: // Método que edita um cômodo previamente inserido.

- ExcluiComodo (): // Método que exclui um ambiente previamente inserido.

- RelacionaComodo (): // Método que relaciona um cômodo a um ambiente.

- SelecionaComodo 0: // Método que seleciona um cômodo pertencente a um ambiente.

- ConverteCoordenadas (): // Método que converte coordenadas cartesianas em formato GPS.

- Dispositivos // Classe de dispositivos que integram o ambiente gerenciado.

- Private Attributes:

- Dispositivo : // Atributo que identifica um dispositivo.

- Icone : // Atributo que armazena o ícone que representa o dispositivo. 
- Estado: // Atributo que informa se o dispositivo está em uso.

- GPS : // Atributo que registra coordenadas de GPS.

- Public Operations:

- InsereDispositivo 0: // Método que insere um dispositivo no sistema.

- EditaDispositivo 0: // Método que edita um dispositivo previamente inserido no sistema.

- ExcluiDispositivo (): // Método que exclui um dispositivo pertencente ao sistema.

- RelacionaDispositivo 0: // Método que relaciona um dispositivo a um cómodo.

- ObtemDispositivo (): // Método que recupera informações sobre um dispositivo do sistema.

- RelacionaTermo (): // Método que relaciona um termo extraído de uma sentença com um dispositivo.

- ConfiguraDispositivo 0 : // Método que permite o ajuste de algumas configurações do dispositivo por parte do administrador do sistema.

- VinculaComodo 0: // Método que relaciona um dispositivo a um cômodo.

- PosicionaIcone (): // Método que posiciona ícone na interface.

- Fuucoes // Classe de funções dos dispositivos do sistema.

- Private Attributes:

- Funcao: // Atributo que identifica uma determinada função.

- Tipo: // Atributo que expressa o tipo a que a função pertence.

- Objeto: // Atributo que identifica os objetos aceitos por uma função. 
- Public Operations:

- Excluifuncao (): //Método que exclui uma função.

- SelecionaFuncao () : // Método que seleciona uma função.

- InsereFuncao (): // Método que insere uma função.

- ObtemTermos (): // Método que obtém dados da função a partir dos termos obtidos da sentença de comando.

- ObtemTermos (): //Método que relaciona os termos da sentença a uma função de um dispositivo.

- FrmAdministrador

// Classe do tipo interface somente permitida ao administrador do sistema.

- Public Operations:

- Selecionaform 0: // Seleciona uma das opções disponíveis.

- ApresentafrmAdministrador (): // Mostra o formulário de administração do sistema.

- AnalisaOpcao (): //Analisa a opção escolhida a fim de executá-la.

- FrmAtenderVisitante

// Classe do tipo interface para atendimento a visitantes diante de portas externas.

- Public Operations:

- AnalisaResposta (): // Método que analisa respostas fornecidas por visitantes.

- EncerraDialogo (): // Método que encerra o diálogo baseado nas respostas obtidas.

- AlocaCanal (): $\quad / /$ Método que aloca um canal de comunicação.

- AtendeCampainha (): // Método que recebe chamado inicial do visitante em frente a uma porta externa.

- EnviaPergunta (): // Método que realiza perguntas ao visitante.

- RecebeResposta (): // Método que aguarda respostas do visitante. 
- VerificaDisponibilidade ():// Método que verifica se 0 morador está disponível para atender o chamado.

- ObtemLocalizacao 0: // Método que obtém a posição do morador na residência.

- FrmCadastraUsuario // Classe do tipo interface para a inserção de novos usuários.

- Public Operations:

- ApresentaFrmInsereUsuario 0 : // Método que apresenta a interface de inserção de novos usuários.

- TerminaFrmInsereUsuario (): // Método que termina a exibição da interface.

- RecebeUsuario 0 : // Método que recebe as informações relativas a um usuário.

- FrmConfigAmbiente // Classe do tipo interface para inserção de ambientes e cômodos.

- Public Operations:

- ApresentaFrmConfigAmb $0:$ // Método que mostra a interface para configuração de ambiente.

- TerminaFrmConfigAmb 0: // Método que termina a exibição da interface.

- RecebeAmbiente (): // Método que recebe informações relativas ao ambiente.

- FrmEditaDispositivo // Classe do tipo interface para edição das configurações de dispositivos.

- Public Operations:

- ApresentaFrmEditaDispositivo (): // Método que exibe a interface para edição de dispositivos.

- TerminateFrmEditaDispositivo (): // Método que termina a exibição da interface.

- AlterarRegistro (): //Método que armazena o novo valor. 
- FrmGeraRelatorio // Classe do tipo interface para a geração de relatórios.

- Public Operations:

- ApresentaFrmGeraRelatorio (): // Método que apresenta a interface de geração de relatórios.

- FormataRelatorio 0: // Método que formata dados em um relatório.

- ImprimeRelatorio (): // Método que trata da impressão de relatórios.

- TerminaFrmGeraRelatorio (): // Método que termina a exibição da interface.

- SelecionaRelatorio 0: // Método para seleção de relatório a ser gerado.

- FrmPreferencias

// Classe de interface que obtém preferências do usuário.

- Public Operations:

- Excluipreferencia (): // Método que exclui uma preferência do usuário.

- ObtemPreferencia (): // Método que obtém preferências do usuário.

- InserePreferencia (): //Método que insere uma preferência do usuário.

- FrmPrincipal // Classe do tipo interface que interpreta e executa sentenças de comando.

- Public Operations:

- RecebeRequisicao (): // Método que recebe sentenças de comando.

- ExtraiTermos (): // Método que extrai os termos principais de uma sentença de comando.

- MontaPacote (): // Método que monta um pacote executável. 
- Funcao_Preferencia // Classe que relaciona várias preferências de vários usuários com relação a várias funções.

- Public Operations:

- InsereFunc_Prefer 0: // Método que insere registros.

- ExcluiFunc_Prefer 0: //Método que exclui registros.

- ObtemFunc_Prefer (): //Método que exclui registros.

- Logs // Classe que registra requisições de execução de funções pelos usuários.

o Private Attributes:

- Registro : // Atributo que registra transações ocorridas.

- Public Operations:

- InsereLog (): //Método que insere um registro.

- ObtemLog 0 : //Método que busca um registro.

- Excluilog (): //Método que exclui um registro.

- Perguntas // Classe de perguntas a serem realizadas a visitantes.

o Private Attributes:

- Pergunta: // Atributo que armazena perguntas possíveis de serem realizadas.

o Public Operations:

- InserePergunta (): // Método que insere pergunta.

- ExcluiPergunta (): // Método que exclui uma pergunta cadastrada.

- EditaPergunta (): // Método que edita uma pergunta anteriormente inserida.

- ObtemPergunta (): // Método que escolhe uma pergunta a ser realizada.

- Permissoes Comodos // Classe que determina as permissões de acesso ao cômodos. 
- Private Attributes:

- Usuario : // Atributo que identifica um usuário.

- Comodo: // Atributo que identifica um cômodo.

- Public Operations:

- InserePermissao (): // Método que atribui uma permissão a um usuário.

- Excluipermissao (): // Método que exclui uma permissão de um usuário.

- ObtemPermissao (): // Método que obtém informação sobre a permissão de um usuário.

- Preferencias // Classe que contém as preferências dos usuários.

- Private Attributes:

- Valor: // Atributo que armazena o valor da preferência.

- Tipo: // Atributo que informa o tipo de função a que a preferência pode ser utilizada.

- Public Operations:

- InserePreferencia (): // Método que insere uma preferência.

- Excluipreferencia (): // Método que exclui uma preferência.

- ObtemPreferencia (): // Método que obtém uma preferência inserida anteriormente.

- Usuarios

// Classe de usuários do sistema.

- Private Attributes:

- Usuario : // Atributo que identifica um usuário.

- Digital : // Atributo que contém a informação biométrica da impressão digital do usuário.

- Face : // Atributo que contém a informação biométrica da face do usuário. 
- Voz: // Atributo que contém a informação biométrica da voz do usuário.

- Íris : // Atributo que contém a informação biométrica da íris de um usuário.

- Grupo: // Atributo que indica o grupo a que o usuário pertence, cada grupo possui um conjunto de permissões.

- Public Operations:

- InsereUsuario (): //Método que insere usuários no sistema.

- ExcluiUsuario (): // Método que exclui um usuário do sistema.

- EditaUsuario (): // Método que edita informações sobre um usuário cadastrado.

- CapturaBiometria () : // Método que captura a biometria de um usuário recém inserido.

- ValidaUsuario 0 : // Método que valida os dados biométricos do usuário requisitante com dados armazenados no sistema.

- Usuario_Dispositivo

// Classe de permissões de um usuário sobre dispositivos.

- Public Operations:

- InsereUsuarioDispositivo (): // Método que insere permissão.

- ExcluiUsuarioDispositivo 0: // Método que exclui permissão.

- SelecionaUsuarioDispositivo (): // Método que seleciona uma permissão. 